Check for updates

Cite this: J. Mater. Chem. A, 2021, 9 19206

Received 28th April 2021

Accepted 22nd June 2021

DOI: $10.1039 / \mathrm{d} 1 \mathrm{ta0} 3572 \mathrm{j}$

rsc.li/materials-a

\section{Interfaces in metal halide perovskites probed by solid-state NMR spectroscopy}

\begin{abstract}
Clayton J. Dahlman, ${ }^{a}$ Dominik J. Kubicki ${ }^{\text {bc }}$ and G. N. Manjunatha Reddy (iD *d
Metal halide perovskites (MHPs) are promising light harvesting and emitting materials that have enabled solar energy conversion efficiencies of over $25 \%$ in solution-processed single-junction cells, and found applications in flexible electronics, detectors and other display technologies. Research on MHPs has achieved significant fundamental and technological advancements over the last decade, in large part due to improvements in characterization approaches to understand these materials. It has become clear that engineering the interfaces between device layers, and within the MHP layer itself, is crucially important to develop stable and efficient optoelectronic devices. Interfaces in MHP-based devices exhibit varying degrees of order, which manifest heterogeneities in compositions, structures and optoelectronic properties. This review assesses the overall prospects for a range of solid-state (ss)NMR spectroscopy techniques to facilitate structure-based understanding of complex interfaces in MHPs and contact layers. The role of sSNMR in elucidating local compositions and structures, intermolecular connectivity, phase transitions, degradation products and molecular passivation at MHP interfaces is discussed. In addition, an overview of different dynamic processes in MHPs probed by ssNMR is provided. Finally, we discuss perspectives on the development of ssNMR spectroscopy for investigating interfaces in MHPs for various optoelectronics.
\end{abstract}

${ }^{a}$ Materials Department, University of California, Santa Barbara, California 93106, USA

${ }^{b}$ Cavendish Laboratory, Department of Physics, University of Cambridge, JJ Thomson Avenue, CB3 OHE, Cambridge, UK

${ }^{c}$ Department of Chemistry, University of Cambridge, Lensfield Road, CB2 1EW, Cambridge, UK
${ }^{d}$ Univ. Lille, CNRS, Centrale Lille, Univ. Artois, UMR 8181 - UCCS - Unité de Catalyse et Chimie du Solide, F-59000 Lille, France. E-mail: gnm.reddy@ univ-lille.fr

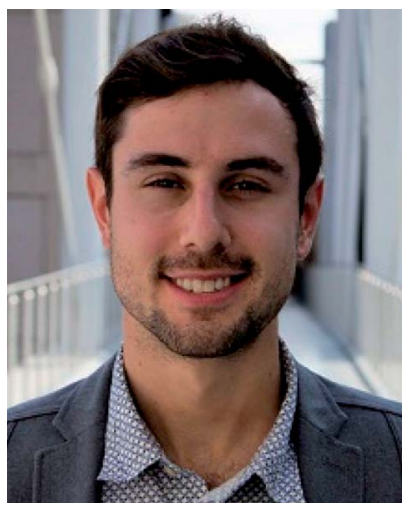

Clayton Dahlman is a postdoctoral researcher in the Materials Department at the University of California, Santa Barbara, working in the research group of Prof. Michael Chabinyc. He received his bachelor's degree from Columbia University in 2011 and a master's degree from the University of California, Berkeley in 2014. He received his $P h D$ from the University of Texas at Austin in 2017 under the supervision of Prof. Delia Milliron. Clayton is interested in the dynamic behavior of solution-processed, colloidal and hybrid organic-inorganic nanomaterials for energy and information technologies.

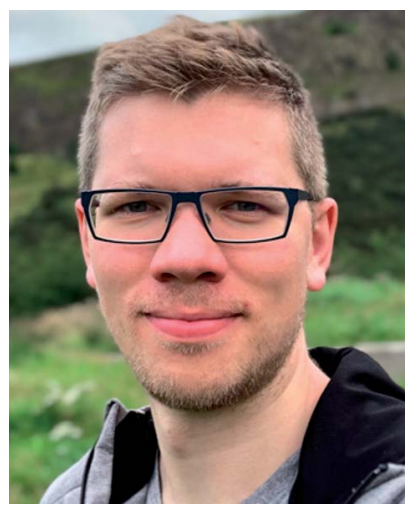

Dominik J. Kubicki is a Marie Skłodowska-Curie Actions Fellow in the Cavendish Laboratory in the group of Sam Stranks and in the Department of Chemistry in the group of Clare Grey at the University of Cambridge (UK). During his PhD at EPFL he was developing $M A S$ $D N P$ strategies to enhance the sensitivity of solid-state NMR. During his subsequent postdoctoral stay with Michael Grätzel, he began applying solid-state NMR to obtain atomic-level structural and dynamic information on lead halide perovskites. He is currently developing new materials for optoelectronics with a particular focus on the structure-property relationships resulting from the local structure and disorder. He received the Young Scientist Award at the 20th International Society of Magnetic Resonance (ISMAR) Conference. 


\section{Introduction}

Metal halide perovskites (MHPs) have garnered considerable interest in the past decade as photoactive materials in low-cost and high-performance optoelectronic devices. Perovskite is originally the name of the mineral $\mathrm{CaTiO}_{3}$, but the term is used to describe isostructural materials with a composition of $\mathrm{ABX}_{3}$, where $\mathrm{X}$ is an anion and $\mathrm{A}$ and $\mathrm{B}$ are various cations. ${ }^{\mathbf{1}}$ In MHPs, $\mathrm{A}$ is a monovalent cation (e.g. $\mathrm{Cs}^{+}$, methylammonium, formamidinium), $\mathrm{B}$ is a divalent metal $\left(\right.$ e.g. $\left.\mathrm{Pb}^{2+}, \mathrm{Sn}^{2+}\right)$ and $\mathrm{X}$ is a halide $\left(\mathrm{I}^{-}, \mathrm{Br}^{-}, \mathrm{Cl}^{-}\right)$. Structures with similar octahedral bonding, coordination and chemical composition are also commonly described as MHPs, ${ }^{2}$ such as layered homologues. ${ }^{3-8}$ Halide perovskites have been heralded as next-generation materials for photovoltaics (PV), ${ }^{9-12}$ with power conversion efficiencies (PCE) currently exceeding 25\%. ${ }^{\mathbf{1 3 , 1 4}}$ MHPs have also been explored for applications including light-emitting diodes (LEDs) ${ }^{15-23}$ phosphors for display technology, ${ }^{24,25}$ lasers, ${ }^{26-30}$ photodetectors, ${ }^{31-35}$ ionizing radiation detectors ${ }^{30,36-40}$ and as quantum emitters. ${ }^{\mathbf{4 1 , 4 2}}$ Significant improvements in device performance have been driven by interfacial engineering, either between layers of a device or within MHP phases. ${ }^{43}$ However, atomic structures and dynamic interactions at MHP interfaces are notoriously difficult to probe. In this review, we discuss the challenges of studying interfaces in MHP materials and devices and how solid-state nuclear magnetic resonance (sSNMR) spectroscopy can access these regions.

MHPs, and particularly lead iodides, stand out from other optoelectronic semiconductors because of their long charge carrier lifetimes and diffusion lengths in spite of the presence of many defects. ${ }^{\mathbf{4 4 , 4 5}}$ The defect tolerance of lead halide perovskites has enabled the manufacture of high-performance devices through a variety of scalable solution-phase processes, ${ }^{46-51}$ solidphase mechanochemical syntheses, ${ }^{52,53}$ and vapor-phase approaches. ${ }^{54}$ MHPs have relatively low formation energies and exhibit low-temperature phase transformations ${ }^{55}$ compared

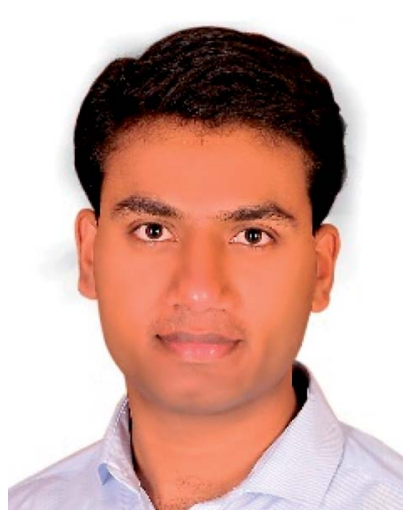

G. N. Manjunatha Reddy is an Assistant Professor of Chemistry at the University of Lille, France. He received his PhD from AixMarseille University, France. Subsequently he has been a postdoctoral researcher at the University of Warwick (UK), and research associate at the University of California Santa Barbara (USA). In 2016, he has been acquired by the Royal Society of Chemistry as member. He received Marie Skłodowska-Curie Individual Fellowship Award in 2017 on behalf of European Union Framework Programme Horizon2020. His research is focused on establishing structure-property relationships in energy materials and self-assembled nanomaterials using solid-state NMR spectroscopy and modelling approaches. to other semiconductors for optoelectronic applications. The substantially ionic character of bonds in MHPs renders them simple to form but also quick to degrade..$^{2,56-58}$ Weak coulombic attractions between large constituent ions, including small organic molecules such as methylammonium, are easily disrupted by polar solvents or vapors, pressure, temperature and high-flux photoexcitation. The weak bonding between constituent ions also leads to significant lattice disorder, polarizability and ion migration. ${ }^{2,59-61}$ For this reason, perovskite active layers possess varying degrees of order and crystallinity between and within layers of MHP based devices. ${ }^{44}$ The desire for probing short-range $(<1 \mathrm{~nm})$ to middle-range $(1-10 \mathrm{~nm})$ structural order and competing interactions at interfaces is particularly relevant here. A bottleneck challenge remains to develop reliable structure-processing-property relationships at different length scales in MHP devices.

Many experimental techniques used to characterize the structure of MHPs, such as X-ray diffraction, are sensitive to bulk crystalline regions. However, MHPs demonstrate heterogeneity and disorder across many length scales - either in the bulk or at interfaces - that are difficult to probe by diffraction alone. ${ }^{44}$ Interfacial regions make up the minority of the material and exhibit atomic-scale disorder, but may have an outsized impact on device performance. ${ }^{43}$ In addition, intrinsic interfaces can form within MHP layers that may dominate optical and electronic properties. For example, low-dimensional Ruddlesden-Popper (RP), Dion-Jacobson (DJ) phases are composed of 2D slabs of MHP sub-phases separated by insulating 'spacer' cations. $^{3-8}$ Characterizing amorphous, disordered and interfacial structures in MHPs remains an experimental challenge. Multi-technique approaches to bridge different length- and timescales, such as diffraction, electron microscopy and sSNMR spectroscopy, are well suited to correlate bulk behaviors with interfacial and atomic-scale structures in MHPs.

SsNMR spectroscopy has emerged as a powerful tool to understand local chemical environments, disorder and dynamic behavior of MHPs. SSNMR techniques have enjoyed decades of development for organic, inorganic and biomolecular materials (e.g. catalysts, energy conversion and storage materials, polymers, glasses, solution-processable semiconductors). ${ }^{\mathbf{6 2 , 6 3}}$ The recent upsurge of interest in MHPs has introduced a new set of compositions, bonding moieties and interfaces for ssNMR spectroscopists to explore. The lengthscales that SSNMR experiments can study range from atomicscale bond lengths to macroscopic diffusion/transport distances. In addition, ssNMR can probe dynamic processes at timescales ranging from picoseconds to hours or days. Sample preparation is also versatile - ssNMR can probe samples with different compositions, morphologies, crystallinity and solid/solution combinations - so realistic synthesis and deposition conditions can be studied. Specifically, wide range of one (1D) and two-dimensional (2D) techniques, surface-enhanced NMR spectroscopy, NMR crystallography, relaxation measurements and analysis, variable temperature NMR, and ex situ and in situ techniques have been employed to study MHPs. ${ }^{64-67}$ The rapid growth in structure-based understanding of this material 
class, and steady improvements in NMR instrumentation, have cultivated a rich field of study for MHPs by sSNMR.

This review describes the growing use of ssNMR spectroscopy as a tool to understand interfacial structures in MHPs. Several reviews have recently explored the role of SSNMR in probing local structures and dynamics in micro- and nanocrystalline MHPs. ${ }^{64-67}$ Here, we focus on how ssNMR techniques can probe the interfaces present in MHPs and on an overarching goal of extending ssNMR capabilities to investigate reactive surfaces and interfaces in device stacks. We begin by categorizing different types of interfaces in MHPs and MHPbased optoelectronic devices. Next, we describe the length and timescales of physical processes that occur in optoelectronic devices and compare these to the scales accessible to SSNMR and other characterization techniques. A practical tutorial on SSNMR methods is provided for both non-experts and NMR spectroscopists to identify opportunities and limitations for relevant techniques. We then highlight recent findings that illustrate state-of-the-art ssNMR spectroscopy approaches to study MHP interfaces in crystalline 3D phases, layered structures and nanocrystals, and contact layers. In addition, an overview of dynamic aspects in MHPs probed by $1 \mathrm{D}$ and 2D sSNMR techniques is provided. Finally, we offer an outlook on opportunities for future research on MHP interfaces by SSNMR methods.

\section{Interfaces in MHPs and devices}

Interfaces in MHPs can be categorized based on the composition of the metal halide phase and its assembly into functional devices or composite materials. Interfaces span different length scales from the molecular level (ঐ) to device scales (mm). In this review we distinguish between (i) extrinsic interfaces between the halide perovskite layer and different contact layers (e.g., charge-transport layers, electrodes, ambient atmosphere), and (ii) intrinsic interfaces that exist within MHPs (e.g., grain boundaries). Both of these interfaces exhibit varying degrees of structural order and manifest heterogeneities. Many, but not all, of these interfaces have been studied by ssNMR techniques in MHPs, yet each type of interface presents a characterization and design challenge.

\subsection{Extrinsic interfaces}

2.1.1. Devices. Optoelectronic devices integrate semiconductor layers between contact layers, such as hole-transport layers (HTLs), electron-transport layers (ETLs), substrates and electrodes, to promote efficient photo-induced charge generation, extraction, and transport. MHP-based devices commonly follow a planar heterojunction architecture. Fig. 1 summarizes typical heterojunction device architectures that contain MHP semiconductors. The interfaces between each layer in MHP devices, or the surfaces exposed to the ambient environment, have distinct structures and impacts on device behavior.

Solar cells and LEDs. Photovoltaic cells are composed of a device stack that sandwiches a photoactive MHP layer between transport layers (ETLs and HTLs), as shown in Fig. 1a. Typically, the MHP layer is several hundred nanometers thick and the contact layers are much thinner (Fig. 1d). In a conventional (n-ip) cell, the ETL (e.g. titanium dioxide, $\mathrm{TiO}_{2}$ ) contacts the transparent conductive substrate (e.g. tin-doped indium oxide (ITO)-coated glass) and the HTL (e.g. 2,2',7,7'-tetrakis-9,9'-spirobifluorene, spiro-OMeTAD) contacts gold electrodes. An inverted cell has an opposite arrangement, where the HTL (e.g. poly(3,4-ethylenedioxythiophene):polystyrene sulfonate, PEDOT:PSS) contacts the transparent substrate and the ETL (e.g. phenyl- $\mathrm{C}_{61}$-butyric acid methyl ester, $\mathrm{PCBM}$ ) contacts silver or aluminum electrodes. Mesoscopic architectures are also common, where the MHP is dispersed within an electrontransporting material scaffold (e.g. mesoporous $\mathrm{TiO}_{2}$ ). The development of improved organic and inorganic transport materials is an active area of research for MHP solar cells and LEDs. ${ }^{68-75}$ Each of these interfaces can have properties that differ from the bulk. For instance, MHPs may become substoichiometric at the interface with contact layers, leading to significant changes in electronic transport. Similarly, the structure of ETL and HTL materials may be perturbed when in contact with MHPs, and electrodes (e.g., gold back-contacts) can diffuse through contact layers to the MHP. Interface management is essential to the development of stable high-performing MHP-based devices, but characterizing interfacial regions remains challenging. ${ }^{\mathbf{4 3}}$

Photodetectors. MHPs have also found use in photodetector applications that do not rely on a photovoltaic architecture. Lateral devices, such as photoconductors and phototransistors, use the MHP layer to detect incident light by transporting photocarriers between a source and drain electrode (Fig. 1b). The geometry of lateral photoconductors and phototransistors may require photocarriers to travel further distances than in vertical photovoltaic cells. Interfacial charging and depletion zones, defect passivation, and structural rearrangements near the gate or substrate interface, are particularly consequential in lateral devices because these regions form electronic transport pathways. Interfacial doping of MHPs through chemical surface treatments has been attempted, but the unique chemistry of MHPs leads to convoluted effects on structure and electronic defect compensation. ${ }^{76-79}$ Photodetectors for ionizing radiation (e.g., X-rays, $\gamma$-rays) often use a scintillator architecture instead of lateral heterostructures. The heavy elements in MHPs can efficiently down-convert high-energy radiation to visible light for detection by optical photodiodes. Scintillators do not rely on electrical contact between transport layers and MHPs, but MHP interfaces may determine device stability and optical characteristics. $^{36,40,80}$

Flexible devices. Mechanically flexible photoactive and contact layers are required for the development of portable, light weight and wearable technology. Substrates such as polyethylene naphthalate (PEN), polyethylene terephthalate (PET), and flexible glass support mechanically flexible devices that can be fabricated using solution-processing methods. ${ }^{83-85}$ Fig. 1c illustrates a flexible perovskite solar cell with a $\mathrm{CH}_{3} \mathrm{NH}_{3} \mathrm{PbI}_{3}$ $\left(\mathrm{MAPbI}_{3}\right)$ absorber layer, organic PEDOT:PSS HTL, and a fullerene $\left(\mathrm{C}_{60}\right)$ ETL, all deposited on a graphene-coated PEN substrate. ${ }^{81}$ Large-scale manufacture of flexible MHP devices 
(a) Photovoltaic cells
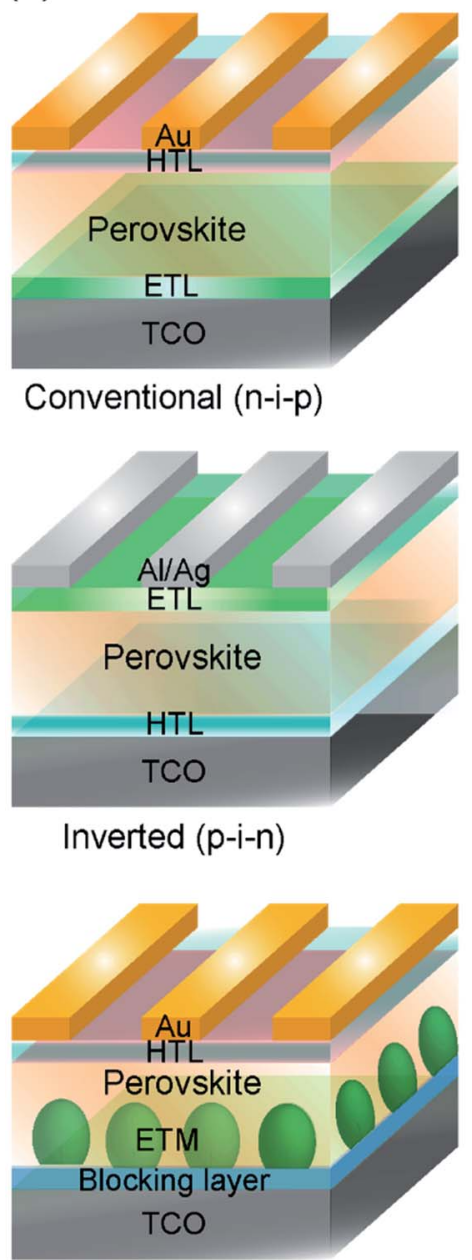

Mesoscopic (n-i-p) (b) Photodetectors

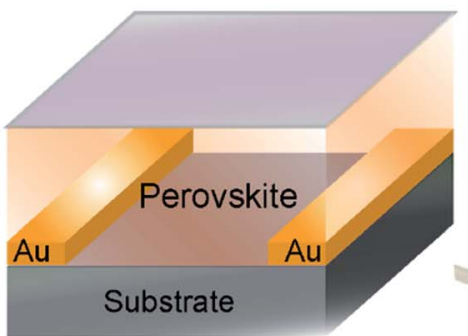

Photoconductor

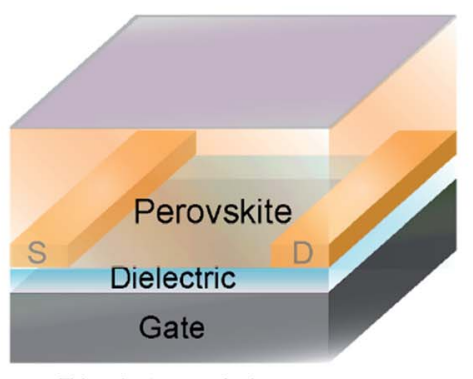

Phototransistor

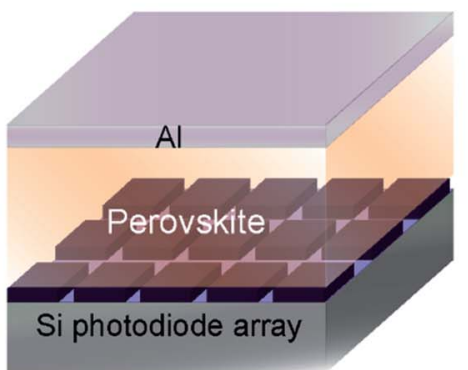

X-ray scintillator (c) Flexible solar cell

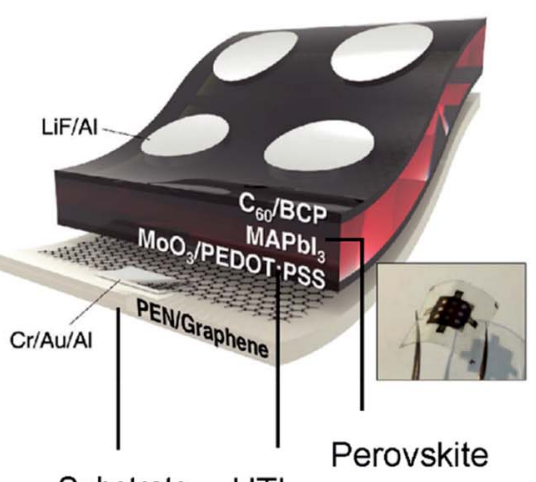

Substrate

HTL

(d) Tandem solar cell

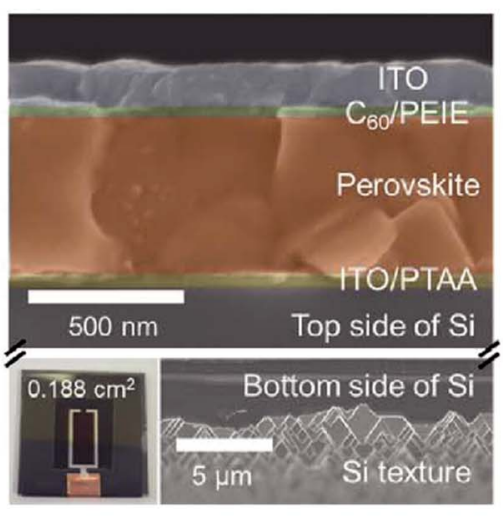

\section{Planar heterojunction devices}

Fig. 1 Perovskite device architectures: (a) planar heterojunction solar cells with mesoporous, conventional and inverted structures. (b) Photodetectors including photoconductor, phototransistor and scintillator architectures. HTL: hole transporting layer, ETL: electron transporting layer, TCO: transparent conductive oxide, ETM: electron transporting material, S: source electrode, D: drain electrode. (c) A schematic and photograph of a flexible solar cell with flexible photoactive thin films, contact layers and substrates. Reproduced from ref. 81 with permission from The Royal Society of Chemistry. (d) A colored SEM cross-section of the top-cell (upper) and back side of the bottom cell (lower) of a tandem perovskite-silicon solar cell. The scale bars in the upper and lower panels are different as indicated. Reproduced from ref. 82 with permission from The Royal Society of Chemistry.

can be accomplished through roll-to-roll printing, ${ }^{86}$ but these processing methods impart interfacial strain and mechanical work to device layers. Interfacial strain impacts the crystalline structure and optical properties of MHPs, ${ }^{87-91}$ but disordered regions at strained interfaces are difficult to probe. Composite materials with MHP particles embedded in a flexible matrix have also been explored for additive manufactured and printable luminescent devices, and may exhibit similar interfacial characterization challenges. ${ }^{92}$

Tandem cells. Multi-junction (tandem) MHP solar cells, have promising commercial applications because of their high efficiencies, which can break the thermodynamic limit for singlejunction cells. ${ }^{93}$ Record setting MHP-Si tandem cells have PCEs approaching $30 \%{ }^{13} \mathrm{~A}$ cross-section of an example MHP-Si tandem cell with PCE $>26 \%$ is shown in Fig. $1 \mathrm{~d}^{82}$ As additional layers are added to MHP-based devices, the properties and behaviors of interfacial regions become more important to characterize and control. The structure and behavior of interfaces between each layer of a tandem MHP can be impacted by other layers, so it is crucial to develop tools to probe these regions.

2.1.2. Ambient environment. The interface between the ambient atmosphere and MHPs or contact layers is of particular concern for device performance and stability. MHPs and contact layers are sensitive to oxygen and water in air, leading to degradation, chemical reactions and phase transformations at interfaces with the atmosphere. ${ }^{43,94-101}$ Great efforts have been made to prevent exposure of device layers to ambient oxygen 
and water, or to otherwise improve ambient stability, through compositional engineering, surface passivation and encapsulation..$^{2,43,58,102-104}$ The precise interactions that occur at the interface of MHP-based device layers and the environment are challenging to probe directly. However, an understanding of these processes will be of crucial importance to the future development of MHP devices with practical lifespans. ${ }^{105}$

\subsection{Intrinsic interfaces}

Intrinsic interfaces exist within MHP layers between different grains, domains or substructures. Unlike the extrinsic interfaces described in the prior section, these interfaces can exist independently of device architecture. The tolerance of MHPs to atomic defects allows for a great diversity of interfaces to form, ranging from the unit cell to the device scale. These interfaces may form under equilibrium conditions due to compositional heterogeneity (e.g. layered Ruddlesden-Popper phases), or during non-equilibrium processes such as film growth and transient light exposure. Fig. 2 illustrates several intrinsic interfaces that may form in MHPs. While interfaces may be defined in various ways, here we consider an expansive set of examples that present exciting opportunities for characterization by SSNMR.

The formation of intrinsic interfaces in MHPs is mediated by the geometry of the halide perovskite crystal structure. The stability of the simplest MHP structure, a cubic $\mathrm{ABX}_{3}$ lattice composed of spherical ions, can be described by the size and bonding character of constituent ions. The 'tolerance factor' (TF) introduced by Goldschmidt in 1926, ${ }^{\mathbf{1 0 6}}$ establishes stability limits for perovskites based on the relative ionic radii $(r)$ of A, B and $\mathrm{X}: \mathrm{TF}=\left(r_{\mathrm{A}}+r_{\mathrm{X}}\right) /\left(\sqrt{2}\left[r_{\mathrm{B}}+r_{\mathrm{X}}\right]\right)$. Another geometric ratio, the 'octahedral factor' $\left(\mu=r_{\mathrm{B}} / r_{\mathrm{X}}\right)$, establishes additional constraints on stability and octahedral distortions. ${ }^{107}$ Covalency of $\mathrm{B}-\mathrm{X}$ bonds, lone pair interactions, and the sterics and hydrogen bonding interactions of small molecules in hybrid organic-inorganic MHPs extend this structural model to a great diversity of materials. ${ }^{2,108-110}$ When these geometric constraints are broken, either due to composition or processing conditions, intrinsic interfaces can form.

2.2.1. Grain and domain boundaries. MHPs are often prepared as polycrystalline films for device applications. Grain boundaries can exist between crystalline domains, even without (a) Grain Boundaries

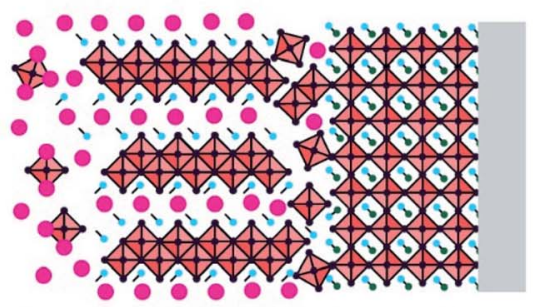

Reconstructive transformations

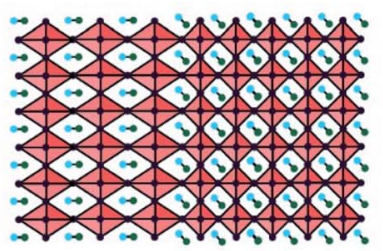

Displacive transformations

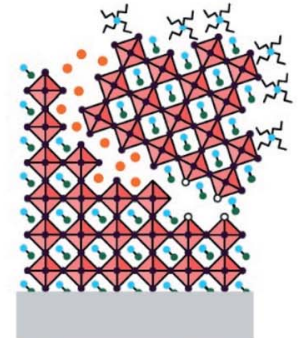

Surface passivation

(b) Solid Solution

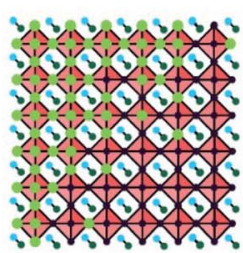

Halide

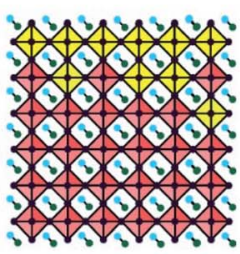

B-site

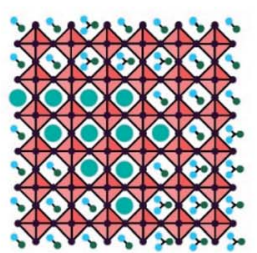

A-site

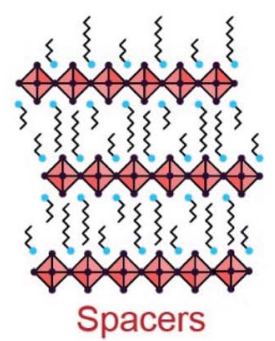

(c) Low-Dimensional

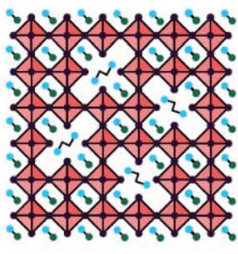

Hollow (3D)

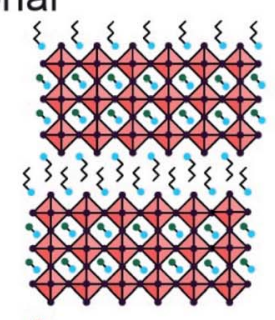

1

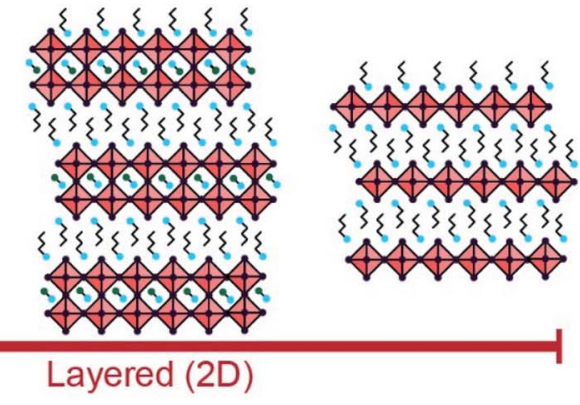

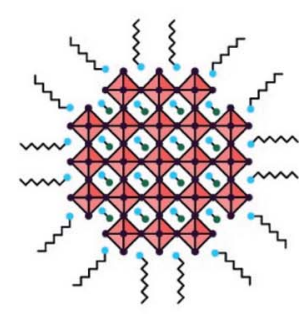

Nanocrystal (OD)

Fig. 2 Intrinsic interfaces in MHPs: interfaces can form within MHP layers due to (a) grain boundaries, (b) interfaces caused by segregation and clustering of mixed anions and cations in MHP solid solutions, and (c) the formation of low-dimensional structures separated by octahedral voids, large spacer cations and ligands. 
compositional heterogeneity (Fig. 2a). Grain boundaries may serve as photocarrier recombination sites, ${ }^{\mathbf{1 1 1}, \mathbf{1 1 2}}$ or as electronic transport pathways due to high concentrations of charged defects. ${ }^{\mathbf{1 1 3 , 1 1 4}}$ Ion transport is also enhanced at grain boundaries. ${ }^{115-117}$ Additives and constituent ions may segregate to grain boundaries in poly-crystalline films, with different effects on defect passivation, electronic and optical properties. ${ }^{118}$ As a consequence, the local structure and behavior of grain boundaries in MHPs is an important area of research that will benefit from multi-scale characterization techniques such as sSNMR.

Reconstructive reactions, either during growth or degradation, inherently occur at grain boundaries. These reactions involve breaking and reforming bonds at an interface. A large body of research has been devoted to tuning grain microstructure in polycrystalline MHPs through processing tech-

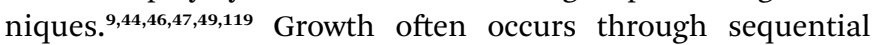
chemical pathways, forming intermediate gel or solvate phases during solution-processing that eventually form MHPs (Fig. 2a). ${ }^{\mathbf{4 6 , 4 7 , 1 2 0 - 1 2 5}}$ The density and composition of grain boundaries in polycrystalline MHPs affects their stability to ambient exposure, heat or illumination. Additive engineering to alter the chemical environment of these grain boundaries has proven fruitful to prevent interfacial degradation in MHPs. ${ }^{43,103,104,118,126,127}$ Moreover, some thermal phase transformations in MHPs are reconstructive and may be catalyzed by solvation or hydration at grain boundaries. For instance, $\mathrm{CsPbIBr}_{2}$ transforms between a low-temperature onedimensional phase and a high-temperature perovskite phase through a reconstructive reaction across a liquid-like interface. ${ }^{128}$ Reconstructive reactions form complex interfacial regions that may be disordered and short-lived. However, these regions determine how MHPs grow and degrade, and present a powerful opportunity for characterization techniques such as sSNMR that can probe reconstruction of interfaces.

Phase transformations can occur in MHPs without atomic reconstruction, forming interfaces between phases or domains (Fig. 2a). Polymorphism in MHPs is well-documented across different temperatures and pressures. ${ }^{55}$ MHP phase transformations are often displacive, without any bonds forming or breaking. As a result, the interfaces that form during displacive transformations are more like the bulk chemical environment than during reconstructive transformations. Nonetheless, these boundaries mediate the phase stability of MHPs, and may develop distinct properties. Ferroelastic displacive transformations can be induced by pressure or anisotropic stress. In this case, interfaces may exist either between distinct phases across a ferroelastic transformation (e.g. between cubic and tetragonal phases), or between different orientations of the same phase (i.e. twinning). ${ }^{\mathbf{9 1 1 2 9 - 1 3 5}}$ Subtle transformations can also occur due to ordering of electronic dipoles or spins in MHPs, creating interfaces between ferroic domains, although there is active debate about ferroic properties in MHPs. ${ }^{\mathbf{1 3 5 - 1 4 1}}$ The interfaces that form across non-reconstructive phase transformations in MHPs may be difficult to observe by sSNMR techniques, but present an important characterization and engineering challenge nonetheless.
2.2.2. Solid solutions. The stability and phase transformations of MHPs can be tuned by mixing different A-site cations during growth. The tolerance and octahedral factors can be continuously varied by mixing A-site cations in a solid solution, leading to desirable phase stability without altering B-X bonding. Some of the highest-performing single-junction MHP solar cells are composed of a mixture of two or three cations (e.g. cesium, methylammonium and formamidinium). ${ }^{\mathbf{9 1 4 2 - 1 5 0}}$ However, mixed A-site cations can cluster into segregated domains in MHPs (Fig. 2b). ${ }^{\mathbf{1 5 1 - 1 5 6}}$ Clustering can introduce local strain, diminish the stability benefits of homogeneous solid solutions, and introduce grain or domain interfaces that may serve as electronic traps or transport pathways. SSNMR is a powerful tool to understand A-site segregation because of its chemical specificity and capacity to probe multiple length scales. ${ }^{151,154}$

The electronic properties and stability of MHPs can also be tuned in solid solutions of mixed halides. Halides participate in octahedral B-X bonds that form the electronic bands of MHPs. Changing the halide composition in MHPs can tune the bandgap continuously across the entire solar spectrum. ${ }^{\mathbf{1 4 9 , 1 5 7 , 1 5 8}}$ However, halide species are mobile in MHPs and can diffuse due to temperature changes, mechanical strain, potential gradients or illumination. ${ }^{59,159}$ For instance, light illumination of $\mathrm{MAPbI}_{1-x} \mathrm{Br}_{x}$ causes a reversible phase segregation into iodide-rich and bromide-rich regions. ${ }^{\mathbf{1 6 0 , 1 6 1}}$ Sustained illumination can also redistribute halides and point defects in singlehalide MHPs such as $\mathrm{MAPbI}_{3}$, leading to photo-brightening (i.e. increased photoluminescence intensity). ${ }^{162,163}$ Clustering of segregated halides in MHPs, or defect-rich and defect-poor regions, forms concentration gradients or interfaces (Fig. 2b) that may behave as semiconductor heterojunctions. ${ }^{164-170}$ Electronic traps can also become clustered during halide redistribution, or segregate to interfaces between domains, with significant impacts on photocarrier recombination. ${ }^{171}$ Halide redistribution is impacted by the A-site cations, and the effect can be minimized in mixed-cation MHPs. ${ }^{150,172}$ SSNMR is wellsuited to characterize halide redistribution because of its sensitivity to the halide coordination environment of B-site cations as well as the ability to probe the local structure of halides. ${ }^{64,67}$

The pursuit of more environmentally friendly and less-toxic lead-free MHPs has inspired the development of halide perovskites with different B-site cations. ${ }^{173-175}$ For instance, divalent tin, ${ }^{\mathbf{1 7 6 - 1 7 9}}$ manganese ${ }^{\mathbf{1 8 0 , 1 8 1}}$ or germanium ${ }^{\mathbf{1 8 2}}$ can be substituted for lead in MHPs, with improvements in stability and optoelectronic properties in some cases. ${ }^{\mathbf{1 8 3 - 1 8 5}}$ Similar to mixed A-site and X-site MHPs, solid-solutions of mixed B-site perovskites may segregate into distinct domains of different cations (Fig. 2b). ${ }^{180}$ Multivalent B-site substitutes, such as tin, present an additional challenge because they can oxidize $\left(\mathrm{Sn}^{2+}\right.$ to $\left.\mathrm{Sn}^{4+}\right)$ and degrade the MHPs. ${ }^{185}$ Understanding the distribution and stabilization of multivalent B-site cations in MHPs is an important characterization challenge. Aliovalent doping of $\mathrm{B}$ site cations has been explored for several years in the pursuit of n- or p-type MHPs. However, MHPs are generally resistant to 
deviations from electroneutrality due to the ease of formation and mobility of compensating defects, so doping remains a challenge. ${ }^{78}$ MHPs can also be composed of heterovalent B-site substitutes including a combination of mono-, di-, tri- and tetravalent cations (e.g., $\left.\mathrm{Ag}^{+}, \mathrm{Cu}^{+}, \mathrm{Bi}^{3+}, \mathrm{In}^{3+}, \mathrm{Sb}^{3+}, \mathrm{Ti}^{4+}\right) \cdot{ }^{183,184}$ For instance, MHPs with a formula unit of $\mathrm{A}_{2} \mathrm{~B}(\mathrm{I}) \mathrm{B}^{\prime}(\mathrm{III}) \mathrm{X}_{6}$ form elpasolite phases, more commonly known as double perovskites. ${ }^{186-189}$ However, photovoltaic device efficiencies of double perovskites have lagged behind single B-site MHPs due to large band-gaps and poor dispersion of electronic bands. ${ }^{184,190}$ The exploration of new compositions and processing routes for Bsite substituted MHPs requires characterization techniques such as SsNMR that are sensitive to the different nuclei and oxidation states present, and that can resolve segregation, domain interfaces and transformations among these cations.

2.2.3. Low dimensional phases. MHPs with substoichiometric B-site compositions (e.g. lead-deficient) can be synthesized by including certain molecular cations that are larger than the tolerance and octahedral factor limits. This recently discovered family of materials are considered a bridge between 3D and lower-dimensional phases because they form interconnected networks of lower-dimensional MHP regions, separated by octahedral voids that form next to the large cations. ${ }^{191}$ The octahedral vacancies are crystallographically ordered in B-site deficient MHPs prepared with hydroxyethylammonium (HEA) and thioethylammonium (TEA) cations. ${ }^{191-193}$ A related family of materials, described as hollow perovskites, are formed by incorporating other large cations (e.g. ethylenediammonium (en) and 1,2,4-triazolium (TzH)) into the host perovskite lattice by generating randomly distributed B-site and X-site vacancy pairs, but without significantly changing the crystallographic structure. ${ }^{194-200}$ For example, adding en to precursors for $\mathrm{FASnI}_{3}$ during growth forms (en) $\mathrm{FASnI}_{3}$ hollow perovskites with the same crystal structure as $\mathrm{FASnI}_{3}$, promising solar cell efficiency $(\mathrm{PCE}=7.14 \%)$ and significantly improved stability for a tin-based MHP. ${ }^{194}$ These voids form random point-like defects rather than extended lowdimensional structures, leading to short-range interfaces within the lattice (Fig. 2c). As a result, it has been challenging to determine the local chemical environment, distribution and other properties of the large cations in hollow perovskites directly. ssNMR is a promising technique for B-site deficient MHPs because it can isolate the local environment and interactions of large cations near ordered or randomly dispersed octahedral voids.

Layered 2D MHP phases can form when large ammonium or diammonium cations are introduced that exceed the tolerance and octahedral factors of perovskites. ${ }^{3-8}$ The layered phases that form bear intrinsic interfaces between spacer molecule and octahedral metal halide substructures. 2D metal halide phases have been explored for decades as promising anisotropic optoelectronic materials. ${ }^{201-204}$ These spacers are typically insulating, although there is currently a strong incentive to make them electroactive to improve charge transport in optoelectronic devices. ${ }^{205-211}$ The insulating layer of spacer molecules induces quantum and dielectric confinement of electronic states in the metal halide octahedra. ${ }^{212-219}$ Therefore, the bandgap, exciton binding and recombination dynamics can be changed by varying the number of metal halide octahedra, $n$, within each perovskite layer. For instance, adding butylammonium (BA) to the growth precursors for $\mathrm{MAPbI}_{3}$ forms layered Ruddlesden-Popper phases $\left(\mathrm{BA}_{2} \mathrm{MA}_{n-1} \mathrm{~Pb}_{n} \mathrm{I}_{3 n+1}\right)$ composed of separated 2D MAPbI ${ }_{3}$ slabs ranging from $n=1$ to about $n=7$ octahedra thick in the layer stacking direction, depending on stoichiometry (Fig. 2c).,5,220-222 Organic ammonium spacer cations containing long-chain alkyl-, aryl-, adamantantyl- and alkylphenyl- and heterocyclic moieties can be readily incorporated to generate layered structures of different compositions. ${ }^{5}$ The lattice plane along which this layering occurs depends on the composition of the MHP. ${ }^{3-5,7}$ Research on low-dimensional halide perovskites is currently flourishing because these materials demonstrate tunable quantum confinement, anisotropic optoelectronic properties and improved ambient stability compared to 3D MHPs. ${ }^{3-8,218}$ The $2 \mathrm{D}$ interfaces that form at the unit-cell scale in layered MHPs require local characterization techniques such as SSNMR that can probe the short-range interactions between organic and inorganic species.

The layered phases present the same variety of intrinsic interfaces as the higher-dimensional MHPs. Grain boundaries of layered MHPs can have distinct optoelectronic properties from the bulk and serve as efficient recombination or transport centers. ${ }^{112,223,224}$ Mixed A-site, halide and B-site solid solutions and heterostructures have also been explored to tune the properties and stability of various layered MHPs. ${ }^{164,225-230}$ Moreover, layered MHPs synthesized from mixtures of different spacer cations can form solid solutions within the spacer substructure (Fig. 2b). ${ }^{231-234}$ During polycrystalline film growth, phase segregation between regions with different 2D confinement indices (the $n$ value from the formula unit $\mathrm{R}_{2} \mathrm{~A}_{n-1} \mathrm{~B}_{n} \mathrm{X}_{3 n+1}$ ) can occur. Layered MHPs with a nominal stoichiometry of $n$ greater than 2 typically segregate into regions of higher and lower $n$-values due to solution-processing kinetics., ${ }^{5,235-241}$ These polycrystalline materials have optical and transport properties characteristic of bulk heterojunctions..$^{239,242-246}$ The desirable stability of layered MHPs have inspired efforts to incorporate these phases within 3D MHPs, or as capping and passivation layers, for high-performing photovoltaic devices., ${ }^{5,8}$ The local structures that form in these mixed low-dimensional MHP films are challenging to characterize and control. Mixtures of layered phases with different $n$-values can form due to epitaxial intergrowth, nanoscale disorder or nucleation and growth of segregated grains. ${ }^{236,238,240,241,247,248}$ Low-dimensional MHPs exhibit interfacial disorder and interactions at the molecular, unit cell and grain scales, and offer a compelling opportunity for study by multinuclear ssNMR methods.

Nanocrystals (NCs) of MHP phases can be synthesized with tunable composition, morphology and interfacial chemistry (Fig. 2c). Controlled nucleation and growth of 0D, 1D and 2D MHP nanostructures can be accomplished from liquid or vapor phases, ranging from quantum-confined nanoparticles to polycrystalline microparticles. ${ }^{56,249-254}$ The structure and properties of MHP NCs are largely defined by their interfaces with the surrounding solution (in colloidal phases) or matrix (in solid composites) because of their large surface-to-volume 
ratio. ${ }^{\mathbf{1 2 6 , 2 5 5 - 2 5 8}}$ There has been tremendous interest in MHP NCs (often called perovskite quantum dots, even for particles larger than the $\sim 5 \mathrm{~nm}$ limit for quantum confinement) for lighting applications because of their near-unity photoluminescence quantum yield, narrow emission and tunable color gamut..$^{15,25,158,257,259,260}$ The unique combination of these optical properties and solution processability makes them suitable candidates for display technologies. MHP NCs can assemble into microparticles and superlattices in dispersions or upon deposition. ${ }^{\mathbf{4 2 , 2 3 3 , 2 6 1 - 2 6 9}}$ Perovskite NC films are promising candidates for optoelectronic devices, but their limited ambient stability and charge transport across ligand-NC interfaces remains a challenge. ${ }^{15,51,257,259,270,271}$ The small size of MHP NCs can also induce strain and modify surface energies, altering the energetics of particular phases (e.g. stabilized cubic $\mathrm{CsPbI}_{3}$ at room temperature). ${ }^{272,273}$ This in turn may cause local distortions and allow for the existence of metastable structures that would not be observed in the bulk. Finally, the growth processes used to synthesize MHP NCs can introduce interfacial species with binding motifs and compositions that would be difficult or impossible to achieve in microcrystalline MHPs. ${ }^{65,274-276}$ All of these properties have attracted a great deal of interest from spectroscopists who have used NMR techniques in the liquid and solid state to explore interfacial phenomena in MHP NCs. ${ }^{64,65,251}$

\section{Length and timescales of physical processes}

The following section outlines the length and time scales of different physical processes occurring in MHPs. We place these interactions in context with commonly used characterization techniques, with an emphasis on ssNMR techniques, and describe practical limitations for experimentalists. Fig. 3 illustrates the length and timescales of dynamic processes in MHPs along with fundamental limits of common characterization techniques, including ssNMR.

The physical processes that affect MHPs for device applications range from sub-femtoseconds (fs) to multi-year timescales. The fastest interactions probed in MHPs are scattering events between incident photons, electrons or ions and constituent atoms. For instance, X-ray diffraction (XRD) relies on elastic scattering of X-rays with core electrons in MHP atoms. At fs time-scales ion positions can be treated as a rigid 'snapshot' during each scattering event (i.e. the adiabatic BornOppenheimer approximation). ${ }^{277,278}$ Ultrafast optical

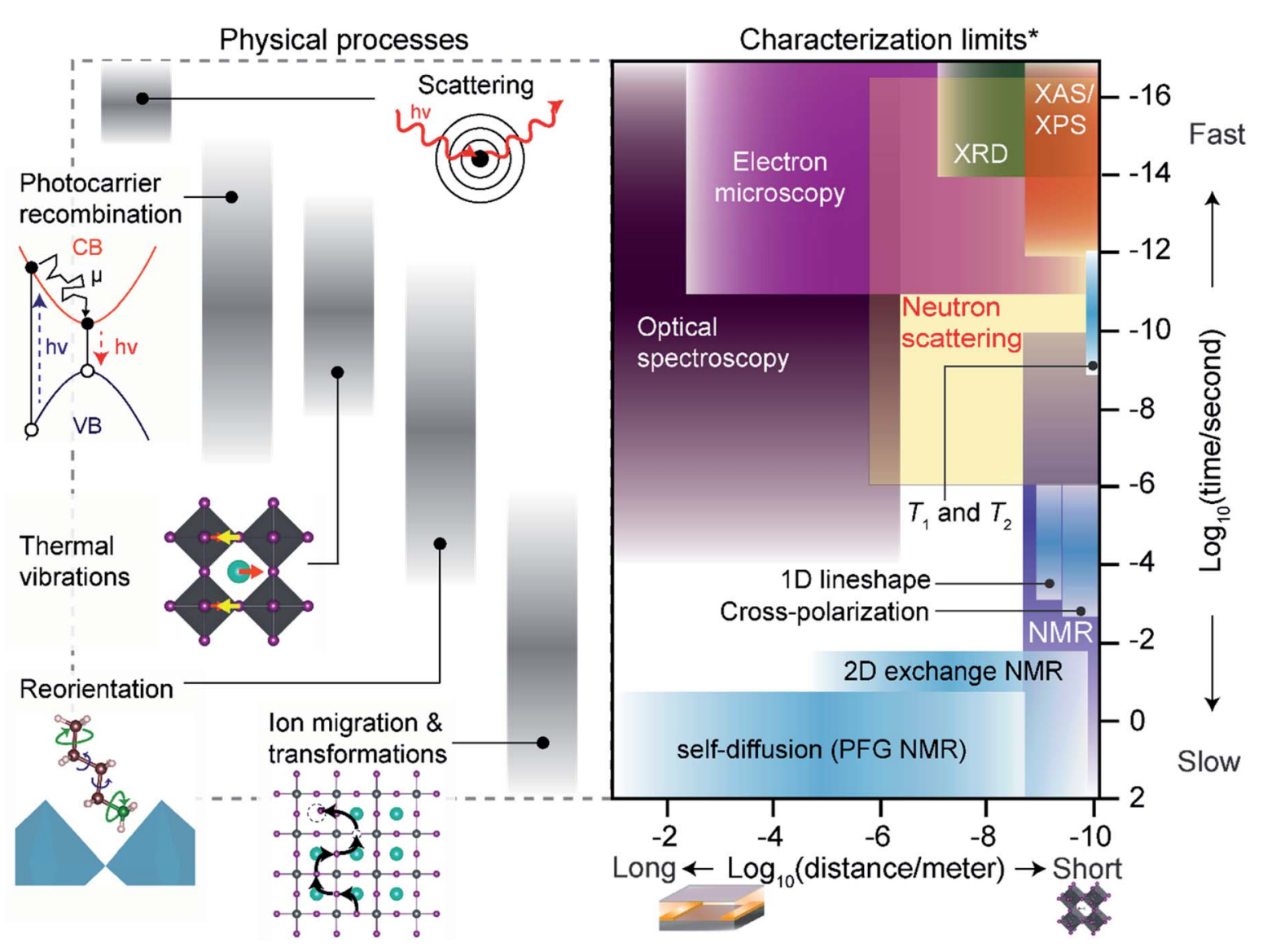

Fig. 3 Comparison of length and timescales: the range of timescales of physical processes in MHPs is presented alongside the fundamental time and length scales that several characterization techniques can probe in MHPs. XRD: X-ray diffraction, XAS - X-ray absorption spectroscopy, XPS - X-ray photoelectron spectroscopy, PFG - pulsed-field gradient, CB - conduction band, VB - valence band. *Characterization limits are defined based on their fundamental interactions, not constraints on acquisition times or sample size. 
spectroscopy of MHPs (e.g. transient absorbance and fluorescence) approach fs resolution, ${ }^{279}$ but direct observations of atom positions by X-ray and electron scattering have recently reached ps resolution. ${ }^{\mathbf{2 8 0 - 2 8 2}}$ Nonetheless, even non-ultrafast scattering integrates distinct 'snapshots' of atomic positions. The photocarriers formed after initial scattering events migrate, scatter and recombine over timescales ranging from fs to $\mu \mathrm{s}$. Photocarrier dynamics in MHPs have attracted a great deal of experimental and theoretical research, ${ }^{279,283-286}$ and impact optoelectronic device performance. Fast radiative recombination rates and strong exciton binding are beneficial for lightemitting applications to prevent non-radiative recombination, ${ }^{15}$ but longer lifetimes and diffusion distances aid in photogenerated charge extraction for photovoltaic devices. ${ }^{286,287}$ The collective motion of ions (i.e. vibrations, phonons) in MHPs occurs at timescales that overlap with photocarrier dynamics in MHPs (Fig. 3). The fastest ionic vibrations occur in the infrared spectrum $(\sim \mathrm{fs})$ for covalent bonds in molecular A-site and spacer cations. Lower-frequency octahedral phonons have important effects on exciton binding, carrier mobility, lifetimes and non-radiative recombination. ${ }^{45,60,288-290}$

Solid-state NMR techniques can access the timescales of photocarrier dynamics and vibrational modes through analysis of $T_{1}$ and $T_{2}$ relaxation times and other techniques (Section 4). ${ }^{66}$ Molecules in MHPs also reorient at longer timescales (nanoseconds to microseconds) than MHP phonon vibrations or photocarrier lifetimes. Molecular reorientations can introduce local octahedral distortions ${ }^{\mathbf{1 1 0 , 2 9 1 , 2 9 2}}$ and transient electronic ${ }^{293,294}$ or dielectric disorder. ${ }^{295}$ Techniques including temperature-dependent broadband dielectric spectroscopy, ${ }^{291,296-298}$ inelastic neutron scattering, ${ }^{292,299-302}$ and NMR dynamics ${ }^{66,291,303-309}$ studies can access the frequencies of different reorientation modes, ranging from fast tumbling of small A-site cations such as methylammonium (ps-ns), to slow rotations $(\mu \mathrm{s})$ of phenylethylammonium spacers in 2D Ruddlesden-Popper phases. When gradients in chemical potential, heat, light and electromagnetic fields are present, ions can diffuse at timescales ranging from nanoseconds to seconds. ${ }^{59,60,310,311}$ Section 6 describes ssNMR approaches to measure halide diffusion in MHPs, but the technique is also well-suited to probe A-site, B-site, spacer, additive and solvent transport. At the longest timescales of device lifetimes (hours to years), most characterization techniques have adequate time resolution to capture in situ or ex situ transformation kinetics.

The practical acquisition times required for the techniques described above may be much more restrictive than their fundamental limits. For instance, a typical $\mathrm{Cu} \mathrm{K} \alpha$ sourced X-ray diffractometer may integrate fs-scale scattering events but require several minutes to obtain useful information. Acquisition times in ssNMR experiments vary tremendously depending on the sample material and interactions probed, but often require hours or days of signal averaging for adequate signal-tonoise ratios. Acquisition time constraints are imposed by equipment, type of nuclei and experiments, and labor costs, as well as the environmental stability of MHPs. For instance, Snbased MHPs often degrade within minutes of ambient exposure, for which acquisition of multidimensional sSNMR experiments is less straightforward. ${ }^{185,312,313}$ Acceleration of acquisition times for ssNMR experiments, particularly for masslimited samples such as thin films, have been pivotal for the characterization of MHPs. ${ }^{\mathbf{3 1 4}}$

The length scales of physical interactions in MHP devices span from the unit-cell $(\AA)$ scale to many cm. Laboratory scale optoelectronic device stacks tend to be roughly a micron thick (not including the substrate) and $\sim \mathrm{cm}^{2}$ in area. Heterogeneity across this entire span of distances can have important effects on optoelectronic device properties. ${ }^{44}$ Fig. 3 highlights the fundamental length scales that some common techniques can access, although practical spatial resolutions (i.e. the resolvable size of the sample or probe) can be much coarser. The atomic (A) scale structure of MHPs can be probed by spectroscopic or scattering techniques with short-wavelength particles (photons, neutrons, electrons, ions). X-ray, electron or neutron scattering can resolve the atomic structure of crystalline materials with sub-A precision. However, the spatial resolution of sample regions that can be probed by these techniques may be much more limited. ssNMR can probe interactions and structure across a particularly wide range of length scales. Homo- and heteronuclear correlation methods can probe distances with atomic-scale resolution, ${ }^{63}$ and pulsed-field gradient (PFG) diffusion and magnetic resonance imaging (MRI) methods resolve $\mathrm{mm}$ scale features and transport distances. ${ }^{315,316}$ However, the length scales that can be probed by SSNMR techniques are generally limited by the sensitivity of the instrument to particular nuclei or type of NMR experiment. MRI techniques have some ability to localize signal to microscopic scales, but this is highly specialized. ${ }^{317,318}$ Practical considerations for the spatial resolution of different ssNMR techniques are described in Section 4.

\section{NMR spectroscopy tutorial}

This section covers some basic aspects, sample preparation and practical considerations of SSNMR spectroscopy for the characterization of MHPs. The essence of SSNMR is elemental specificity and natural abundance of NMR active isotopes (Fig. 4a), which can be separately excited and detected. The MHPs and the contact layers contain several NMR active nuclei: ${ }^{1} \mathrm{H},{ }^{7} \mathrm{Li},{ }^{11} \mathrm{~B},{ }^{13} \mathrm{C}$, ${ }^{14} \mathrm{~N},{ }^{15} \mathrm{~N},{ }^{19} \mathrm{~F},{ }^{27} \mathrm{Al},{ }^{33} \mathrm{~S},{ }^{35} \mathrm{Cl},{ }^{37} \mathrm{Cl},{ }^{39} \mathrm{~K},{ }^{41} \mathrm{~K},{ }^{49} \mathrm{Ti},{ }^{55} \mathrm{Mn},{ }^{63} \mathrm{Cu},{ }^{65} \mathrm{Cu}$, ${ }^{67} \mathrm{Zn},{ }^{73} \mathrm{Ge},{ }^{79} \mathrm{Br},{ }^{81} \mathrm{Br},{ }^{85} \mathrm{Rb},{ }^{87} \mathrm{Rb},{ }^{107} \mathrm{Ag},{ }^{109} \mathrm{Ag},{ }^{113} \mathrm{Cd},{ }^{119} \mathrm{Sn},{ }^{121} \mathrm{Sb}$, ${ }^{123} \mathrm{Sb},{ }^{123} \mathrm{Te},{ }^{125} \mathrm{Te},{ }^{127} \mathrm{I},{ }^{133} \mathrm{Cs},{ }^{207} \mathrm{~Pb}$, and ${ }^{209} \mathrm{Bi}$. A wide variety of NMR interactions such as chemical shift (characterized by chemical shift anisotropy, CSA), dipole-dipole couplings, quadrupolar interactions, knight shifts, hyperfine interactions and paramagnet-induced interactions can be used to characterize local bonding environments and inter- and intramolecular interactions at the sub-nanometer to nanometer length scales. For a detailed description of basic concepts of NMR and different nuclear spin interactions, we refer the reader to textbooks. ${ }^{319-321}$ Chemical shifts are sensitive to local bonding environments. Dipole-dipole couplings are sensitive to through-space inter- and intramolecular proximities between specific nuclei and the fluctuations in the local structures. Quadrupolar interaction arises from the electric field gradient at the nucleus, which is sensitive 

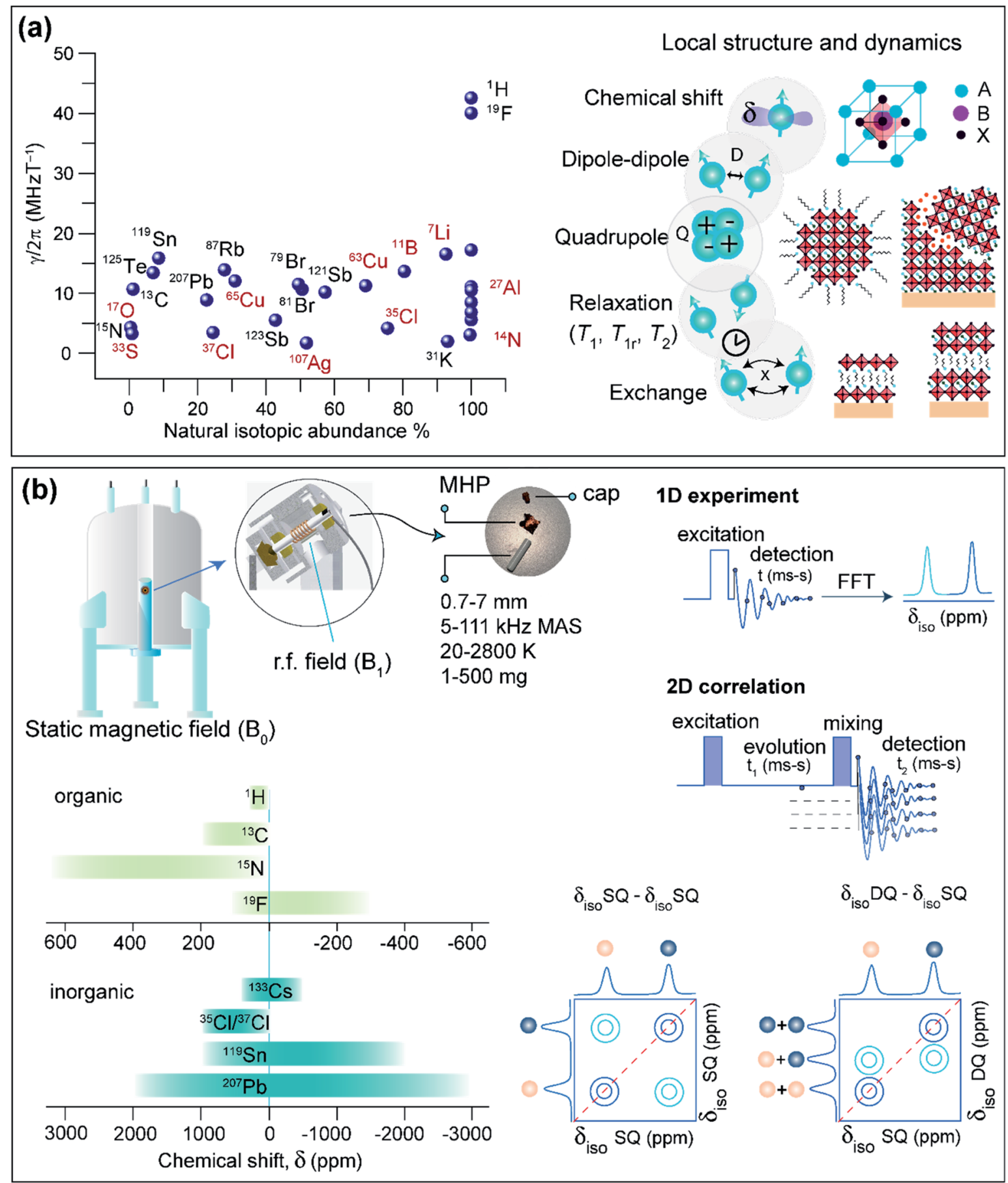

Fig. 4 ssNMR spectroscopy of MHPs: (a) NMR nuclei relevant for MHPs characterization plotted as a function of sensitivity and natural abundance, and a schematic of nuclear spin interactions, relaxation and exchange that can be used to elucidate structures and dynamics. (b) schematic of solid-sate NMR setup along with the acquisition of $1 \mathrm{D}$ and 2D ssNMR experiments, and chemical shift ranges of organic and inorganic sites in MHPs. FFT - Fast Fourier-Transformation; $\gamma$ - gyromagnetic ratio; rf - radiofrequency; $\delta_{\text {iso }}-$ isotropic chemical shift; SQ Single-Quantum; DQ - Double-Quantum.

to symmetry of the local bonding environments and structural changes in the coordination sphere and molecular fluctuations. The dynamic motion associated with various molecular processes can be investigated at different time scales through SSNMR spectroscopy techniques.

\subsection{Sample preparation, data acquisition and analysis}

Solid-state NMR spectra of MHPs, HTMs, ETMs and their blends can be acquired in a variety of forms, such as microcrystalline powders, thin films scraped off from glass substrates, crushed thin films, or slurry-like materials. These samples can be packed into cylindrical zirconia or ceramic 
sample holders, referred to as rotors (Fig. 4b). A packed rotor is then inserted into a probehead placed in a static magnetic field $\left(B_{0}\right)$, and excited with a radio frequency (rf) pulse or a sequence of rf pulses and delays. Most of the solid-state NMR experiments are performed under Magic-Angle Spinning (MAS) conditions, that is by spinning rotors at a set angle $54.74^{\circ}$ with respect to the external field $\left(B_{0}\right)$. MAS approach partially or even completely averages out the anisotropic interactions that broaden static NMR spectra. Today, probeheads and rotors of varying diameters in the range of $0.7 \mathrm{~mm}$ to $7 \mathrm{~mm}$ (which can be filled with $\sim 1 \mathrm{mg}$ to up to $1 \mathrm{~g}$ of material), capable of achieving spinning speeds in the range of $5 \mathrm{kHz}$ to over $111 \mathrm{kHz}$, are available for carrying out MAS NMR experiments. Most of the rotors used in MAS experiments are air-tight such that the moisture sensitive samples can be characterized. Variable Temperature (VT) experiments can be performed in the range of 20-450 K, although dedicated high temperature probes increase this extent up to $2800 \mathrm{~K}^{\mathbf{3 2 2 - 3 2 4}}$ High pressure experiments of up to $90 \mathrm{GPa}$ are feasible, ${ }^{325}$ and a combination of high temperatures and pressures can be achieved. ${ }^{326}$ In addition, static NMR experiments of bulk crystals and intact thin films may be carried out as functions of moisture exposure and light illumination. ${ }^{327,328}$

In a simple 1D NMR experiment, a single pulse rf excitation is applied to acquire a time domain signal which is referred to as free-induction decay (FID). The fast Fourier transformation (FFT) of the time-domain signal yields a frequency domain spectrum. If the MAS rate is high enough to average out anisotropic interactions, 1D signals corresponding to chemically distinct sites can be resolved (at least for spin-1/2 nuclei in crystalline materials). The isotropic chemical shifts $\left(\delta_{\text {iso }}\right)$ are characteristic to the local chemical environments and structures, which can be obtained in most cases by analyzing 1D NMR spectra.

A sequence of rf pulses and delays can be applied to acquire 2D NMR spectra. 2D pulse sequences can be generally classified into excitation, evolution, mixing and detection steps (Fig. 4b). Each step can be engineered to obtain specific information on structure and dynamics. The analysis of $2 \mathrm{D}$ correlation spectra allows the local structures and intermolecular interactions to be elucidated in MHPs. 2D correlation experiments involving isotropic chemical shifts $\left(\delta_{\text {iso }}-\delta_{\text {iso }}\right), \delta_{\text {iso }}$ and dipolar couplings $\left(\delta_{\text {iso }}-\mathrm{D}\right), \delta_{\text {iso }}$ and $J$-couplings $\left(\delta_{\text {iso }} J\right)$ are widely used to characterize materials including MHPs. For example, information about through-bond connectivity or through-space interactions can be obtained by analyzing scalar $(J)$ and dipolar(D)-mediated 2D correlation spectra. The Double-Quantum (DQ) signals can be excited and detected for spatially proximate and dipole-dipole coupled spin pairs (e.g., through-space ${ }^{1} \mathrm{H}-{ }^{1} \mathrm{H}$ proximities within 5 A). ${ }^{329}$ In a 2D Double-Quantum-Single-Quantum (DQ-SQ) correlation experiment, the DQ signal $\left(\delta_{\mathrm{DQ}}\right)$ evolves at the sum of the SQ signals $\left(\delta_{\mathrm{SQ}}\right)$ leading to $2 \mathrm{D}$ peaks on the diagonal that originate from chemically equivalent sites, or off-diagonal 2D peaks between chemically distinct sites within the same molecule or between neighboring molecules (Fig. 4b). Notably, homonuclear DQ-SQ correlation $\left({ }^{1} \mathrm{H}-{ }^{1} \mathrm{H},{ }^{19} \mathrm{~F}-{ }^{19} \mathrm{~F},{ }^{13} \mathrm{C}-{ }^{13} \mathrm{C}\right)$ spectroscopy provides information on the intermolecular interactions and interatomic distances. Of particular interest is the magnetization exchange, also referred to as the spin diffusion (SD) experiment, which allows the through-space proximities between neighboring sites to be probed and analyzed. Spin diffusion experiments mediated through dipolar couplings (2D SQ-SQ correlation, Fig. 4b) extend the NMR length scales beyond a nanometer by enabling the magnetization to propagate between more distant chemical sites through a network of dipolar coupled spins. 2D ${ }^{1} \mathrm{H}-{ }^{1} \mathrm{H}$ DQ-SQ and SD experiments are particularly suitable to probe intrinsic and extrinsic interfaces in MHPs, as will be discussed in Section 5. Likewise, 2D heteronuclear correlation experiments $\left({ }^{1} \mathrm{H}_{-}{ }^{13} \mathrm{C},{ }^{1} \mathrm{H}_{-}{ }^{207} \mathrm{~Pb}\right.$ and $\left.{ }^{1} \mathrm{H}_{-}{ }^{133} \mathrm{Cs}\right)$ can be carried out to probe the chemical nature and vicinities between $\mathrm{A}$ and $\mathrm{B}$ sites in MHPs at sub-nm to $\mathrm{nm}$ distances, facilitating NMR-based structure elucidation.

\subsection{Resolution and sensitivity}

NMR spectral resolution plays an important role in the structural elucidation of material solids such as MHPs. Resolution in sSNMR spectra can be attained by carrying out experiments at high magnetic fields, fast MAS or a combination of these two. When a fast-spinning limit is reached, i.e., the MAS frequency is greater than the chemical-shift anisotropy and multitudes of dipole-dipole couplings, high-resolution can be fulfilled. Resolution enhancement can also be attained by decoupling of dipole-dipole couplings between homo- $\left(\text { e.g., }{ }^{1} \mathrm{H}-{ }^{1} \mathrm{H}\right)^{330,331}$ and heteronuclei $\left(\text { e.g. },{ }^{13} \mathrm{C}-{ }^{1} \mathrm{H}\right)^{332}$ and/or by Combined Rotation and Multiple Pulse Spectroscopy (CRAMPS) ${ }^{333}$ which employs moderate MAS rates (often $<15 \mathrm{kHz}$ ) in conjunction with decoupling sequences. Motional averaging of A-site cations $\left(\mathrm{MA}^{+}, \mathrm{FA}^{+}\right)$, specific functional groups such as $-\mathrm{CH}_{3},-\mathrm{NH}_{3}$ and phenyl groups in spacer cations, or translational mobilities of cations in the voids of $\mathrm{BX}_{6}$ octahedra lead to partially averaged anisotropic interactions, which improves resolution in the ssNMR spectra. As discussed in the previous section, 2D NMR spectroscopy provides improved resolution by spreading the signals into two frequency dimensions. In contrast, ssNMR spectra of B site cations and X site anions face a resolution challenge due to the large chemical shift anisotropy (CSA) and quadrupolar interactions, respectively. CSA scales linearly with $B_{0}$, whereas quadrupolar interaction is inversely proportional to $B_{0}$. In this respect, a combination of high $B_{0}$ and fast MAS are expected to help to enhance the resolution in the NMR spectra of quadrupolar nuclei $\left({ }^{11} \mathrm{~B},{ }^{14} \mathrm{~N},{ }^{27} \mathrm{Al}\right.$, ${ }^{33} \mathrm{~S},{ }^{35} \mathrm{Cl},{ }^{37} \mathrm{Cl},{ }^{39} \mathrm{~K},{ }^{41} \mathrm{~K},{ }^{49} \mathrm{Ti},{ }^{55} \mathrm{Mn},{ }^{63} \mathrm{Cu},{ }^{65} \mathrm{Cu},{ }^{67} \mathrm{Zn},{ }^{73} \mathrm{Ge},{ }^{79} \mathrm{Br}$, ${ }^{81} \mathrm{Br},{ }^{85} \mathrm{Rb},{ }^{87} \mathrm{Rb},{ }^{121} \mathrm{Sb},{ }^{123} \mathrm{Sb},{ }^{127} \mathrm{I},{ }^{133} \mathrm{Cs}$ and ${ }^{209} \mathrm{Bi}$ ), and the resolution in ${ }^{207} \mathrm{~Pb}$ and ${ }^{119} \mathrm{Sn}$ NMR spectra can be improved using fast MAS at relatively low $B_{0}$.

Sensitivity gain in ssNMR can be achieved by acquiring the spectra at higher magnetic fields. Static magnetic fields in the range of $2.4 \mathrm{~T}$ to $35.2 \mathrm{~T}\left({ }^{1} \mathrm{H}\right.$ Larmor frequency range from 100 $\mathrm{MHz}$ to $1.5 \mathrm{GHz}$ ) are available to carryout ssNMR experiments of material solids. Other methods of sensitivity enhancements include Cross-Polarization (CP) MAS NMR experiments. CPMAS experiments exploit the transfer of polarization from abundant nuclei $\left(\right.$ e.g. , $\left.\mathrm{a}={ }^{1} \mathrm{H},{ }^{19} \mathrm{~F}\right)$ to dilute nuclei $\left(e . g ., \mathrm{b}={ }^{13} \mathrm{C}\right.$, ${ }^{15} \mathrm{~N}$ ) through the network of dipole-dipole interactions, which 
results in a signal-to-noise $(\mathrm{S} / \mathrm{N})$ ratio increased by a factor of up to $\gamma_{\mathrm{a}} / \gamma_{\mathrm{b}}, \gamma$ being the corresponding gyromagnetic ratios.

One of the most important techniques in the context of atomic-level studies of surfaces is Dynamic Nuclear Polarization Surface Enhanced NMR Spectroscopy (DNP SENS). ${ }^{334}$ DNP SENS makes it possible to substantially increase the sensitivity of NMR by transferring the electron spin polarization to nuclei via hyperfine interactions. This leads to a theoretical sensitivity gains of a factor of $\gamma_{e} / \gamma_{n}$, where $\gamma_{e}$ and $\gamma_{n}$ are the gyromagnetic ratios of the electron and nuclear spins, respectively. Accordingly, enhancements of up to $\sim 660, \sim 2600$, and $\sim 6600$ for ${ }^{1} \mathrm{H}$, ${ }^{13} \mathrm{C}$, and ${ }^{15} \mathrm{~N}$, respectively, can be attained. The source of the unpaired electrons is typically a stable nitroxide biradical, which is introduced as a dilute solution in a solvent which does not dissolve the material under study (i.e. an antisolvent with respect to the solid material). One successful implementation of this protocol is the incipient wetness impregnation method, in which the amount of radical-containing solution is just enough to coat the particles without making the powder excessively wet. Since the radical resides on the surface of the particles, the DNP effect is most pronounced for the surface sites, which are enhanced preferentially compared to the bulk of the crystallites. The high surface polarization can also be used to increase the sensitivity of the nuclei in the bulk by taking advantage of spin diffusion (SD). ${ }^{335}$ While in typical organic solids SD relies on the dense network of ${ }^{1} \mathrm{H}$ nuclei, it has also been demonstrated to occur in proton-free solids, considerably extending the applicability of DNP in inorganic materials. ${ }^{336}$ Taken together, DNP can enhance the sensitivity of species starting from those located directly at the surface to those tens to hundreds of nanometers away from the surface inside the bulk, depending on the material, type of SSNMR experiment and how the experiment is set up. DNP experiments are typically carried out at low temperatures ( $100 \mathrm{~K})$ but protocols have been devised to make it feasible up to room temperature. ${ }^{337}$

DNP of MHPs has only been moderately successful so far with the reported ${ }^{1} \mathrm{H}_{-}{ }^{207} \mathrm{~Pb}$ enhancements not exceeding 20 (for nanocrystalline $\mathrm{MAPbCl}_{3}$ ) and no measurable enhancement for $\mathrm{MAPbI}_{3} \cdot{ }^{314,338}$ This is caused by the short ${ }^{1} \mathrm{H} T_{1}$ times under the typical DNP experimental conditions, which in turn make ${ }^{1} \mathrm{H}-{ }^{1} \mathrm{H}$ SD inefficient and prevent the polarization of deeper sites which are far from the surface. Piveteau et al. have reported DNP SENS of $\mathrm{CsPbBr}_{3}$ nanocrystals in a frozen solution, although in that case the enhancement was not quantified because of the high dilution of the material. ${ }^{338}$ Enabling high efficiency DNP SENS for MHPs remains an ongoing challenge.

\section{Interfaces in MHPs probed by solid-state NMR}

Traditional multinuclear NMR approaches can be used for the characterization of local chemical environments in a wide variety of MHPs including 3D phases, solid solutions, defectengineered phases, 2D layered structures, and surfacepassivated MHPs. Despite the strong similarities in molecular topologies, MHPs exhibit structurally diverse interfaces. ssNMR can resolve pertinent questions about the interfacial chemistry of MHPs, including (i) short-range order and disorder in A sites and $\mathrm{BX}_{6}$ octahedra, (ii) the degree of A-cation intermixing and phase separation, (iii) spacer cation packing arrangements in low-dimensional MHPs, (iv) the extent of octahedral tilt and local structural distortions, (v) structural transformations and degradation products, and (vi) slow dynamic processes at organic-inorganic interfaces including reorientational modes of organic cations, cation diffusion and halide migration.

The local environments of $\mathrm{A}$ and $\mathrm{B}$ site cations can be identified and distinguished by analyzing ${ }^{1} \mathrm{H},{ }^{13} \mathrm{C},{ }^{14} \mathrm{~N},{ }^{15} \mathrm{~N},{ }^{133} \mathrm{Cs}$, ${ }^{207} \mathrm{~Pb}$ and ${ }^{119} \mathrm{Sn}$ chemical shifts. In addition, through-space proximities of A-A sites, B-B sites, and A-B sites can be probed through the dipolar-based $2 \mathrm{D}$ correlation experiments such as, for example, ${ }^{1} \mathrm{H}-{ }^{1} \mathrm{H},{ }^{133} \mathrm{Cs}-{ }^{1} \mathrm{H},{ }^{207} \mathrm{~Pb}-{ }^{1} \mathrm{H}$ and ${ }^{207} \mathrm{~Pb}-{ }^{207} \mathrm{~Pb} \quad 2 \mathrm{D}$ correlation NMR spectra, which manifest weak and strong $2 \mathrm{D}$ peaks corresponding to long and short distances, respectively. In addition, quadrupolar nuclei $\left(\right.$ e.g. $,{ }^{35} \mathrm{Cl},{ }^{79} \mathrm{Br},{ }^{81} \mathrm{Br},{ }^{115} \mathrm{In},{ }^{127} \mathrm{I}$, ${ }^{209} \mathrm{Bi}$ ) exhibit large quadrupolar interactions, which make these nuclei amenable to both NMR and NQR, providing information on the local chemical environments of halogen atoms. SSNMR experiments have also been employed to map the A-site cation distribution, interfacial structures, degradation products, point defects and dynamics in MHPs, as discussed below. For a recent summary on SSNMR studies of MHPs, we refer the reader to the reviews by Franssen et al. (structural and dynamical aspects), ${ }^{67}$ Bernard et al. (dynamics of MA in $\mathrm{MAPbX}_{3}$ ), ${ }^{306}$ Moudrakovski (dynamics in MHPs), ${ }^{66}$ Senocrate et al. (ion conduction), ${ }^{311}$ Smock et al. (MHP nanocrystal surfaces) ${ }^{65}$ and Piveteau et al. (ssNMR and NQR of MHPs). ${ }^{64}$ In the subsequent sections, we demonstrate how SSNMR techniques can be used to probe intrinsic and extrinsic interfacial structure and properties in MHPs.

\subsection{Cations, anions and degradation products in 3D MHPs}

Pure and mixed-cation/anion MHPs exhibit various organicinorganic interfaces. In 3D crystalline phases, the local structures and interactions involving $\mathrm{BX}_{6}$ and chemically diverse monovalent cations have been investigated by $1 \mathrm{D}$ and $2 \mathrm{D}$ SSNMR techniques. ${ }^{\mathbf{1 5 2 - 1 5 4 , 1 5 4 , 3 3 9 - 3 4 1}}$ Specifically, analysis of multinuclear $\left({ }^{1} \mathrm{H},{ }^{2} \mathrm{H},{ }^{13} \mathrm{C},{ }^{14} \mathrm{~N},{ }^{15} \mathrm{~N},{ }^{39} \mathrm{~K},{ }^{87} \mathrm{Rb}\right.$, and $\left.{ }^{133} \mathrm{Cs}\right){ }_{\mathrm{NMR}}$ chemical shifts has been shown to be an effective approach to gain insight into the local structural environments of monovalent cations in MHPs. ${ }^{153,154,304,339,342-348}$ Kubicki et al. studied cation doping in 3D MHPs using ${ }^{39} \mathrm{~K},{ }^{87} \mathrm{Rb}$ and ${ }^{133} \mathrm{Cs}$ NMR spectroscopy, and revealed that the $\mathrm{K}^{+}$and $\mathrm{Rb}^{+}$ions do not incorporate into the 3D perovskite structure of MHPs, while $\mathrm{Cs}^{+}$ ions do. ${ }^{153,154}$ Atomic-level understanding including local order in $\mathrm{BX}_{6}$ octahedra and mapping of cation distributions and interactions between them is expected to help to better understand the optoelectronic properties.

In a study by Grüninger et al., 2D ${ }^{1} \mathrm{H}-{ }^{1} \mathrm{H}$ DQ-SQ correlation NMR (Fig. 5) was combined with molecular dynamics (MD) simulations using machine-learning force-fields (MLFFs) to unravel the clustering of $\mathrm{MA}^{+}$and $\mathrm{FA}^{+}$in mixed composition $\mathrm{MA}_{1-x} \mathrm{FA}_{x} \mathrm{PbI}_{3}(x=0.25,0.5$ and 0.75$)$ and $\mathrm{MA}_{0.15} \mathrm{FA}_{0.85} \mathrm{PbI}_{2.55^{-}}$ $\mathrm{Br}_{0.45} \cdot{ }^{151}$ Fig. 5a shows the ${ }^{1} \mathrm{H}$ DQ-SQ signal intensities 
(a)

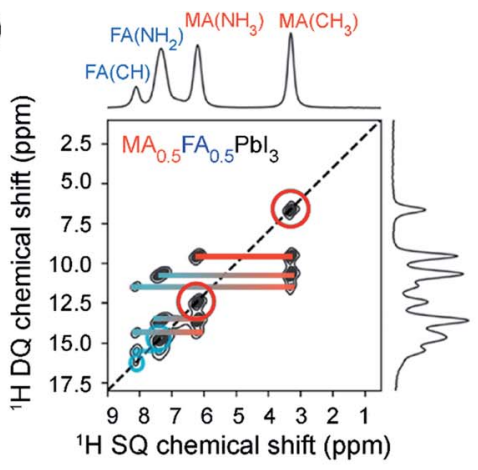

(b)

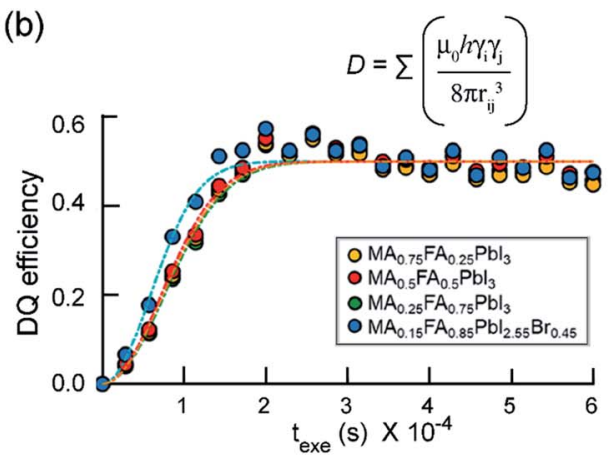

(c)
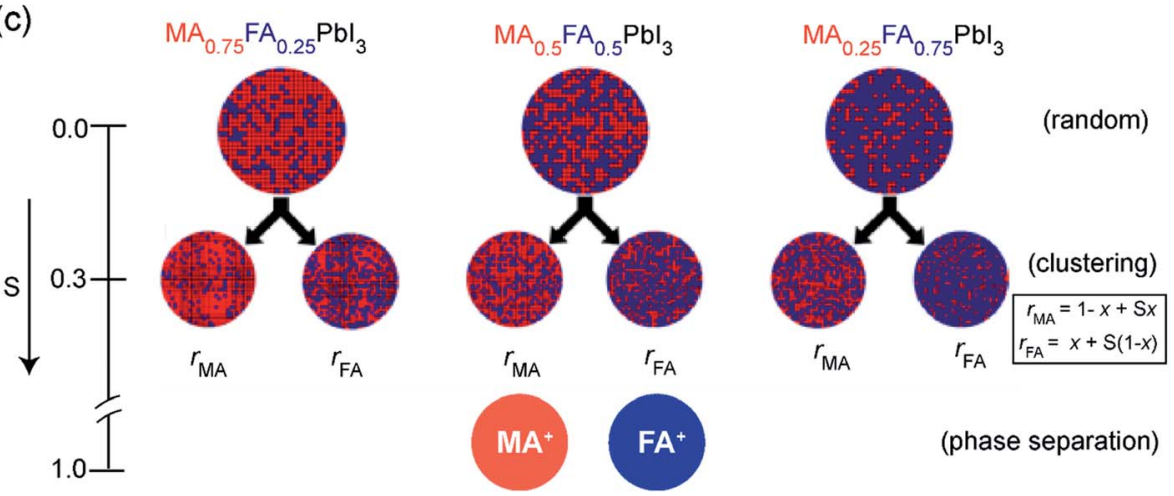

(phase separation)

Fig. 5 Clustering of cations in mixed A-site MHPs: (a) $2 \mathrm{D}{ }^{1} \mathrm{H}-{ }^{1} \mathrm{H} D Q-S Q$ correlation spectra of mixed A-site cation and anion MHPs: thick horizontal lines depict intramolecular ${ }^{1} \mathrm{H}-{ }^{1} \mathrm{H}$ proximities associated with MA cations (red), FA cations (blue), and intermolecular $\mathrm{H}-\mathrm{H}$ proximities between $\mathrm{MA}$ and $\mathrm{FA}$ cations (blue-to-red) in $\mathrm{MA}_{0.5} \mathrm{FA}_{0.5} \mathrm{Pbl}_{3}$. (b) Comparison of ${ }^{1} \mathrm{H} \mathrm{DQ}$ build-up curves in $\mathrm{MA}_{1-x} \mathrm{FA}_{x} \mathrm{Pbl}{ }_{3}$ (yellow, red, green) as well as $\mathrm{MA}_{0.15} \mathrm{FA}_{0.85} \mathrm{Pbl}_{2.55} \mathrm{Br}_{0.45}$ (blue) formulations. The dashed lines are fits of the DQ build-up curves based on analytical expression (ref. 151, eqn (2)) which allow to calculate the average dipolar couplings. (c) Schematic representation of MA(red)/FA(blue) cation distributions within $\mathrm{MA}_{1-x} \mathrm{FA}_{x} \mathrm{Pbl}_{3}(x=0.25,0.50,0.75)$ perovskites following random statistics $(S=0), \mathrm{MA} / \mathrm{FA}$ clustering with $S=0.3$ parametrized using $r_{\mathrm{MA}}$ and $r_{\mathrm{FA}}$, and phase separation $(S=1)$, respectively. As the experimental $D Q$ intensity buildup analysis does not provide information about domain sizes of MA-rich and FA-rich regions, arbitrary sized circles were chosen to represent the statistical distribution of cations. Adapted with permission from ref. 151. Copyright 2021 American Chemical Society.

originating from intramolecular ${ }^{1} \mathrm{H}-{ }^{1} \mathrm{H}$ proximities within MA (red circles and red thick line) and FA (blue circle and blue thick line), and intermolecular ${ }^{1} \mathrm{H}^{-1} \mathrm{H}$ proximities between MA and FA cations (blue-to-red-gradient thick lines). The ${ }^{1} \mathrm{H}$ DQ intensity buildup curves associated with intermolecular FA-MA proximities have been analyzed using a second moment approach in order to estimate the average ${ }^{1} \mathrm{H}^{1}{ }^{1} \mathrm{H}$ dipolar coupling strengths between $\mathrm{FA}^{+}$and $\mathrm{MA}^{+}$(Fig. $5 \mathrm{~b}$ ). ${ }^{151,349,350}$ These results are corroborated by MD simulations which indicate that the intramolecular dipolar couplings within the A cation $\left(\mathrm{MA}^{+}\right.$, $\mathrm{FA}^{+}$) are averaged through the rapid reorientation at the SsNMR time scales (micro to milliseconds), thus intermolecular ${ }^{1} \mathrm{H}-{ }^{1} \mathrm{H}$ dipolar interactions are attributed to the $\mathrm{DQ}$ signal intensity build-up. For three different $\mathrm{MA}_{1-x} \mathrm{FA}_{x} \mathrm{PbI}_{3}$ mixed formulations $(x=0.25,0.5$ and 0.75$)$, the average ${ }^{1} \mathrm{H}^{-1}{ }^{1} \mathrm{H}$ dipolar couplings and theoretical populations of MA-FA contacts are calculated. The populations of FA-MA contacts are analyzed (see ref. 151 for a detailed procedure) by means of an order parameter $\mathrm{S}$, which takes different values in the range of $0-1$ depending on the degree of FA-MA mixing: $S=0$ for random cation distribution, $0<S<1$ for clustering, $S=1$ for phase segregation. The clustering tendency and the A-site occupancies $\left(r_{\mathrm{MA}}\right.$ and $\left.r_{\mathrm{FA}}\right)$ have been parametrized as $r_{\mathrm{MA}}=(1-x)+\mathrm{S} x$ and $r_{\mathrm{FA}}=x+S(1-x)$.
The calculated populations indicated that partial MA-MA and FA-FA clustering occurs for $x=0.25$ and $x=0.5$ ( $\mathrm{S}$ values in the range of $0.2-0.4)$, whereas majority-FA formulations $(x=0.75)$ have slightly more random distributions ( $S$ values in the range of 0-0.3, Fig. $5 \mathrm{c}$ ). This work suggests that heterogeneities in the cation distributions lead to local variations in the electrostatic interactions at the organic-inorganic sublattice (Section 2, Fig. 2), which influence the optoelectronic properties. ${ }^{351,352}$

The type of halogen atom forming the $\mathrm{BX}_{6}$ octahedra strongly influences the chemical shifts and lineshapes of B-site cations $\left(\mathrm{Pb}^{2+}, \mathrm{Sn}^{2+}\right) \cdot{ }^{152,153,312,314,345,353-357}$ In this context, ${ }^{207} \mathrm{~Pb}$ and ${ }^{119} \mathrm{Sn}$ NMR studies have been increasingly pursued to examine the local environments of $\mathrm{BX}_{6}$ octahedra in lead and tin halide perovskites, respectively. The subtle changes in the organicinorganic interfaces such as electrostatic interactions, cation dynamics and octahedral tilts and $\mathrm{B}-\mathrm{X}$ bond distances and phase transitions may have dramatic effects on the ${ }^{207} \mathrm{~Pb}$ and ${ }^{119}$ Sn NMR lineshapes. In lead MHPs, the substantial chemical shift range of ${ }^{207} \mathrm{~Pb}$ signals of up to $3000 \mathrm{ppm}$ and peak widths (full-width-at-half-maximum, FWHM in the range of a fraction of $\mathrm{kHz}$ to several tens of $\mathrm{kHz}$ ) provides a powerful way to characterize structural properties such as $\mathrm{Pb}-\mathrm{X}$ distances, $\mathrm{Pb}-$ $\mathrm{X}-\mathrm{Pb}$ bond angles and octahedral tilts in the $\mathrm{PbX}_{6}$ 


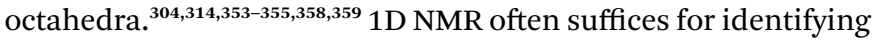
and distinguishing the local coordination spheres and the impact of $\mathrm{A}$ and $\mathrm{X}$ site doping on the ${ }^{207} \mathrm{~Pb}$ and ${ }^{119} \mathrm{Sn}$ shifts in $\mathrm{ABX}_{6}$ MHPs. In addition, $2 \mathrm{D}{ }^{207} \mathrm{~Pb}$ exchange spectroscopy has been used to gain insight into the solid-solution behavior of $\operatorname{MAPbX}_{3}(\mathrm{X}=\mathrm{Cl}, \mathrm{Br}, \mathrm{I})$ obtained from mechanochemical synthesis. ${ }^{360}$

In tin-based MHPs, the ${ }^{119} \mathrm{Sn}$ chemical shifts provide a wealth of structural and dynamics information. ${ }^{312,313,361-364}$ ${ }^{119} \mathrm{Sn}$ chemical shifts span a wide range $(\sim 12000 \mathrm{ppm}$, e.g., $\delta(\mathrm{Sn}$ metal $)=7500 \mathrm{ppm}$ and $\left.\delta\left(\mathrm{MA}_{2} \mathrm{SnI}_{6}\right)=-4684 \mathrm{ppm}\right)$ and typically exhibit chemical shift anisotropy, which is readily averaged out in iodide- and bromide-based tin halide perovskite compositions due to halide hopping. Knight shifts, resulting from the interaction of nuclear spins with itinerant electrons, have also been reported. ${ }^{312,363,364}$ It has been shown that the ${ }^{119} \mathrm{Sn}$ chemical shift is a sensitive local probe of the A-site cation (Cs, MA, FA) composition. ${ }^{312}$ In addition, ssNMR has been shown to be particularly useful for probing B-site cation mixing in MHPs by specifically probing the local structure of each of the contributing cations. Cadmium doping in hybrid and allinorganic MHPs has been investigated by ${ }^{113} \mathrm{Cd}$ SSNMR spectroscopy. $\mathrm{Cd}^{2+}$ ions can be incorporated into $\mathrm{PbI}_{2}$ and $\mathrm{CsPbBr}$, whereas $\mathrm{Cd}^{2+}$ ions phase segregate into non-perovskite halocadmates in MHPs based on MA and FA. ${ }^{365}$

Another important feature of ssNMR is the ability to study and distinguish B site cations in double perovskites. In a study by Michaelis and co-workers, halide double perovskites (HDPs) with the general formula $\left(\mathrm{A}(\mathrm{I}) 2 \mathrm{~B}^{\prime}(\mathrm{III}) \mathrm{B}^{\prime \prime}(\mathrm{I}) \mathrm{X} 6\right)$ have been investigated by ssNMR, XRD and DFT modelling. A series of $\mathrm{Bi}^{3+} / \mathrm{In}^{3+}$ mixed-cation $\mathrm{Cs}_{2} \mathrm{Bi}_{1-x} \mathrm{In}_{x} \mathrm{AgCl}_{6}$ solid solutions has been characterized by ${ }^{115}$ In and ${ }^{209} \mathrm{Bi}$ ssNMR spectroscopy (Fig. 6). ${ }^{366}$ The impact of short to medium-range octahedral symmetry in the first B'(III) coordination sphere of $\mathrm{Cs}_{2} \mathrm{Bi}_{1-x} \mathrm{In}_{x} \mathrm{AgCl}_{6}$ compounds on the ${ }^{209} \mathrm{Bi}$ and ${ }^{115} \mathrm{In}$ quadrupolar lineshapes is analyzed and compared with the calculated quadrupolar coupling constants (CQ) of ${ }^{115} \mathrm{In}$ and ${ }^{209} \mathrm{Bi}$ sites in the supercells (Fig. 6a). In particular, when the symmetry starts to breakdown in $\left(\mathrm{BiCl}_{6}\right)$ $\left\{\mathrm{AgCl}_{6}\right\}_{6}\left[\mathrm{BiCl}_{6}\right]_{12}$ - that is the central $\left(\mathrm{BiCl}_{6}\right)^{3-}$ unit surrounded by six $\left(\mathrm{AgCl}_{6}\right)^{3-}$ and twelve $\left[\mathrm{BiCl}_{6}\right]^{3-}$ octahedra - upon doping with one or more $\left[\mathrm{InCl}_{6}\right]^{3-}$ in the first coordination sphere, the central ${ }^{209} \mathrm{Bi}$ sites experience different local chemical environments, leading to significant changes in the calculated ${ }^{209} \mathrm{Bi} C Q$ values (Fig. 6a, top). For example, a replacement of four and eight $\left[\mathrm{BiCl}_{6}\right]^{3-}$ sites (blue dots) by $\left[\mathrm{InCl}_{6}\right]^{3-}$ sites (red dots) in the first coordination sphere causes change in the CQ values of central ${ }^{209} \mathrm{Bi}$ sites up to 35.8 and $45.9 \mathrm{MHz}$. In contrast, the replacement of all twelve $\left[\mathrm{BiCl}_{6}\right]^{3-}$ octahedra by $\left[\mathrm{InCl}_{6}\right]^{3-}$ results in only subtle changes in the CQ values $(0.4 \mathrm{MHz})$ because of the recreation of the symmetry. Similar trends are observed in the CQ values of ${ }^{115} \mathrm{In}$ (25.7 $\mathrm{MHz}$ for nearly equal $\mathrm{Bi} / \mathrm{In}$ populations) when the symmetry in $\left(\mathrm{InCl}_{6}\right)\left\{\mathrm{AgCl}_{6}\right\}_{6}\left[\mathrm{InC}_{16}\right]_{12}$ is interrupted upon doping with $\left[\mathrm{BiCl}_{6}\right]^{3-}$ sites. Specifically, high-field (21.14 T) ssNMR enabled the local bonding environments of ${ }^{115}$ In and ${ }^{209} \mathrm{Bi}$ sites in mixed-cationic HDPs to be resolved (Fig. 6b and c), whereby ${ }^{115} \mathrm{In}$ and ${ }^{209} \mathrm{Bi}$ signals corresponding to different (a)
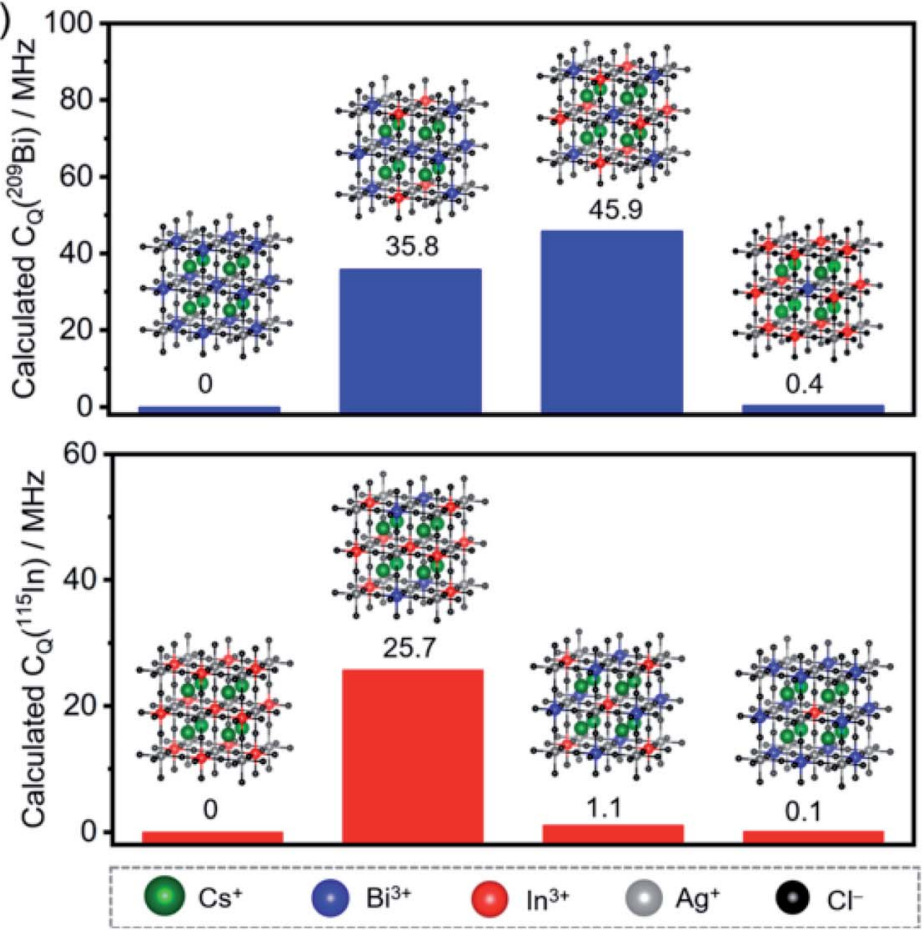

(b)

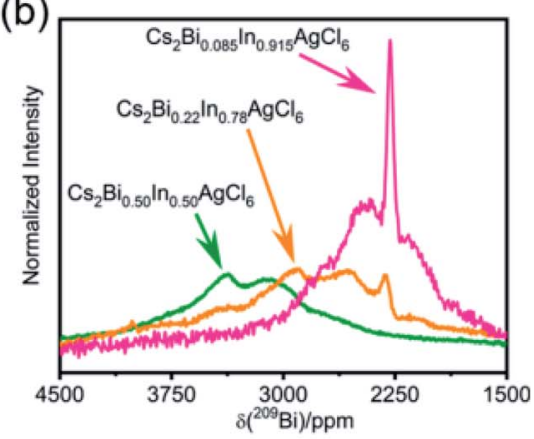

(c)

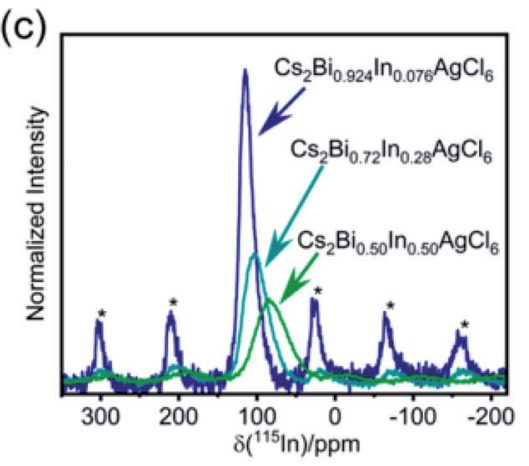

Fig. 6 Local chemical environments of B-site cations in halide double perovskites: (a) calculated $C_{Q}$ (quadrupolar coupling constants) of the central ${ }^{209} \mathrm{Bi}$ and ${ }^{115}$ In sites depending on the nearest neighbors in the first $\mathrm{B}^{\prime}(\mathrm{III})$ coordination sphere (insight, blue and red dots) in the superlattice. Experimental (b) ${ }^{209} \mathrm{Bi}$ and (c) ${ }^{115} \mathrm{In}$ NMR spectra acquired at $21.14 \mathrm{~T}$ under static and MAS (18 kHz) conditions, respectively. Asterisks in (c) indicate spinning side bands. Adapted with permission from ref. 366. Copyright 2020 American Chemical Society. 
octahedral sites and symmetries in the first coordination sphere are identified and distinguished. This study showed that there is a high degree of $\mathrm{B}^{\prime}(\mathrm{III}) / \mathrm{B}^{\prime \prime}(\mathrm{I})$ cation ordering and cation mixing in $\mathrm{Cs}_{2} \mathrm{Bi}_{1-x} \mathrm{In}_{x} \mathrm{AgCl}_{6}$ HDPs. The high degree of $\mathrm{Bi} / \mathrm{In}$ alloying allows a delicate tuning of the band-gap and light emitting properties of HDPs. The combined high field SSNMR, XRD, PL and computational modelling has been used to establish structure-based understanding of broad-band white-light emission properties.

The environmental stability and degradation processes of a wide variety of 3D MHPs have been investigated by multinuclear $\left({ }^{1} \mathrm{H},{ }^{207} \mathrm{~Pb},{ }^{119} \mathrm{Sn},{ }^{133} \mathrm{Cs}\right)$ ssNMR spectroscopy tech-

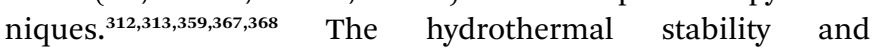
degradation of $\mathrm{MAPbI}_{3}$ has been characterized through 1D ${ }^{207} \mathrm{~Pb}$ NMR spectroscopy, and revealed that pristine $\mathrm{MAPbI}_{3}$ and its degradation products, $\mathrm{MAPbI}_{3} \cdot \mathrm{H}_{2} \mathrm{O}$, and $\mathrm{PbI}_{2}$, have distinct chemical shifts (Fig. 7a). This analysis shows that $\mathrm{MAPbI}_{3}$ degrades into $\mathrm{MAPbI}_{3} \cdot \mathrm{H}_{2} \mathrm{O}$ upon exposure to moisture, while no $(\mathrm{MA})_{4} \mathrm{PbI}_{6} \cdot 2 \mathrm{H}_{2} \mathrm{O}$ or $\mathrm{PbI}_{2}$ is formed as a decomposition product upon prolonged exposure to moderate humidity $(\sim 40 \%$ $\mathrm{RH}$ or below) at ambient temperature. Nevertheless, simultaneous exposure of $\mathrm{MAPbI}_{3}$ to heat and humidity, or liquid water, leads to the irreversible formation of $\mathrm{PbI}_{2}$. These results are corroborated by in situ XRD and electron microscopy techniques, which also show the formation of $\mathrm{MAPbI}_{3} \cdot \mathrm{H}_{2} \mathrm{O}$ and $\mathrm{PbI}_{2}$ upon exposure to moisture at room temperature under controlled humidity ( $85 \% \mathrm{RH}$, relatively humidity). ${ }^{368}$
Ex situ ${ }^{119} \mathrm{Sn}$ NMR has been used to probe the degradation products in tin based MHPs (Fig. 7b). ${ }^{312}$ For example, (hydro) thermal degradation of $\mathrm{MASnBr}_{3}$ (exposed to air for $1 \mathrm{~h}$ at $523 \mathrm{~K}$ ) leads to the formation of $\mathrm{MA}_{2} \mathrm{SnBr}_{6}, \mathrm{SnO}_{2}, \mathrm{SnBr}_{4}$, and dilute concentrations of ionic species as a result of the reaction between tin(II) and decomposition products of the organic cation. By comparison, $\mathrm{FASnBr}_{3}$ exposed to air for 5 days at RT yields signals corresponding to $\mathrm{SnO}_{2}$ and $\mathrm{FA}_{2} \mathrm{SnBr}_{6}$, while still containing signals corresponding to undegraded $\mathrm{FASnBr}_{3}$ ( $\sim 45 \%$ of the pristine material). However, exposure at $523 \mathrm{~K}$ leads to a complete degradation of the perovskite phase. In the case of $\mathrm{CsSnBr}_{3}$, exposure to air for $0.5 \mathrm{~h}$ at $623 \mathrm{~K}$ leads to the formation of $\mathrm{SnO}_{2}$ and $\mathrm{Cs}_{2} \mathrm{SnBr}_{6}$. Similar trends have been observed for ternary tin(II) iodides (halostannates(II)), which degrade into different byproducts and traces of metallic $\beta$-Sn. There is a high degree of complementarity between the MHP degradation processes studied by different analytical techniques such as XRD, SEM, SSNMR and thermogravimetric analysis (TGA). While the crystalline inorganic degradation products are amenable to the XRD and SEM techniques, MHPs often degrade into disordered phases which are better identified by SSNMR techniques. For example, the degradation of tinbased perovskites into $\mathrm{SnO}_{2}$ and $\mathrm{SnX}_{4}$ has been studied by TGA. ${ }^{369}$ However, ${ }^{119} \mathrm{Sn}$ NMR study refines this picture by identifying other intermediate products corresponding to tin(IV) halostannates, $\mathrm{A}_{2} \mathrm{SnX}_{6} \cdot{ }^{312}$ (a) ${ }^{207} \mathrm{~Pb}$ NMR

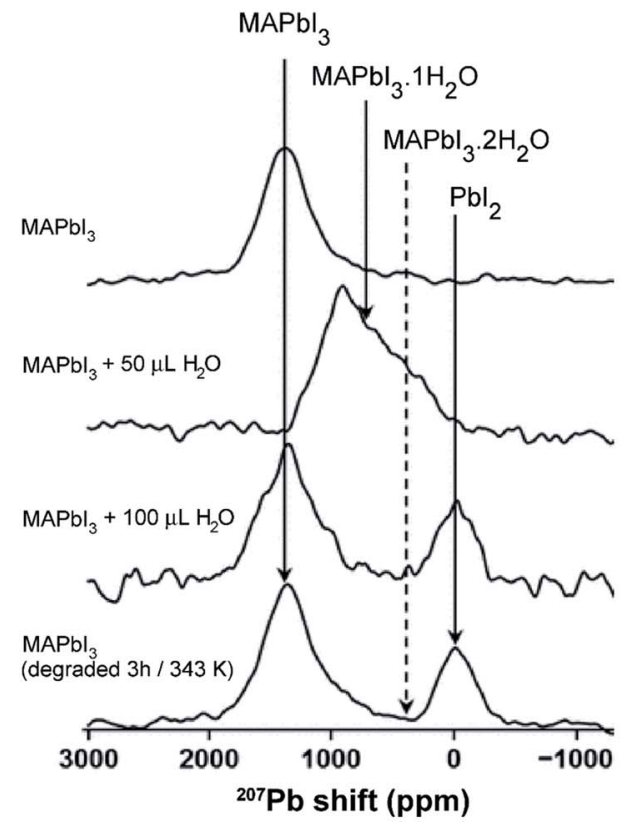

(b) ${ }^{119} \mathrm{Sn}$ NMR

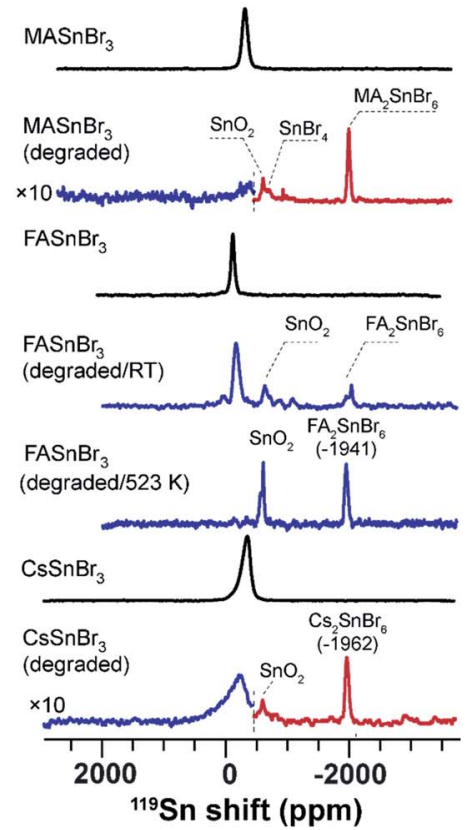

Fig. 7 Probing degradation of MHPs through ssNMR: (a) static 1D ${ }^{207} \mathrm{~Pb}$ NMR spectra (7.05 T, $294 \mathrm{~K}$ ) of pristine MAPbl 3 and the same material after the addition of $50 \mu \mathrm{L}$ and $200 \mu \mathrm{L}$ of $\mathrm{H}_{2} \mathrm{O}$, and the water treated MAPbl 3 after heated for $3 \mathrm{~h}$ at $343 \mathrm{~K}$. The ${ }^{207} \mathrm{~Pb}$ signals associated with $\mathrm{MAPbl}_{3}$ and degraded byproducts are shown in solid lines, and the dotted lines correspond to proposed decomposition product (not observed). Adapted with permission from ref. 367. Copyright 2017 American Chemical Society. (b) ${ }^{119} \mathrm{Sn}$ MAS NMR spectra (4.7 T, $12 \mathrm{kHz}$ MAS, $298 \mathrm{~K}$ ), from top-to-bottom: fresh $\mathrm{MASnBr}_{3}$, aged $\mathrm{MASnBr}_{3}$ ( $1 \mathrm{~h}$ at $523 \mathrm{~K}$ in air); and fresh $\mathrm{FASnBr}_{3}$, aged $\mathrm{FASnBr}_{3}$ ( 5 days at $\mathrm{RT}$ in air), aged $\mathrm{FASnBr} 3$ ( $0.5 \mathrm{~h}$ at 523 $\mathrm{K}$ in air); and fresh $\mathrm{CsSnBr}_{3}$, aged $\mathrm{CsSnBr}_{3}(0.5 \mathrm{~h}$ at $623 \mathrm{~K}$ in air). The dashed vertical lines represent the combined spectra acquired at different transmitter offsets (blue and red). Adapted with permission from ref. 312. Copyright 2020 American Chemical Society. 
Much interest has been directed towards ssNMR study of halides $\left({ }^{19} \mathrm{~F},{ }^{35} \mathrm{Cl},{ }^{79} \mathrm{Br}\right)$, which provides a suitable complementary method to explore halogen sites in MHPs. For instance, ${ }^{19} \mathrm{~F}$ NMR has been used to investigate local structures and halogen bonding in MHPs doped with fluorine-containing organic species. ${ }^{370,371}$ However, the scenario becomes complicated with NMR investigations of MHPs involving halides such as ${ }^{35} \mathrm{Cl},{ }^{79} \mathrm{Br}$ and ${ }^{127} \mathrm{I}$, due to the very large quadrupole interaction associated with these nuclei, which leads to relatively broad spectra for non-symmetric local environments. In the case of bulk and nanocrystalline $\mathrm{CsPbX}_{3}(\mathrm{X}=\mathrm{Cl}, \mathrm{Br}, \mathrm{I})$, local halide sites have been characterized by ${ }^{35} \mathrm{Cl}$ and ${ }^{79} \mathrm{Br}$ SSNMR, and compared with ${ }^{79} \mathrm{Br}$ and ${ }^{127}$ I NQR results. ${ }^{64,372} \mathrm{NQR}$ is readily applicable to static samples with minimum restrictions on the material type, and is thus expected to help in the analysis of halide perovskites and the associated optoelectronic devices.

\subsection{B-site deficient perovskites}

The incorporation of large A-site cations in MHPs that exceed perovskite tolerance factors can produce crystalline phases with improved environmental stability and optoelectronic properties. Lead-deficient perovskites with periodically localized octahedral vacancies have recently been synthesized by adding hydroxyethylammonium $\left(\mathrm{HEA}^{+}\right)$or thioethylammonium $\left(\mathrm{TEA}^{+}\right)$ to $\mathrm{MAPbI}_{3}, \mathrm{FAPbI}_{3}$ or $\mathrm{FASnI}_{3}$ precursors during growth. ${ }^{\text {191-193 }}$
Analysis of $1 \mathrm{D}^{207} \mathrm{~Pb}$ NMR lineshapes and intensities provides an insight into the local environments of $\mathrm{Pb}^{2+}$ cations in 3D-like lead-deficient $\mathrm{MAPI}_{3}$ (d-MAPbI ${ }_{3}$ ). Specifically, ${ }^{207} \mathrm{~Pb}$ NMR signal intensities are relatively lower in $\mathrm{d}-\mathrm{MAPbI}_{3}$ than in pristine $\mathrm{MAPbI}_{3},{ }^{191}$ which corroborates the reduced lead content in $\mathrm{Pb}$ deficient perovskites. The different distributions of large cations in the $3 \mathrm{D}$ lattice and their local chemical environments have been characterized by ${ }^{13} \mathrm{C}$ and ${ }^{1} \mathrm{H}$ ssNMR. ${ }^{191,192}$ While the reduced ${ }^{207} \mathrm{~Pb}$ signal intensity in $\mathrm{d}-\mathrm{MAPI}_{3}$ indicates the presence of defects, ${ }^{13} \mathrm{C}$ NMR spectral analysis of $(\mathrm{MA})_{1-2.48 x}(-$ HEA $)_{3.48 x}\left[\mathrm{~Pb}_{1-x} \mathrm{I}_{3-x}\right] \quad(x=0.1,0.13,0.16,0.19$ and 0.2$)$ compounds showed that the ${ }^{13} \mathrm{C}$ signal intensities of $\mathrm{HEA}^{+}$ increase as the $x$ value increases, indicating the progressive incorporation of HEA cations into the perovskite framework.

B-site deficient MHP phases can also be formed with randomly distributed pairs of large cations and octahedral voids (Fig. 8a). ${ }^{194}$ These phases are commonly described as hollow perovskites (Section 2). Although single crystals suitable for X-ray diffraction studies can be grown, ${ }^{\mathbf{1 9 4 - 1 9 8 , 2 0 0}}$ the local environments of the large cations in hollow perovskites are exceedingly challenging to obtain. Spanopoulos et al. used 1D and $2 \mathrm{D}{ }^{1} \mathrm{H}$ MAS NMR to elucidate the local structures of organic cations in ethylene diammonium (en) incorporated $\mathrm{FAPbBr}_{3}$ hollow perovskites. ${ }^{373}$ The ${ }^{1} \mathrm{H}$ signals corresponding to FA (7.5 and $8.1 \mathrm{ppm}$ ) and $e n$ (4.1 and $7.5 \mathrm{ppm}$ ) cations are distinguished when sufficient en is incorporated. The lineshape associated

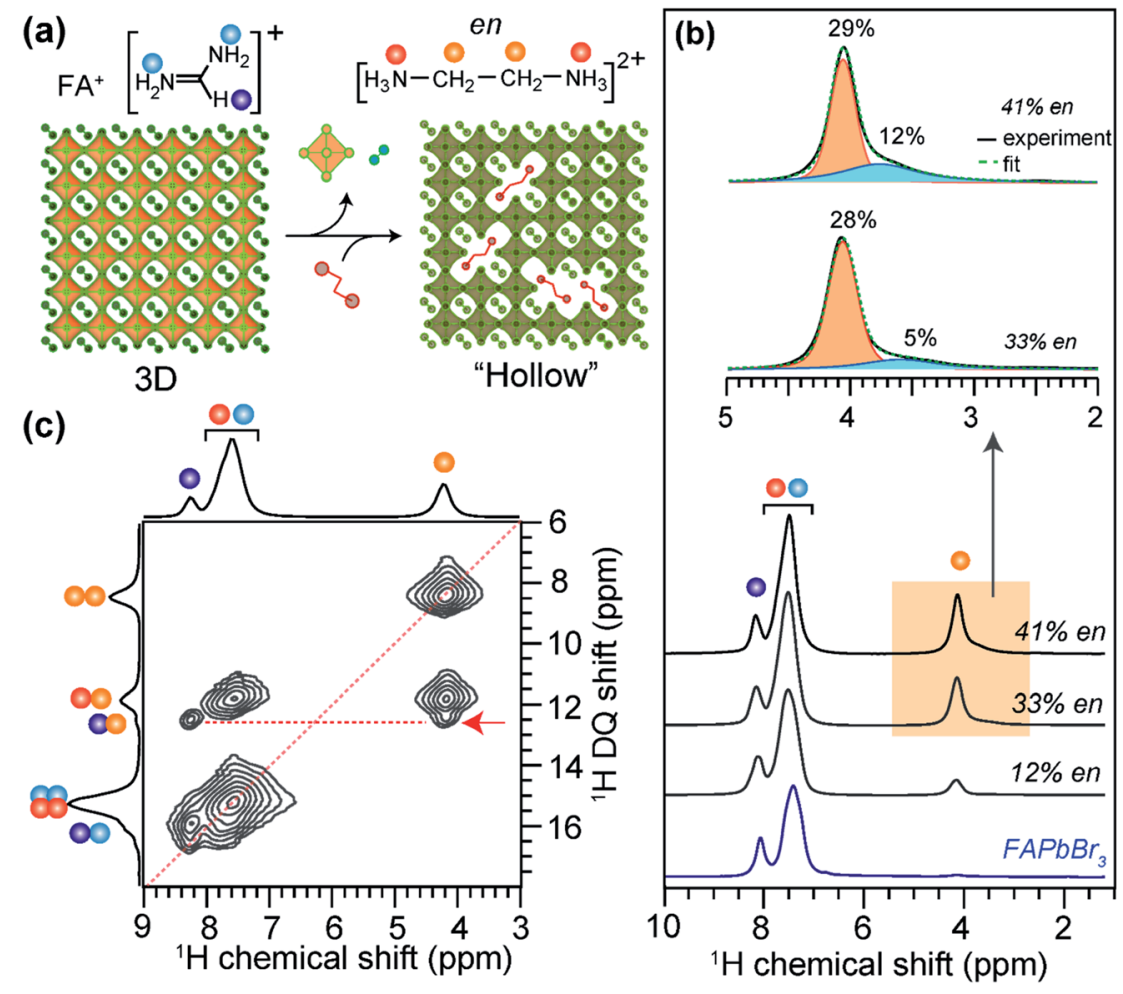

Fig. 8 Large cation incorporation in hollow $\mathrm{FAPbBr}_{3}$ : (a) schematic of the formation of hollow perovskites, (b) solid-state ${ }^{1} \mathrm{H}$ MAS NMR spectra of $\mathrm{FAPbBr}_{3}$ and (en) $\mathrm{FAPbBr}_{3}$, (en content $=12 \%, 33 \%$ and $41 \%$ of available sites) hollow perovskites together with the assignment of signals corresponding to $\mathrm{FA}^{+}$and en protons depicted in color dots as shown in the figure inset. (c) $2 \mathrm{D}^{1} \mathrm{H}-{ }^{1} \mathrm{H} \mathrm{DQ}-\mathrm{SQ}$ correlation NMR spectra of $41 \%$ en/ $\mathrm{FAPbBr}_{3}$ exhibit the cross peaks (red arrow) indicating the sub-nm molecular proximity between $\mathrm{FA}^{+}$and en. Adapted with permission from ref. 373. Copyright 2021 American Chemical Society. 
with the ${ }^{1} \mathrm{H}$ signal at $\sim 4.1 \mathrm{ppm}$ can be deconvoluted into broad and narrow features, which are attributable to en cations in the perovskite framework and phase segregated regions, respectively. This result demonstrates that en cations are not homogeneously distributed in hollow $(e n) \mathrm{FAPbBr}_{3}$, at least at stoichiometries of $33 \%$ or higher. A quantitative ${ }^{1} \mathrm{H}$ NMR analysis of $12 \%, 33 \%$ and $44 \%$ en $\mathrm{FAPbBr}_{3}$ reveals that up to $\sim 29 \%$ en can be incorporated into the perovskite framework (Fig. 8b), while en loadings greater than $30 \%$ leads to the formation an additional type of en defect in the crystal structure. In the case of $33 \%$ en and $41 \%$ en $\mathrm{FAPbBr}_{3}$, there is $\sim 5 \%$ and $\sim 12 \%$ aggregation of the total $e n$ cations, as depicted by the broad signals in the deconvoluted ${ }^{1} \mathrm{H}$ NMR spectra (Fig. 8b, inset). This result is consistent with the changes in the bulk optoelectronic properties and 3D lattice expansion determined $\mathrm{XRD}$ as function of \%en incorporation into $\mathrm{FAPbI}_{3}$, although diffraction and optoelectronic measurements alone would not have revealed this phase segregation of en.

Insight into local chemical environment of organic cations in $41 \%$ en $\mathrm{FAPbBr}_{3}$ were obtained by analyzing $2 \mathrm{D}{ }^{1} \mathrm{H}-{ }^{1} \mathrm{H} \mathrm{DQ}-$ SQ correlation spectrum (Fig. 8c). The on-diagonal DQ signals associated with $-\mathrm{CH}_{2}-$ groups of en $(8.2 \mathrm{ppm})$ and $=\mathrm{CH}-$ site of $\mathrm{FA}^{+}(15.6 \mathrm{ppm})$ are distinguishable, and a broad feature at $\sim 15 \mathrm{ppm}$ is attributed to overlapped contributions from the
$-\mathrm{NH}_{3}{ }^{+}$groups in en and $\mathrm{FA}^{+}$. The resolved off-diagonal peak at $12.2 \mathrm{ppm}$ (red arrow) indicates the intermolecular throughspace ${ }^{1} \mathrm{H} \cdots{ }^{1} \mathrm{H}$ proximity $(<0.5 \AA)$ between $-\mathrm{CH}_{2}-$ groups of en and $=\mathrm{CH}-$ group of $\mathrm{FA}^{+}$, confirming the incorporation of en cations into the perovskite framework. Such structural details obtained from ssNMR analysis are highly complementary to Xray diffraction and pair distribution function (PDF) analysis of hollow perovskites.

\subsection{D layered perovskites}

There is a growing interest in the use of layered 2D perovskites as a strategy to develop MHP-based optoelectronic devices, owing to their outstanding stability and structural diversity. The emerging field of 2D perovskite-based optoelectronics has inspired research to develop a systematic understanding of the impact of organic spacer cations on the structure and optoelectronic properties of layered phases. ssNMR spectroscopy is a powerful characterization tool to understand the local molecular structures of spacer cations, and their interactions with A sites and $\mathrm{X}$ sites within the perovskite slabs. ${ }^{232,309,374,375}$ One notable example is the use of ${ }^{1} \mathrm{H}^{2}{ }^{207} \mathrm{~Pb}$ heteronuclear correlation NMR to gain insights into the octahedral structures of $2 \mathrm{D} \mathrm{BA}_{2} \mathrm{MA}_{n-1} \mathrm{~Pb}_{n} \mathrm{I}_{3 n+1}$ ( $n=1$ to $n=4$, a value determining the thickness of the lead halide octahedral layer) Ruddlesden-

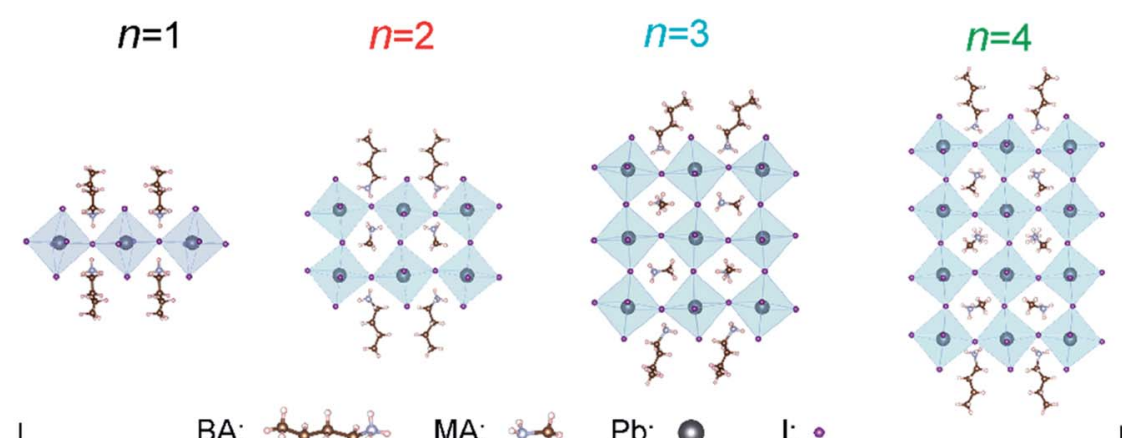

BA: की
1

$$
\mathrm{BA}_{2} \mathrm{MA}_{\mathrm{n}-1} \mathrm{~Pb}_{\mathrm{n}} \mathrm{I}_{3 \mathrm{n}+1} \text { (2D Ruddlesden-Popper phases) }
$$

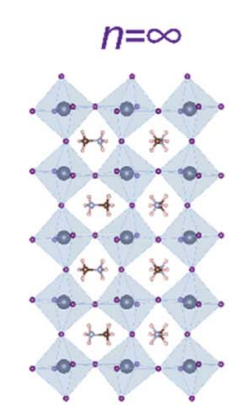

$\mathrm{MAPbl}_{3}$ (3D perovskite)
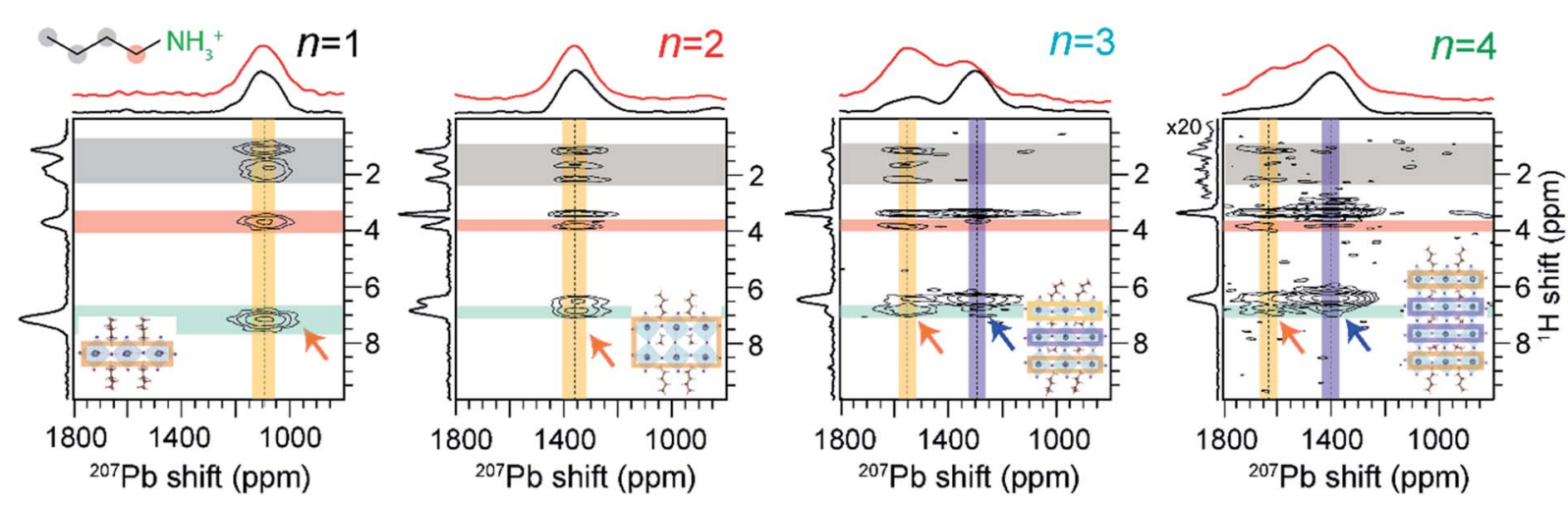

Fig. 9 Layer-by-layer identification of $2 \mathrm{D}$ RP phases: $2 \mathrm{D}{ }^{1} \mathrm{H}$-detected ${ }^{207} \mathrm{~Pb}-{ }^{1} \mathrm{H}$ correlation NMR spectra of $\mathrm{RP} \mathrm{BA}_{2} \mathrm{MA}_{n-1} \mathrm{~Pb}_{n} \mathrm{l}_{3 n+1} \mathrm{materials}$ acquired under fast $(62.5 \mathrm{kHz})$ MAS with CP contact time of $4 \mathrm{~ms}$. The top horizontal spectra compare the skyline 1D projections (black) and the $1 \mathrm{D}^{207} \mathrm{~Pb}$ direct polarization spectra (red). In each 2D spectrum, the vertical yellow and blue bands indicate the ${ }^{207} \mathrm{~Pb}$ signals corresponding to outer and inner $\mathrm{Pb}^{2+}$ sites, respectively, as depicted in the insets. Adapted with permission from ref. 374 . Copyright $2021 \mathrm{American}$ Chemical Society. 
Popper phases with butylammonium (BA) spacers (Fig. 9). ${ }^{374}$ These investigations by Lee et al. enabled layer-by-layer identification of $2 \mathrm{D}$ halide perovskites by $n$ value, whereby the surface ("outer") and bulk ("inner") $\mathrm{Pb}^{2+}$ sites in the octahedral slabs could be distinguished and resolved.

The octahedral tilts associated with $3 \mathrm{D}$-like "inner" $\mathrm{PbX}_{6}$ sites differ substantially from the surface-like "outer" $\mathrm{PbX}_{6}$ sites, which manifests in different isotropic ${ }^{207} \mathrm{~Pb}$ chemical shifts. A correlation between ${ }^{207} \mathrm{~Pb}$ NMR shifts and mean $\mathrm{Pb}-\mathrm{I}$ bond lengths has been established. The intermolecular interactions between $\mathrm{PbX}_{6}$ and spacer cations are characterized by $2 \mathrm{D}{ }^{207} \mathrm{~Pb}-{ }^{1} \mathrm{H}$ correlation spectroscopy for different layered MHPs of varying $n$ values (Fig. 9). For $n=1$ and $n=2$ RP phases, $2 \mathrm{D}$ correlation peaks occur between $\mathrm{BA}\left(-\mathrm{NH}_{3}\right)$ and $\mathrm{MA}\left(-\mathrm{NH}_{3}\right)$ protons (orange arrows) and $\mathrm{Pb}$ at a single ${ }^{207} \mathrm{~Pb}$ resonance. Thus, only a single $\mathrm{Pb}$ chemical environment is present in $n=1$, 2 phases. This result also confirms that through-space correlations can be resolved between outer $\mathrm{Pb}$ nuclei and remote spacer protons, which may be up to $6 \AA$ away from the octahedral slab. In the case of $n=3$ and $n=4 \mathrm{RP}$ phases, two distinct ${ }^{207} \mathrm{~Pb}-{ }^{1} \mathrm{H}$ correlation peaks are observed, indicating throughspace proximity between MA/BA protons and the "outer" $\mathrm{Pb}$ sites (depicted in orange arrows) and the peaks attributed to "inner" Pb sites (depicted in blue arrows). This ssNMR study confirmed that octahedral distortions in $n=3$ and 4 RP phases lead to two distinct bonding environments for $\mathrm{Pb}$ in these materials, which are reflected in different ${ }^{207} \mathrm{~Pb}$ signals.

SsNMR spectroscopy has been employed to probe the molecular arrangement of spacer molecules in layered MHPs. The packing arrangement of different spacer cations in $n=1$ lead iodide RP phases, including butylammonium $\{\mathrm{C} 4\}$, octylammonium $\{\mathrm{C} 8\}$, dodecylammonium $\{\mathrm{C} 12\}$ and aromatic phenylethylammonium $\{$ PEA $\}$ cations, have been analyzed by multinuclear $\left({ }^{1} \mathrm{H},{ }^{13} \mathrm{C}\right.$ and $\left.{ }^{15} \mathrm{~N}\right)$ ssNMR spectroscopy. ${ }^{309}$ In these 2D MHPs, the ${ }^{1} \mathrm{H}$ chemical shift (7.2 ppm) associated with the spacer cation $\mathrm{NH}_{3}{ }^{+}$groups in the $n=1 \mathrm{RP}$ phases is shifted to a higher frequency than the ${ }^{1} \mathrm{H}$ chemical shift ( $6.3 \mathrm{ppm}$ ) of $\mathrm{NH}_{3}{ }^{+}$ groups in 3D $\mathrm{MAPbI}_{3}$, indicating stronger affinity interactions (e.g. H-bonding) between RP spacer cations and lead iodide octahedra. In addition, 2D ${ }^{1} \mathrm{H}$ DQ-SQ spectra (Fig. 10) show signals corresponding to an interleaved arrangement of long alkyl spacer cations within the spacer region of $\{\mathrm{C} 4\}_{2} \mathrm{PbI}_{4}$, $\{\mathrm{C} 8\}_{2} \mathrm{PbI}_{4}$ and $\left\{\mathrm{C}_{12}\right\}_{2} \mathrm{PbI}_{4}$. Specifically, the off-diagonal $2 \mathrm{D}$ peaks that are characteristic to the side chain interdigitation (red arrows) are observed in $\{\mathrm{C} 4\}_{2} \mathrm{PbI}_{4},\{\mathrm{C} 8\}_{2} \mathrm{PbI}_{4}$. In the case of $\{\mathrm{C} 4\}_{2} \mathrm{PbI}_{4}$, the ${ }^{1} \mathrm{H}$ DQ signals at $1.8+3.7=5.5 \mathrm{ppm}, 3.7+7.2=$ $10.9 \mathrm{ppm}$, and at $1.1+7.2=8.3 \mathrm{ppm}$ indicate the through-space proximities in $\mathrm{CH}_{2} \leftrightarrow \mathrm{CH}_{2}, \mathrm{CH}_{2} \leftrightarrow \mathrm{NH}_{3}$ and $\mathrm{CH}_{3} \leftrightarrow \mathrm{NH}_{3}$ pairs
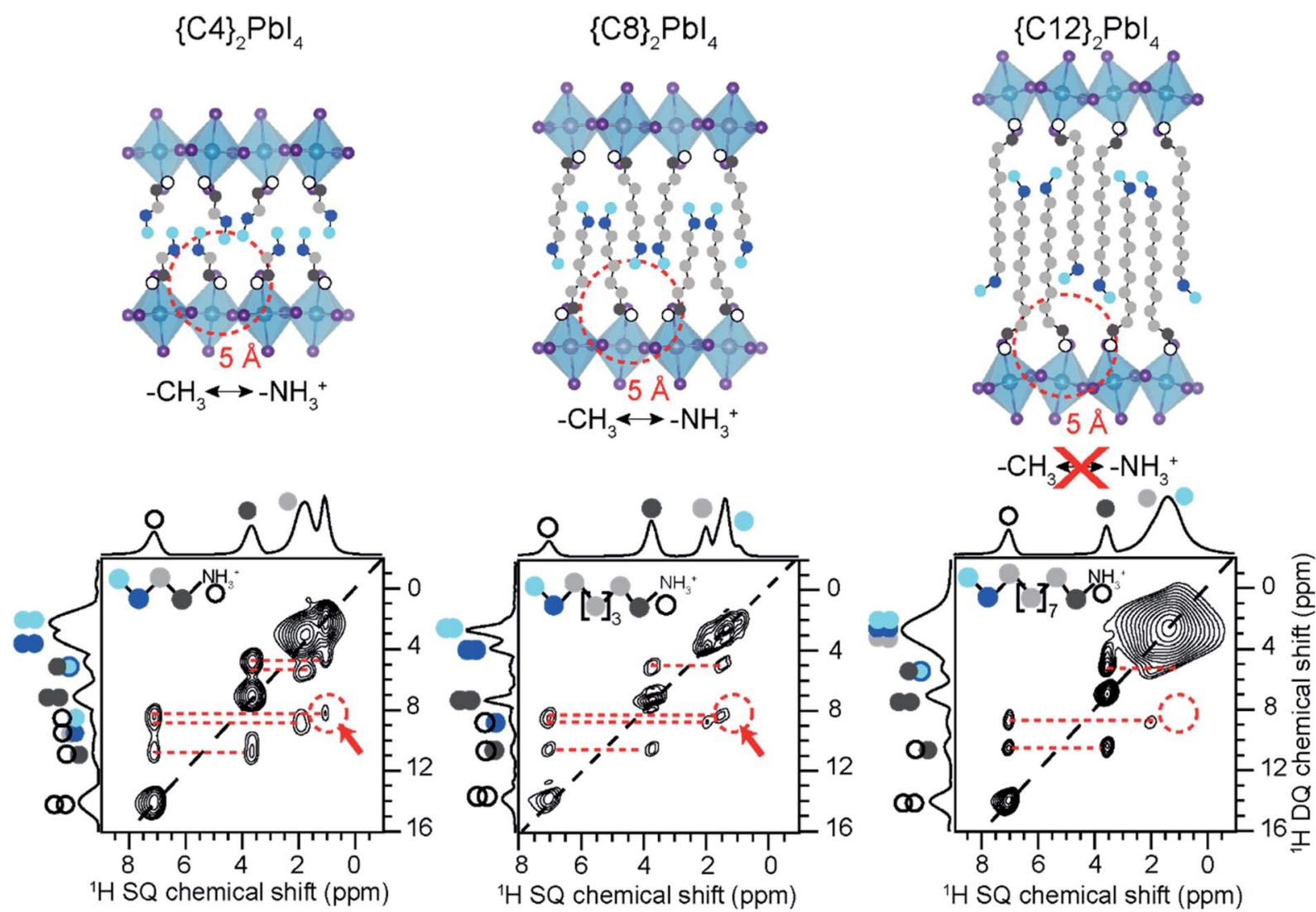

Fig. 10 Spacer cation packing interactions in 2D RP phases: $2 \mathrm{D}^{1} \mathrm{H}-{ }^{1} \mathrm{H}$ DQ-SQ NMR correlation spectra acquired at $18.8 \mathrm{~T}$ and at $50 \mathrm{kHz} M A S$ of $\{\mathrm{C} 4\}_{2} \mathrm{Pbl}_{4},\{\mathrm{C} 8\}_{2} \mathrm{Pbl}_{4}$ and $\{\mathrm{C} 12\}_{2} \mathrm{Pbl}_{4}$. The corresponding skyline projections are shown along the top ${ }^{1} \mathrm{H}$ SQ horizontal and left ${ }^{1} \mathrm{H} D Q$ vertical axes, respectively. Correlated signal intensity originates from dipolar-coupled ${ }^{1} \mathrm{H}-{ }^{1} \mathrm{H}$ pairs and are depicted in colored circles. Adapted with permission from ref. 309. Copyright 2021 American Chemical Society. 
(a) Experimental ${ }^{13} \mathrm{C}$ and ${ }^{19} \mathrm{~F}$ NMR spectra

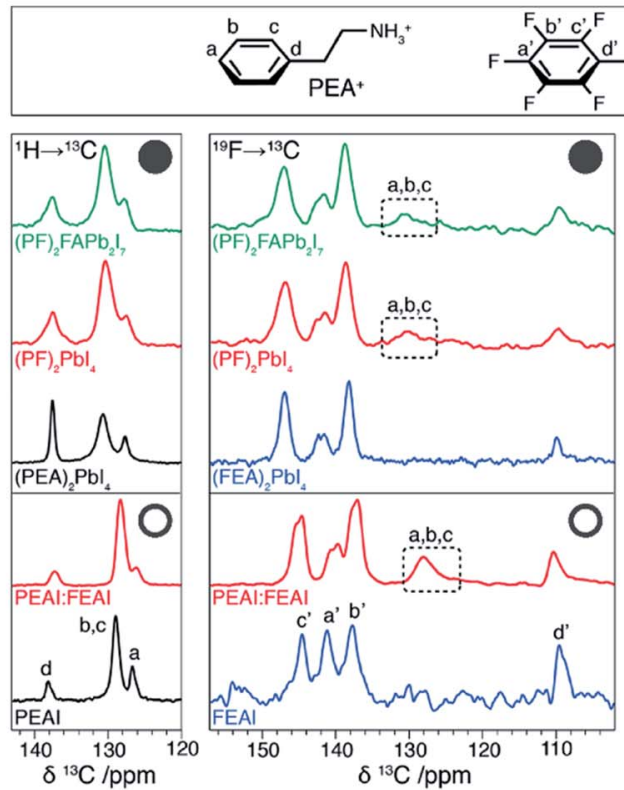
$\mathrm{FEA}^{+}$ (c) DFT vs. expt. chemical shifts
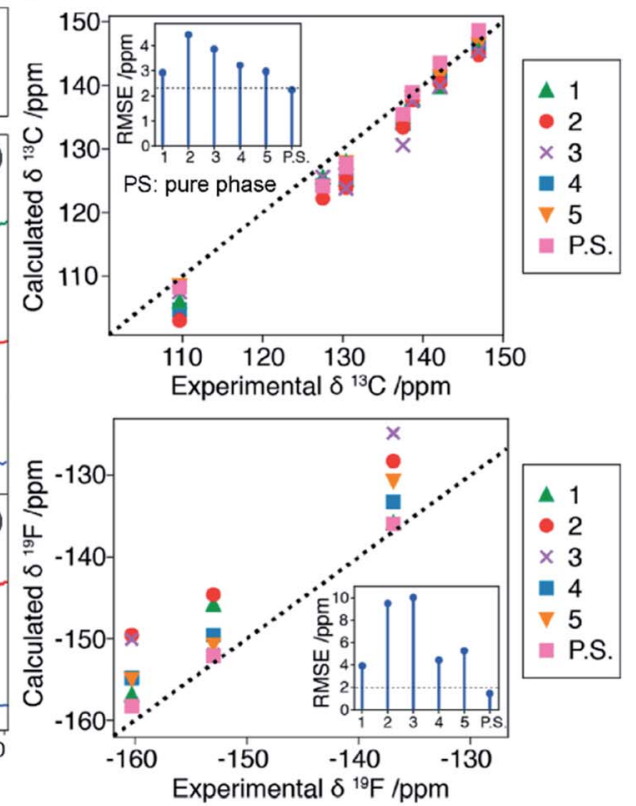

(b) Trial structures
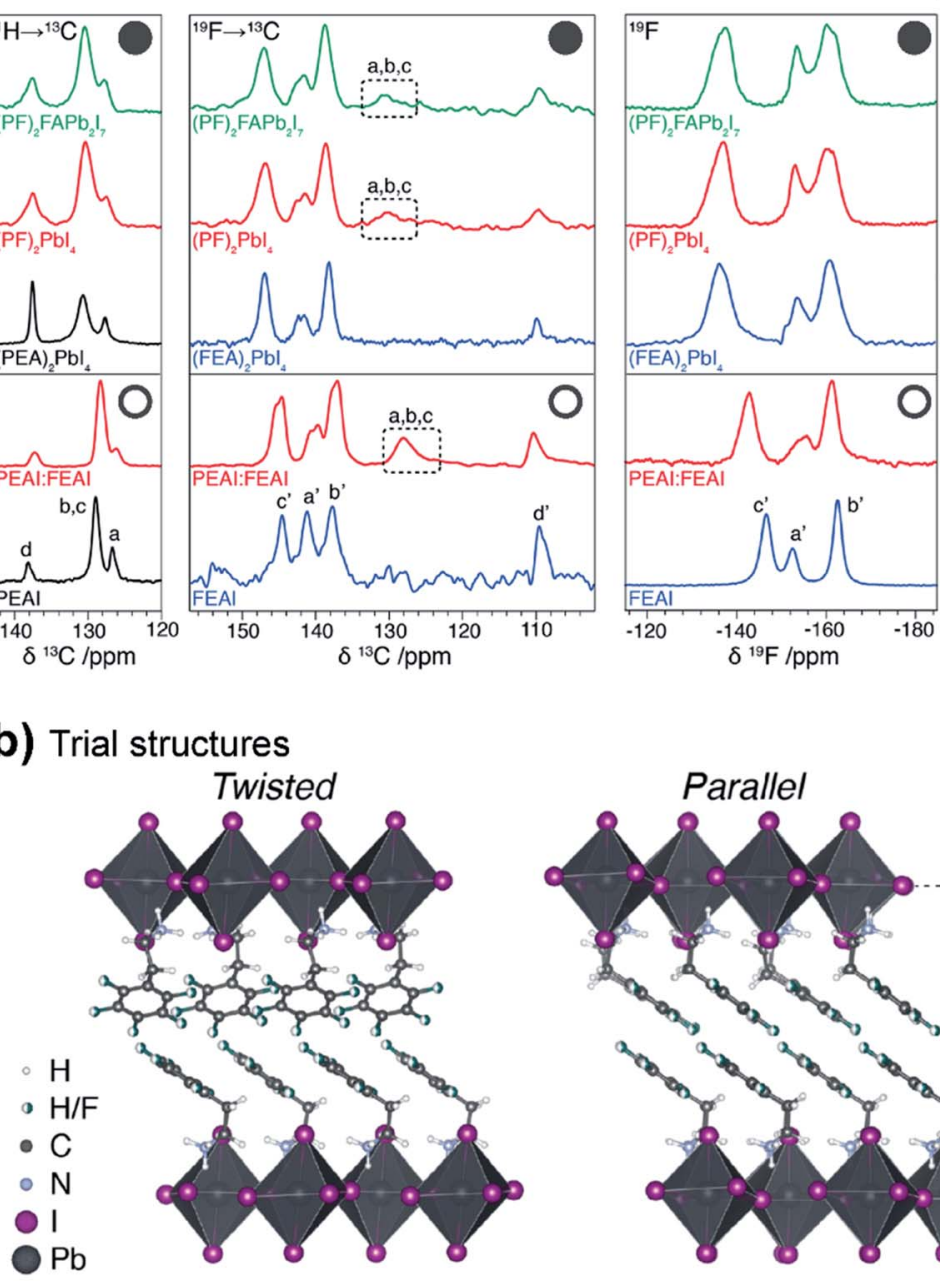

$\mathrm{FEA}^{+} \mathrm{NH}_{3}{ }^{+}$


within the same spacer or between adjacent $\mathrm{C} 4$ chains. The closest $\mathrm{CH}_{3} \leftrightarrow \mathrm{NH}_{3}$ distance between adjacent molecules in the refined crystal structure of $\{\mathrm{C} 4\}_{2} \mathrm{PbI}_{4}$ is $\approx 5 \AA$, similar to the endto-end distance between $\mathrm{NH}_{3}$ and $\mathrm{CH}_{3}$ groups in a single $\{\mathrm{C} 4\}$ molecule, indicating that the $\mathrm{CH}_{3} \leftrightarrow \mathrm{NH}_{3}$ off-diagonal peak (red arrow) is expected to show signal from both inter and intramolecular ${ }^{1} \mathrm{H}-{ }^{1} \mathrm{H}$ proximities.

The longer spacer cations are too large to produce an offdiagonal peak corresponding to an intramolecular $\mathrm{H}-\mathrm{H}$ proximity between the endgroups. The intrachain distance from $\mathrm{CH}_{3}$ to $\mathrm{NH}_{3}$ is $\approx 10 \AA$ for $\{\mathrm{C} 8\}_{2} \mathrm{PbI}_{4}$ and $\approx 15 \AA$ for $\{\mathrm{C} 12\}_{2} \mathrm{PbI}_{4}$ in the extended trans orientation (Fig. 10, top), which is too far for through-space correlations to show well-resolved features. The $2 \mathrm{D}{ }^{1} \mathrm{H}$ DQ-SQ NMR spectra of both $\{\mathrm{C} 8\}_{2} \mathrm{PbI}_{4}$ and $\{\mathrm{C} 12\}_{2} \mathrm{PbI}_{4}$ show intramolecular off-diagonal features between $\mathrm{NH}_{3}$ and nearby $\mathrm{CH}_{2}$ groups (dark and light grey dots), but no intermolecular correlations with terminal $\mathrm{CH}_{3}$ or $\mathrm{CH}_{2}$ groups (light blue, dark blue). However, the DQ features between $\mathrm{CH}_{2} \leftrightarrow \mathrm{CH}_{3}$ (dark grey to light blue) for long $\{\mathrm{C} 8\}$ and $\{\mathrm{C} 12\}$ spacers can only be caused by intermolecular correlations between the interleaved spacers. The nearest intermolecular $\mathrm{CH}_{2} \leftrightarrow \mathrm{CH}_{3}$ (dark grey to light blue) distance is $4.7 \AA$ in the published crystal structures (Fig. 10, top), which is consistent with the DQ-SQ NMR analysis. Single crystal XRD analysis of light atoms in RP structures is often impractical, and $2 \mathrm{D}{ }^{1} \mathrm{H}$ DQ-SQ NMR data provides an alternative means to characterize the molecular arrangement of spacers in these phases.

Protocols that combine ssNMR spectroscopy, X-ray scattering and modelling approaches (i.e., NMR crystallography) have been employed to characterize the structures and intermolecular interactions in MHPs and other perovskite materials. $^{\text {232,376 }}$ Development of such integrated methods are important to understand the chemical nature of mixed spacer cations in layered MHPs at the atomic scale, which is a challenge for conventional diffraction-based techniques or sSNMR spectroscopy alone. Hope et al. applied an NMR crystallography approach to elucidate the supramolecular structure of the mixed cation organic spacers in layered hybrid perovskites. ${ }^{232}$ By using this approach, 3D structures of layered hybrid perovskites consisting of 2-phenylethylammonium $\left(\mathrm{PEA}^{+}\right)$and 2-(perfluorophenyl)ethylammonium $\left(\mathrm{FEA}^{+}\right)$moieties have been proposed. This study revealed that the spacer cations in a mixed arene-fluoroarene model system most closely resemble those of phase-segregated $\mathrm{PEA}^{+} / \mathrm{FEA}^{+}$compositions, rather than a solid solution (Fig. 11). Nonetheless, it was found that there are local interfacial contacts between $\mathrm{PEA}^{+}$and $\mathrm{FEA}^{+}$in the spacer layer.

To understand how the spacer cation chemical environment changes upon formation of layered 2D perovskites, a suite of $1 \mathrm{D}$ ${ }^{1} \mathrm{H} \rightarrow{ }^{13} \mathrm{C},{ }^{19} \mathrm{~F} \rightarrow{ }^{13} \mathrm{C} \mathrm{CP}$-MAS and ${ }^{19} \mathrm{~F}$ MAS spectra of layered $2 \mathrm{D}$ perovskites (Fig. 11a, filled circles), precursor salts and their blends (Fig. 11a, open circles) were analyzed and compared. The ${ }^{13} \mathrm{C}$ and ${ }^{19} \mathrm{~F}$ signals associated with $2 \mathrm{D}$ perovskites (Fig. 11a, filled circles) are displaced and change intensities compared to the iodide salts (Fig. 11a, open circles). To establish a correlation between the ${ }^{13} \mathrm{C}$ and ${ }^{19} \mathrm{~F}$ chemical shifts and the atomiclevel structures, NMR chemical shielding calculations were carried out for a range of modelled structures.
Trial structures of $n=1$ RP phases with pure PEA and FEA spacer cations were created based on previously published structures, and modelled using Molecular Dynamics (MD) simulations. ${ }^{232}$ For pure cation RP phases of $(\mathrm{PEA})_{2} \mathrm{PbI}_{4}$ and (FEA) ${ }_{2} \mathrm{PbI}_{4}$ (Fig. 11b, top), structural models to imitate the nanoscale phase segregation of twisted or parallel packing arrangements were considered. For trial structures of pure (PEA) $)_{2} \mathrm{PbI}_{4}$ and (FEA) ${ }_{2} \mathrm{PbI}_{4}$ phases (Fig. 11b, top), the NMR shieldings were calculated using DFT (Density Functional Theory). In the case of $(\mathrm{PEA})_{2} \mathrm{PbI}_{4}$, the DFT-calculated ${ }^{13} \mathrm{C}$ chemical shifts of twisted structure agree better with the experimental ${ }^{13} \mathrm{C}$ shifts than the parallel structure, which is consistent with the previously reported single crystal structure. In contrast, for $(\mathrm{FEA})_{2} \mathrm{PbI}_{4}$, the DFT-calculated ${ }^{13} \mathrm{C}$ and ${ }^{19} \mathrm{~F}$ chemical shifts of parallel structure are in better agreement with the experimental ${ }^{13} \mathrm{C}$ and ${ }^{19} \mathrm{~F}$ chemical shifts. In the case of mixed-spacer $(\mathrm{PF})_{2} \mathrm{PbI}_{4}(\mathrm{PF}=\mathrm{PEA}$ :FEA) formulation, putative structures with different packing arrangements, such as layered, checkerboard and striped (Fig. 11b, bottom), were examined.

A comparison between DFT calculated chemical shifts and the experimental ${ }^{13} \mathrm{C}$ and ${ }^{19} \mathrm{~F}$ chemical shifts (Fig. 11c) for the trial structures of $(\mathrm{PF})_{2} \mathrm{PbI}_{4}$ and the phase-segregated (PEA) $)_{2}$ $\mathrm{PbI}_{4}$ and $(\mathrm{FEA})_{2} \mathrm{PbI}_{4}$ structures reveal that segregated models are in better agreement. It is noteworthy that the hydrogen, carbon and fluorine atoms close to the heavy $\mathrm{Pb}$ and I atoms may require fully relativistic treatment to obtain a good correlation between DFT and experimental results, though it has been shown that these relativistic effects do not significantly influence the agreement between experimental and calculated ${ }^{1} \mathrm{H}$ and ${ }^{13} \mathrm{C}$ chemical shifts. ${ }^{377}$ The root-mean-square errors (RMSEs) for the ${ }^{13} \mathrm{C}$ and ${ }^{19} \mathrm{~F}$ chemical shifts for the segregated models are less than the expected RMSE in DFT calculated chemical shifts for ${ }^{13} \mathrm{C}(2.32 \mathrm{ppm})$ and ${ }^{19} \mathrm{~F}$ (1.98 ppm). It has been suggested that the layered hybrid perovskite structure comprises of segregated regions of $\mathrm{PEA}^{+}$and $\mathrm{FEA}^{+}$spacers with nanoscale domain sizes. This is further corroborated by comparing the ${ }^{13} \mathrm{C}$ signals of $\mathrm{PEA}^{+}$sites in the ${ }^{19} \mathrm{~F} \rightarrow{ }^{13} \mathrm{C}$ CP MAS spectra (Fig. 11a, middle column, dashed rectangles), which are enhanced by the ${ }^{19} \mathrm{~F}$ sites from $\mathrm{FEA}^{+}$in both $(\mathrm{PF})_{2} \mathrm{PbI}_{4}$ and physical mixture (PEA) ${ }_{2} \mathrm{PbI}_{4} /(\mathrm{FEA})_{2} \mathrm{PbI}_{4}$, hence the two spacers in the $(\mathrm{PF})_{2} \mathrm{PbI}_{4}$ phase are in close proximity despite the nanoscale domain segregation. Overall, this study demonstrates the potential of NMR crystallography to elucidate structures and organic-organic interfaces in low-dimensional MHPs.

\subsection{Molecularly passivated MHPs}

Electronic defects at the interface between the perovskite film and the transport layers, or between grains within the MHP layer, can be effectively passivated with ammonium salts to augment the stability and performance of MHPs. ${ }^{118}$ A wide verity of ammonium salts have been employed to passivate MHPs. ssNMR has been used to study how a few of these salts, including choline, ethylammonium (EA), imidazolium, guanidinium (G) and tetrapropylammonium iodide (TPA), can passivate defects in MHPs. ${ }^{375,378-382}$ One important question 
presented by passivated MHPs is how the passivating agents incorporate within the device. Do the passivating salts mix microscopically with MHP grains, form a layer at the surface of the MHP film, or segregate away from the MHP layer? Passivating salts are often chemically similar to A-site cations in MHPs, so NMR signals arising from passivating agents and MHP constituent ions can be difficult to deconvolute. Structure elucidation of passivating overlayers is also challenging because of their small thickness and dilute concentrations in MHP films and devices. Nevertheless, 2D ssNMR spectroscopy has been applied to investigate the local proximities and interactions between MHP surfaces and passivating agents, and to elucidate the microscopic mechanisms of surface passivation. ${ }^{375,378,379,381,382}$ Unlike the 2D ${ }^{1} \mathrm{H}^{-}{ }^{1} \mathrm{H}$ DQ-SQ correlation experiment that probes through-space ${ }^{1} \mathrm{H}-{ }^{1} \mathrm{H}$ proximities within $5 \AA$, the $2 \mathrm{D}{ }^{1} \mathrm{H}_{-}{ }^{1} \mathrm{H}$ SD experiment extends the length scale from sub-nanometer to several nanometers, and is thus well-suited to gain insight into intermolecular interactions and passivation mechanism in surface-modified MHPs.

Interfaces between MHPs and passivating cations in ethylammonium iodide (EAI)-treated (FA:Cs:MA)Pb(I:Br) ${ }_{3}$ films have been probed by sSNMR spectroscopy. In a study by Alharbi et al., 2D ${ }^{1} \mathrm{H}^{-1} \mathrm{H}$ spin diffusion spectrum of an EAI-treated $\mathrm{FA}_{0.93^{-}}$ $\mathrm{Cs}_{0.07} \mathrm{PbI}_{3}$ thin film has been analyzed to shed light on the through-space atomic-level contact between $\mathrm{FA}^{+}$and $\mathrm{EA}^{+}$in the passivated material. ${ }^{379}$ The off-diagonal 2D peaks between ethylammonium $\left(\mathrm{EA}^{+}, 3.0-4.3 \mathrm{ppm}\right)$ and $\mathrm{FA}^{+}(\sim 7.5 \mathrm{ppm})$ cations
(Fig. 12a, dashed orange lines), indicate close through-space proximity between these two cations (i.e. between the passivating agent and MHP phase). This result implies that $\mathrm{EA}^{+}$ passivating salts are in intimate contact with A-site cations in $\mathrm{FA}_{0.93} \mathrm{Cs}_{0.07} \mathrm{PbI}_{3}$ films.

Defect passivation using a Lewis-acid (tetrapropylammonium, TPA) has been employed to enhance the stability of $\mathrm{MAPbI}_{3}$-based single junction solar cells. ${ }^{381}$ Krishna et al. applied 2D ssNMR techniques to understand the molecular passivation mechanism in $\mathrm{TPA}_{x} \mathrm{MA}_{1-x} \mathrm{PbI}_{3}(x=0.04)$ thin films. Isotropic chemical shifts of $\mathrm{NCH}_{2}(4.8 \mathrm{ppm})$ and $\mathrm{CH}_{2}(1.3 \mathrm{ppm})$ groups of TPA ${ }^{+}$are distinguishable from the ${ }^{1} \mathrm{H}$ signals of $\mathrm{CH}_{3}$ (3.3 ppm) and $\mathrm{NH}_{3}(6.3 \mathrm{ppm})$ groups of $\mathrm{MA}^{+}$. The close proximity between passivating $\mathrm{TPA}^{+}$and $\mathrm{MAPbI}_{3}$ is confirmed by the analysis of $2 \mathrm{D}{ }^{1} \mathrm{H}-{ }^{1} \mathrm{H}$ spin diffusion spectrum. The off-diagonal peaks corresponding to the intramolecular proximities between $\mathrm{MA}^{+}$and $\mathrm{TPA}^{+}$cations (Fig. 12b, dashed orange lines) were resolved, indicating that the $\mathrm{TPA}^{+}$cations reside close to $\mathrm{MAPbI}_{3}$ A-site cations.

In a more recent study by Su et al., a combined ssNMR and DFT modelling has been used to understand the passivation mechanism of surface uncoordinated lead sites by a crown ether (DB24C8). ${ }^{382}$ The close proximity between MHP layers and the passivating agent (DB24C8) were elucidated by $2 \mathrm{D}^{1} \mathrm{H}-{ }^{207} \mathrm{~Pb}$ and ${ }^{1} \mathrm{H}-{ }^{1} \mathrm{H}$ correlation NMR. These results are corroborated by DFT modelling of DB24C8 passivated perovskite structures. In particular, the analysis of a $2 \mathrm{D}^{1} \mathrm{H}-{ }^{1} \mathrm{H}$ spin diffusion spectrum (a)

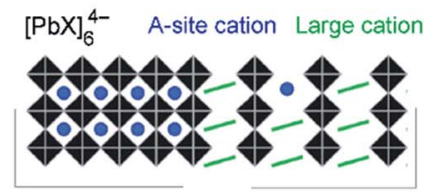

3D perovskite $1 \mathrm{D}$ passivation layer

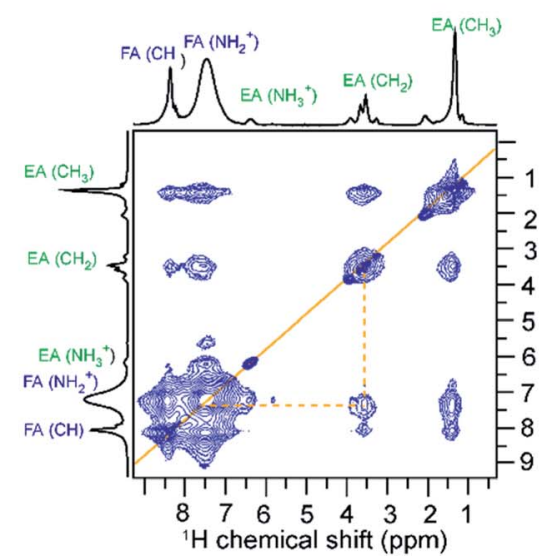

(b)
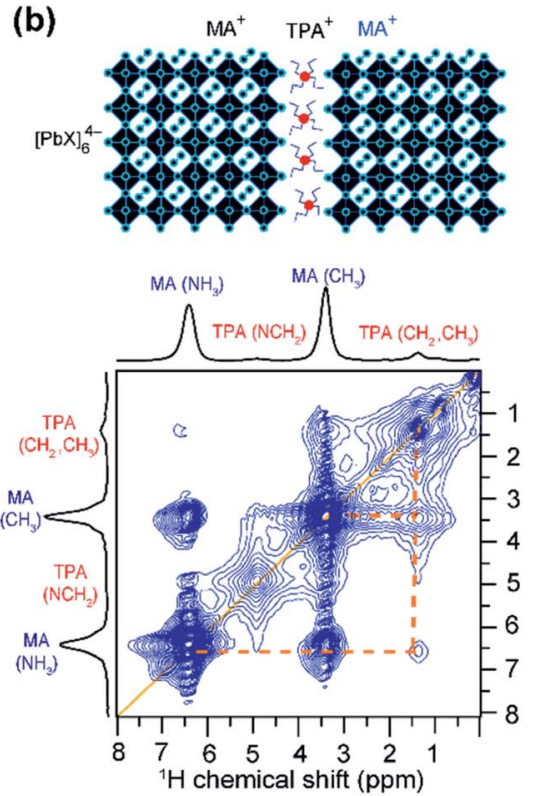

(c)
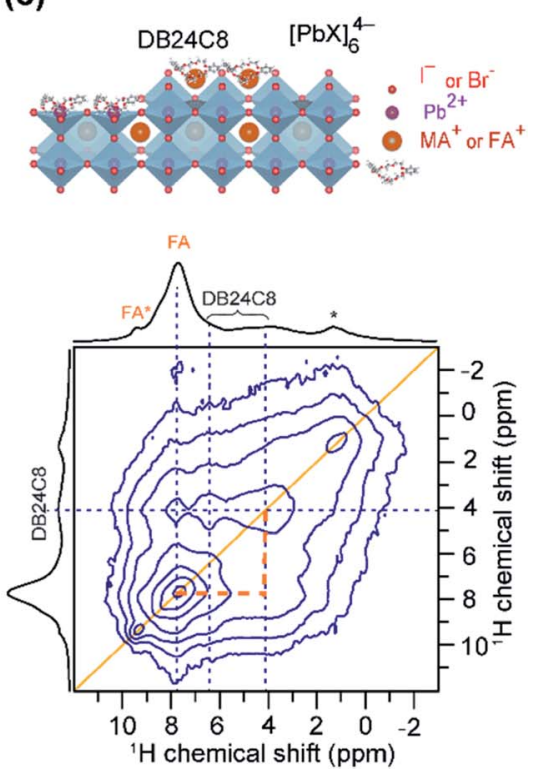

Fig. 12 Elucidating interfacial structures in molecularly passivated MHPs: (a) $2 \mathrm{D}^{1} \mathrm{H}-{ }^{1} \mathrm{H}$ spin-diffusion spectrum $(21.1 \mathrm{~T}, 20 \mathrm{kHz} \mathrm{MAS}, \mathrm{mixing}$ time $=50 \mathrm{~ms}$ ) evidencing atomic-level proximity between $\mathrm{FA}^{+}$and $\mathrm{EA}^{+}$in the $\mathrm{FA}_{0.9} \mathrm{EA}_{0.1} \mathrm{Pbl}_{3}$, thin film treated with $5 \mathrm{mg} \mathrm{ml}^{-1} \mathrm{EAl}(\mathrm{FA} / \mathrm{EA}$ yellow dotted lines). Adapted from ref. 379. (b) $2 \mathrm{D}^{1} \mathrm{H}-{ }^{1} \mathrm{H}$ spin-diffusion NMR spectrum of $\mathrm{TPA}_{x} \mathrm{MA}_{1-x} \mathrm{Pbl}_{3}(x=0.04)$ acquired at $18.8 \mathrm{~T}$ (35 kHz MAS, mixing time $=100 \mathrm{~ms}$ ) shows cross-peaks corresponding to intra-molecular ${ }^{1} \mathrm{H}-{ }^{1} \mathrm{H}$ dipolar interactions between MA ${ }^{+}$and TPA ${ }^{+}$cations (yellow dotted lines). Adapted with permission from ref. 381. Copyright 2020, John Wiley and Sons. (c) $2 \mathrm{D}{ }^{1} \mathrm{H}-{ }^{1} \mathrm{H}$ spin-diffusion NMR spectrum of crown ether (DB24C8) modulated $\mathrm{FAPb}_{3}\left(11.7 \mathrm{~T}, 40 \mathrm{kHz}\right.$ MAS, mixing time $=10 \mathrm{~ms}$ ) indicate the close proximity between DB24C8 and FA ${ }^{+}$proton sites depicted in yellow dashed lines. The asterisk $(*)$ indicates polypropylene from the ball-milling jar. The top panels depict the schematic illustration of proposed passivation mechanisms and potential interaction sites. Adapted with permission from ref. 382 . Copyright 2020 American Chemical Society. 
revealed through-space proximities between the ${ }^{1} \mathrm{H}$ sites in crown ether $(\sim 4 \mathrm{ppm})$ and A-site $\mathrm{FA}^{+}$cations $(\sim 7.8 \mathrm{ppm})$ at the sub-surface perovskite layers (Fig. 12c, black dashed lines).

\subsection{MHP nanoparticles}

Halide perovskite nanocrystals (NCs) have gained significant attention as next-generation optoelectronic materials. However, their properties are highly dependent on the interface between the perovskite crystals and organic ligands. The interfacial structure of MHP NCs can be substantially different from the bulk, and lead to changes in phase stability, defect compensation and transport, and surface passivation effects. ${ }^{65,255,256} \mathrm{~A}$ variety of non-covalent bonding interactions can occur between MHP surfaces and capping ligands, leading to a corresponding diversity of structural and optoelectronic properties in MHP NCs. It is crucially important to understand how MHP interfacial chemistry changes upon treatment or exchange with different ligands. To this end, some fundamental questions pertaining to the surfaces of precipitated or assembled MHP NCs, such as atomic surface termination, binding interactions, and molecular structure of ligands at the surface can be addressed by ssNMR spectroscopy. ${ }^{64,65,372,383}$

A recent study by Rossini and coworkers illustrates how sSNMR can probe the interfaces of precipitated ligand-capped $\mathrm{CsPbBr}_{3}$ NCs. MHP-ligand proximities and distances between ligands and terminal MHP atoms can be determined by analyzing dipolar couplings between dodecylammonium, oleate, and/or 10-undecenylphosphonate $-\mathrm{NH}_{3}{ }^{+}$protons and the surface/subsurface $\mathrm{Cs}$ and $\mathrm{Pb}$ sites. ${ }^{383}$ ssNMR results are complemented by the simulation of multi-spin dipolar dephasing curves to provide an atomistic picture of NC termination. The results demonstrated that $\mathrm{CsPbBr}_{3}$ NCs are terminated by $\mathrm{CsBr}$, rather than $\mathrm{PbBr}_{2}$, and that alkylammonium ligands substitute $\mathrm{Cs}^{+}$at some surface sites. These results are corroborated by analyzing $2 \mathrm{D}{ }^{207} \mathrm{~Pb}-{ }^{1} \mathrm{H}$ and ${ }^{133} \mathrm{Cs}-{ }^{1} \mathrm{H}$ HETCOR spectra, as well as previous computational models of NC surfaces. ${ }^{258}$ The binding chemistry of alkylphosphonate ligands on $\mathrm{CsPbBr}_{3}$ nanocrystals has been probed by ${ }^{31} \mathrm{P}-{ }^{1} \mathrm{H}$ HETCOR analysis upon different surface and washing treatments. ${ }^{\mathbf{3 8 4 , 3 8 5}} \mathrm{In}$ addition, ${ }^{207} \mathrm{~Pb}$ NMR has been employed to characterize local ${ }^{207} \mathrm{~Pb}$ environments in MHP NCs. ${ }^{34,354}$ These studies revealed that ${ }^{207} \mathrm{~Pb}$ spectra of NCs exhibited much broader signals than the analogous 3D MHPs due to structural disorder at the NC interface. Solid-state DNP SENS has also been used to study the core and surface of MHP-inspired $\mathrm{Cs}_{2} \mathrm{ZrCl}_{6} \mathrm{NCs}$, including the composition of the surface ligands and exposed atomic sites. ${ }^{386}$ Such atomic-level insights into the MHP NC interfaces, precipitated solids or dispersed colloids, may enable rational design of new ligands and provide opportunities to develop molecular passivation strategies.

SsNMR studies of colloidal MHP NCs can build on the literature of solution-state NMR studies of dispersed MHP colloids. Colloidal nanocrystals exhibit rich solution phase chemistry, enabled by the broad range of interactions between ligands, solvent molecules and MHPs. ${ }^{274}$ Solution-phase NMR experiments have been used to determine how ligands interact and exchange at the surface of MHP NCs within a liquid environment. ${ }^{6,251,275,387-391}$ For example, solution ${ }^{1} \mathrm{H}$ NMR studies have been used to quantify the thermodynamics of ligand binding to $\mathrm{CsPbBr}_{3}$ QDs, and revealed that both oleic acid and oleylamine ligands dynamically interact with $\mathrm{CsPbBr}_{3}$ QD surface. ${ }^{390}$ Pulse-Field-Gradient (PFG) based ${ }^{1} \mathrm{H}$ diffusion ordered spectroscopy (DOSY) experiments have also been used to gain insight into the self-diffusion of surface bounded oleicspecies and free ligands in solution. ${ }^{389}$ In this respect, highresolution DOSY experiments are expected to aid the analysis of different diffusion behaviors of ligands at solid-solution interfaces. ${ }^{392,393}$

\section{Dynamics at organic-inorganic interfaces in MHPs}

Dynamic motion of molecules and ions at the interface between photoactive and contact layers, or at intrinsic interfaces within MHPs, influence the overall bulk optoelectronic properties in MHP-based devices. Although fast ion migration and charge carrier dynamics in MHPs at fs-ps time scales can be characterized by ultrafast spectroscopy, many relevant photophysical processes extend to slower timescales accessible by NMR (Fig. 3). The wide range of timescales (ns-s) associated with ssNMR spectroscopy has sparked interest in studying different dynamic processes in MHPs with site specificity. ${ }^{66,312}$ In MHPs, relaxation, lineshape analysis and exchange measured by sSNMR spectroscopy techniques reveal information on different dynamic processes associated with A, B and X sites in MHPs. For example, fast dynamics on the timescale of tens of ps to hundreds of ns can be studied by measuring $T_{1}$ and $T_{2}$ values. Dynamic processes and structural transformations that occur at much slower timescales, in the order of milliseconds to minutes (or slower), can be measured by carrying out 2D exchange spectroscopy and time-resolved experiments. The analysis of ${ }^{2} \mathrm{H}$ quadrupole splittings of deuterated cations and ${ }^{14} \mathrm{~N}$ spectral lineshapes provides insights into the correlation times and modes of reorientation of A-site organic cations in MHPs. The above experiments are typically carried out as a function of temperature to determine the activation energies and correlation times associated with the cation reorientation, diffusion and ion migration, as well as to evaluate the homogeneous (order, rotational or translational mobility) and inhomogeneous (disorder) contributions to lineshapes, and as discussed in the below sections.

The structure and, to a lesser extent, photophysical properties of high-performing MHP absorbers such as $\mathrm{MAPbI}_{3}$ are influenced by the dynamics of A-site reorientations. ${ }^{291,394,395}$ The different dynamic processes of A-site reorientations in $\mathrm{MAPbX}_{3}$ have been investigated by ${ }^{1} \mathrm{H},{ }^{2} \mathrm{H},{ }^{13} \mathrm{C}$, and ${ }^{14} \mathrm{~N},{ }^{15} \mathrm{~N}$ ssNMR spectroscopy, ${ }^{152,291,304,306,343,344}$ revealing the presence of various degrees of freedom at different temperatures. ${ }^{14} \mathrm{~N}$ NMR has been used in conjunction with DFT calculations to understand the symmetry and orientational dynamics of $\mathrm{MA}^{+}$cations in $\mathrm{MAPbI}_{3} \cdot{ }^{306}$ These trends have been extended to study the dynamic motion of other A-site cations such as $\mathrm{MA}^{+}, \mathrm{FA}^{+}, \mathrm{DMA}^{+}$ 
(dimethylammonium) and $\mathrm{G}^{+}$(guanidinium) or inorganic monovalent cations in MHPs ${ }^{153,154,291,339,340}$ along with solid solutions of cations such as $\mathrm{FA}_{0.67} \mathrm{MA}_{0.33} \mathrm{PbI}_{3}, \mathrm{DMA}_{1-x} \mathrm{MA}_{x} \mathrm{PbI}_{3}$ and $\mathrm{G}_{0.25} \mathrm{MA}_{0.75} \mathrm{PbI}_{3} \cdot{ }^{152,345,396}$ In another example, a broad ${ }^{2} \mathrm{H}$ NMR signal envelope has been observed in a 1D non-perovskite $\mathrm{G}\left(\mathrm{d}_{6}\right) \mathrm{PbI}_{3}$ indicating no rotational dynamics of the $\mathrm{C}-\mathrm{N}$ bond of $G$, whereas narrow envelopes were observed for $G$ in $G\left(d_{6}\right)_{0.25^{-}}$ $\mathrm{MA}_{0.75} \mathrm{PbI}_{3}$ confirming the nearly isotropic reorientation of the $\mathrm{G}$ moiety in that material. The correlation times associated with the $\mathrm{G}$ reorientation are shorter than $(18 \pm 8) \mathrm{ps}$, which has been correlated with high charge carrier lifetimes and promising performance of this material in solar cells. ${ }^{345}$

The dynamic nature of both A-site cations and halides influences the local $\mathrm{BX}_{6}$ octahedral structure. For instance, ion hopping should manifest itself as the presence of exchange between ${ }^{207} \mathrm{~Pb}$ environments associated with different halide coordination. 2D ${ }^{207} \mathrm{~Pb}$ exchange spectroscopy (EXSY) does indeed confirm that the different $\mathrm{Pb}$ environments exchange their halides. ${ }^{35,360}$ An important practical consideration is the choice of the recycle delay to optimize the sensitivity in ${ }^{207} \mathrm{~Pb}$ NMR experiments. There are several mechanisms that drive $T_{1}$
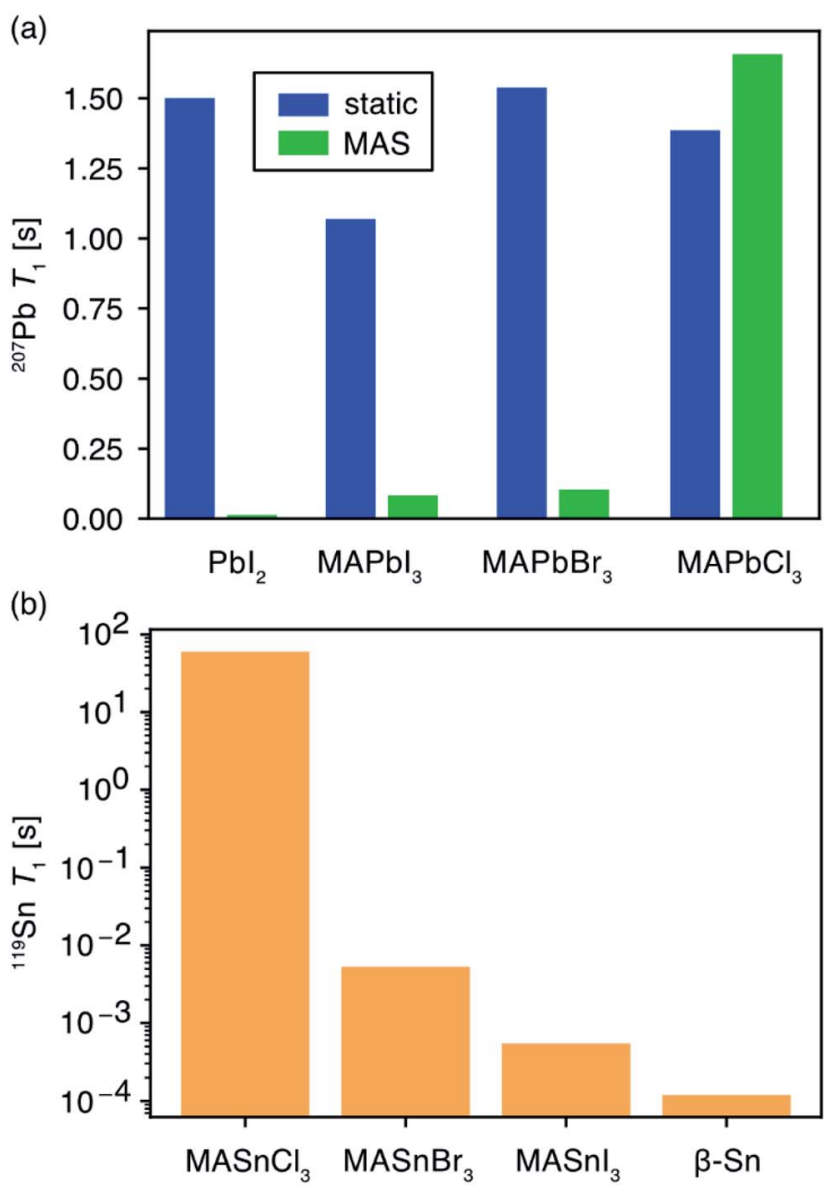

Fig. 13 Longitudinal relaxation times in lead-and tin-based MHPS: (a) Comparison of spin-lattice $\left(T_{1}\right)$ relaxation rates of ${ }^{207} \mathrm{~Pb}$ nuclei in different MHPs. MAS-induced longitudinal relaxation enhancement is a process leading to a substantial shortening of ${ }^{207} \mathrm{~Pb} T_{1}$ when the sample is spun. (b) ${ }^{119} \mathrm{Sn} T_{1}$ span 6 orders of magnitude and are strongly dependent on the halide composition. relaxation of ${ }^{207} \mathrm{~Pb}$ nuclei in MHPs, which depend on the experimental condition, structure and composition of the material. We first highlight a mechanism known as the MASinduced heteronuclear longitudinal relaxation enhancement, which occurs in lead iodides and bromides, and leads to a dramatic reduction of $T_{1}$ when the sample is spun (Fig. 13a). This behavior is related to the crossing between the energy levels of the spin-1/2 nucleus $\left({ }^{207} \mathrm{~Pb}\right)$ and the very fast relaxing quadrupolar spin $\left({ }^{127} \mathrm{I},{ }^{79 / 81} \mathrm{Br}\right)$ during sample rotation. ${ }^{397}$ The effect is absent in $\mathrm{MAPbCl}_{3} .{ }^{207} \mathrm{~Pb}$ sensitivity benefits substantially from spinning, which leads to a significant ( 2 orders of magnitude) decrease in the necessary recycle delay.

In tin-based MHPs, ${ }^{119} \mathrm{Sn}$ ssNMR has been applied to probe the mixing of halides and local dynamics of $\left[\mathrm{SnX}_{6}\right]^{4-}$ sites. ${ }^{312,313}$ Longitudinal relaxation times $\left(T_{1}\right)$ of ${ }^{119} \mathrm{Sn}$ sites in tin-based MHPs span 6 orders of magnitudes owing to the presence of different relaxation mechanisms depending on the halide composition. For example, in tin halides, the ${ }^{119} \mathrm{Sn} T_{1}$ is determined by the strength of the ${ }^{119} \mathrm{Sn}-\mathrm{X}$ scalar couplings, which is as follows: ${ }^{1} J_{\mathrm{Sn}-\mathrm{I}}>{ }^{1} J_{\mathrm{Sn}-\mathrm{Br}}>{ }^{1} J_{\mathrm{Sn}-\mathrm{Cl} \cdot} \cdot{ }^{398,399}$ The presence of multiple composition-dependent relaxation mechanisms for ${ }^{119} \mathrm{Sn}$ lead to a large spread of $T_{1}$ values (Fig. 13b). For example, the dominating relaxation mechanism in $\mathrm{MASnBr}_{3}$ is scalar relaxation caused by the modulation of the ${ }^{119} \mathrm{Sn}-{ }^{79 / 81} \mathrm{Br} J$-coupling. If this relaxation pathway is not effective, other mechanisms, such as CSA or dipolar, may be at play. In tin metal ( $\beta$-Sn), the dominant sources of relaxation are the conduction electrons, leading to efficient Korringa relaxation. ${ }^{\mathbf{4 0 0}}$ This variability highlights the importance of choosing the recycle delay judiciously, especially if quantitative spectra are required of materials containing multiple species with different relaxation characteristics.

Activation energies $\left(E_{\mathrm{a}}\right)$ associated with halide migration in MHPs have been measured by ssNMR spectroscopy and compared with other bulk techniques (Table 1). In $\mathrm{MAPbI}_{3}$, the activation energies of iodine migration are in the range of $0.17-$ $0.44 \mathrm{eV}$ as determined from SSNMR, NQR and electrical measurements. However, in the mixed-halide compositions $\mathrm{MAPbI}_{3-x} \mathrm{Cl}_{x}$, these values are in the range of $0.31-0.55 \mathrm{eV}$, indicating that in chloride-doped $\mathrm{MAPbI}_{3}$, iodine migration requires higher activation energies. By comparison, in tin-based perovskites the activation energy for bromide hopping in $\mathrm{MASnBr}_{3}$ is $0.37 \mathrm{eV}$ (determined from variable-temperature ${ }^{119} \mathrm{Sn} T_{1}$ relaxation at multiple magnetic fields), which is consistent with the a.c. and d.c. conductivity measurements as well as DFT calculations. Overall, ssNMR spectroscopy provides a wealth of information on the dynamic motion of organic cations and halides in MHPs.

Low-dimensional MHPs exhibit different ion dynamics and reorientational modes than the $3 \mathrm{D}$ MHPs. For example, different trends in ion motion have been reported for 2D layered perovskites. Lin et al. employed ion conductivity measurements to characterize ion dynamics and showed that the ion motion is suppressed in low-dimensional perovskites compared to $3 \mathrm{D}$ perovskites, both in the dark and under illumination. ${ }^{414,415}$ Jiang et al. used Scanning Kelvin Probe Microscopy (SKPM) to study ion migration in layered 2D perovskites with varying 
Table 1 Activation energies associated with halide migration probed by ssNMR spectroscopy and other complementary techniques. $V_{1}-$ iodide vacancy and $I_{i}$ - iodide interstitial

\begin{tabular}{|c|c|c|c|}
\hline MHP & $E_{\mathrm{a}}(\mathrm{eV})$ & Technique & Reference \\
\hline \multirow[t]{8}{*}{$\mathrm{MAPbI}_{3}$} & 0.17 & ssNMR & 344 \\
\hline & 0.17 & ${ }^{127}$ I NQR & 344 \\
\hline & 0.43 & Impedance & 401 \\
\hline & 0.5 & Thermally stimulated current & 402 \\
\hline & 0.44 & Ab initio/DFT & 403 \\
\hline & 0.33 & $\begin{array}{l}\text { Temperature dependent } J-V \\
\text { curves }\end{array}$ & 404 \\
\hline & 0.29 & Transient ion drift & 405 \\
\hline & 0.44 & $A b$ initio simulations & 406 \\
\hline \multirow[t]{3}{*}{$\mathrm{MAPbI}_{3-x} \mathrm{Cl}_{x}$} & 0.55 & Impedance and IMVS & 407 \\
\hline & 0.45 & $\begin{array}{l}\text { Temperature dependent } \\
\text { capacitance }\end{array}$ & 408 \\
\hline & 0.31 & $\begin{array}{l}\text { Temperature dependent } \\
\text { current }\end{array}$ & 409 \\
\hline \multirow[t]{6}{*}{$\mathrm{MASnBr}_{3}$} & 0.44 & $\operatorname{ssNMR}(4.7 \mathrm{~T})$ & 312 \\
\hline & 0.33 & $\operatorname{ssNMR}(9.4 \mathrm{~T})$ & \\
\hline & 0.35 & SsNMR (17.6 T) & \\
\hline & 0.37 & ssNMR (average) & \\
\hline & 0.30 & a.c. conductivity & 410 \\
\hline & 0.31 & d.c. conductivity & 411 \\
\hline $\mathrm{MASnI}_{3}$ & $\begin{array}{l}0.37\left(\mathrm{~V}_{\mathrm{I}}\right), 0.65 \\
\left(\mathrm{I}_{\mathrm{i}}\right)\end{array}$ & DFT & 412 \\
\hline $\mathrm{CsPbCl}_{3}$ & 0.27 & Diffusion/DFT & 413 \\
\hline $\mathrm{CsSnBr}_{3}$ & 0.29 & ${ }^{119} \mathrm{Sn}$ ssNMR $(11.75 \mathrm{~T})$ & 313 \\
\hline
\end{tabular}

dimensionality. ${ }^{\mathbf{4 1 6}}$ For $n$-butylammonium lead iodide perovskites $\mathrm{BA}_{2} \mathrm{PbI}_{4}(n=1)$, and methylammonium-incorporated quasi-2D perovskites $\left(\mathrm{BA}_{2} \mathrm{MA}_{3} \mathrm{~Pb}_{4} \mathrm{I}_{13}\right)\langle n\rangle=4$, different ion motion was observed under the effects of illumination and temperature. Activation energies associated with ion motion in 2D perovskites studied by SKPM technique are compared in Table 2. This study proposes that ion motion in neat $\mathrm{BA}_{2} \mathrm{PbI}_{4}$ perovskite films is dominated by paired halide and halide vacancy, whereas in the case of quasi-2D $\mathrm{BA}_{2} \mathrm{MA}_{3} \mathrm{~Pb}_{4} \mathrm{I}_{13}$ perovskites it can be viewed as a collective motion of both halide and methylammonium (vacancy) migration. This study indicates that the dimensionality plays a significant role in ion dynamics in layered perovskites.

There is a tremendous diversity of organic spacer cations and packing interactions in layered and nanocrystalline MHPs, so it is less straightforward to probe molecular dynamics of spacer cations with atomic site specificity. The typical method of analyzing dynamics in MHPs is to perform temperaturedependent relaxation experiments (and/or ${ }^{2} \mathrm{H}$ or ${ }^{14} \mathrm{~N}$ lineshape analysis). However, this approach becomes impractical in larger organic spacers with many different local environments and convoluted 1D NMR spectra. Organic spacer cations may also show glassy packing arrangements at elevated temperatures, ${ }^{\mathbf{4 1 7}}$ further complicating interpretations of dynamics by NMR. Dynamics can instead be probed at different temperatures using $1 \mathrm{D}$ and 2D CP-MAS ssNMR methods. This approach has been used to understand spacer dynamics in some layered Ruddlesden-Popper phases. For instance, temperaturedependent measurements of $T_{1}$ and line-broadening, using
Table 2 Activation energies $\left(E_{\mathrm{a}}\right)$ associated with ion motion in lowdimensional perovskites, consistent with the iodine motion, presented in ref. 416. SKPM: Scanning Kelvin Probe Microscopy

\begin{tabular}{lll}
\hline Material & $E_{\mathrm{a}}(\mathrm{eV})$ & Technique \\
\hline $\mathrm{BA}_{2} \mathrm{PbI}_{4}(n=1)$ & 0.61 & SKPM, dark (negative potential) \\
& 0.55 & SKPM, dark (positive potential) \\
& 0.37 & SKPM, light (negative potential) \\
$\mathrm{BA}_{2} \mathrm{MA}_{3} \mathrm{~Pb}_{4} \mathrm{I}_{13}(\langle n\rangle=4)$ & 0.30 & SKPM, light (positive potential) \\
& 0.64 & SKPM, dark (negative potential) \\
& 0.24 & SKPM, dark (positive potential) \\
& 0.39 & SKPM, light (negative potential) \\
& 0.25 & SKPM, light (positive potential)
\end{tabular}

1D ${ }^{1} \mathrm{H} \rightarrow{ }^{13} \mathrm{C}$ CP-MAS spectra, distinguished activation energies of different reorientation modes of phenylethylammonium spacers in $2 \mathrm{D}$ lead iodide RP phases $(n=1)$ from 110 to 400 $\mathrm{K} .^{307,308}$ However, many MHPs, including $\mathrm{PEA}_{2} \mathrm{PbI}_{4}$, undergo phase transitions in the typical temperature range $(\sim 100-400 \mathrm{~K})$ of variable-temperature MAS ssNMR experiments. ${ }^{55,418}$ Therefore, other approaches that do not rely on large temperature variations can be helpful to understand cation dynamics in MHPs with narrow ranges of phase stability.

At room temperature, rotational and librational motions of spacer cations in RP phases typically occur on much faster timescales than CP transfer (microseconds to milliseconds). However, the CP transfer efficiency is affected by reorientation rates, so CP transfer kinetics can be used to compare molecular dynamics on the scale of $\mu$ s to ms. In a study by Dahlman et al., the room temperature dynamic motion of different organic spacer cations in layered RP phases has been characterized by CPMAS ssNMR techniques. ${ }^{309}$ Fig. 14 a compares the CP buildup rate for different carbon sites in a butylammonium $\{\mathrm{C} 4\} \mathrm{RP} n=1$ crystal, $\{\mathrm{C} 4\}_{2} \mathrm{PbI}_{4}$ (an alternative notation for $\mathrm{BA}_{2} \mathrm{PbI}_{4}$ ). A comparison of ${ }^{1} \mathrm{H} \rightarrow{ }^{13} \mathrm{C} \mathrm{CP}$ build-up time constants (shown as $T_{\mathrm{CP}}=1 / k_{\mathrm{CP}}$, where $k$ defines the rate at which CP signal intensity builds up) for different carbon sites of linear alkylammonium spacers is shown (Fig. 14b), alongside a complementary measure of site-specific disorder, $U_{\text {iso }}$, obtained from single-crystal X-ray diffraction refinements. The isotropic displacement parameter $\left(U_{\text {iso }}\right)$ from single-crystal XRD measurements can help to visualize site-specific spatial disorder in spacer cations, which can be compared to the $\mathrm{CP}$ buildup rates of different carbon sites. A larger $U_{\text {iso }}$ from XRD indicates greater atomic spatial disorder as the average of many X-ray scattering events $(\sim \mathrm{fs})$, either due to static disorder or dynamic fluctuations. CP build-up rates $\left(k_{\mathrm{CP}}\right)$ probe dynamic motion on the scale of $\mu$ s to ms, which may manifest as spatial disorder during X-ray scattering. Intramolecular trends in $U_{\text {iso }}$ are consistent with CP build-up rates; for $\{\mathrm{C} 4\}_{2} \mathrm{PbI}_{4}$ the $\mathrm{CH}_{2}$ groups near to $\mathrm{NH}_{3}{ }^{+}$sites exhibit faster $\mathrm{CP}$ intensity buildup and smaller atomic displacement compared to carbon sites further away. Similar trends between CP time constants and $U_{\text {iso }}$ values are observed for the RP phases with longer spacer cations, $\{\mathrm{C} 8\}_{2} \mathrm{PbI}_{4}$ and $\{\mathrm{C} 8\}_{2} \mathrm{PbI}_{4}$. The agreement between XRD and SSNMR indicates that $U_{\text {iso }}$ values are determined by dynamic fluctuations that affect CP build-up, rather than static disorder. Thus, ssNMR provides complementary 
(a)
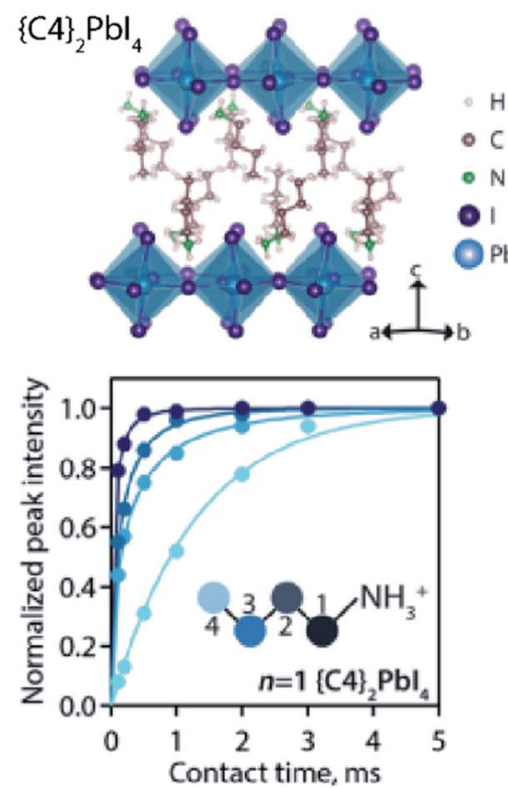

(b)

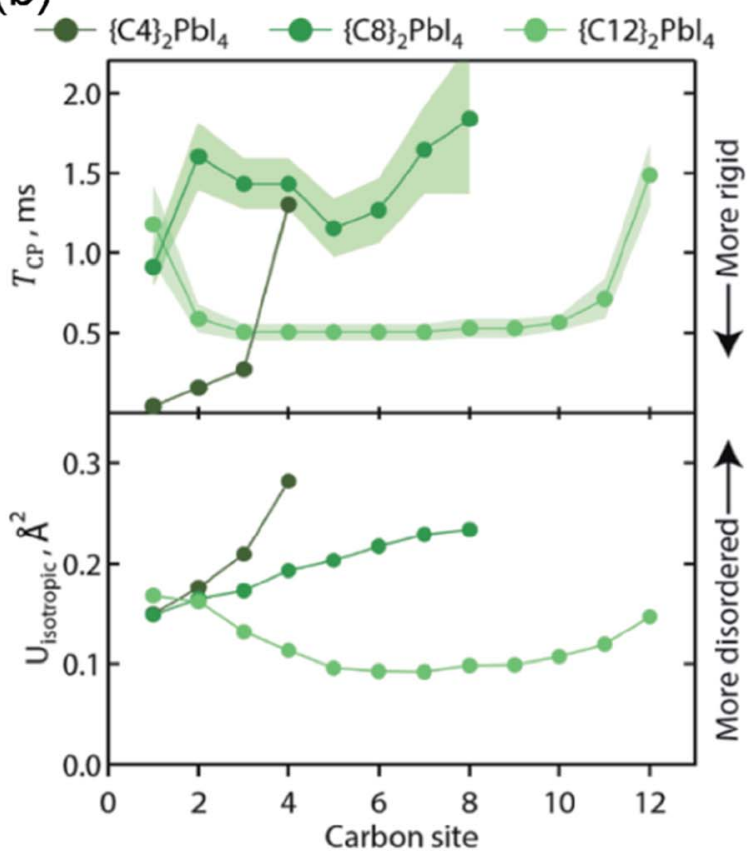

(d)
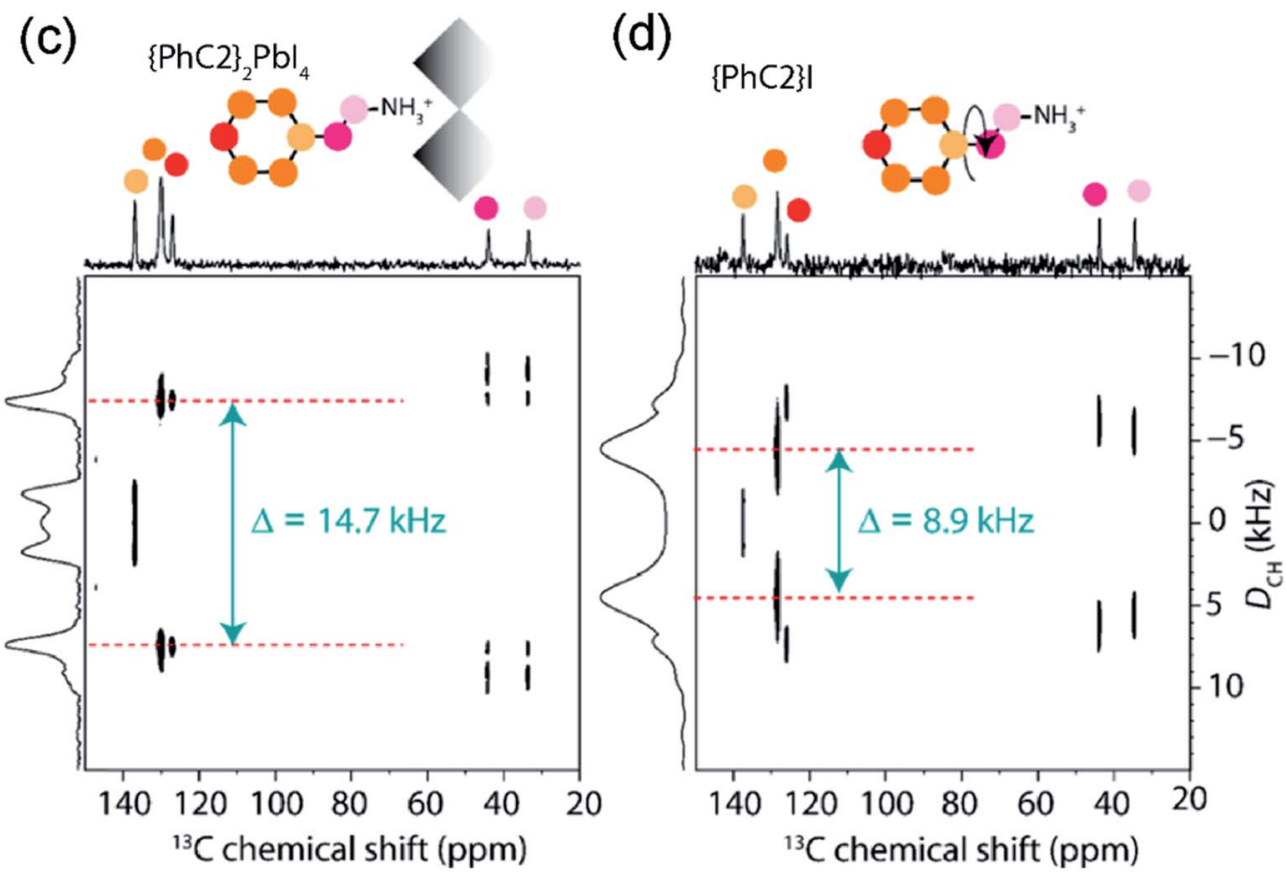

Fig. 14 Dynamic motion of spacer cations in layered perovskites: (a) crystal structure of $\{C 4\}_{2} P b l_{4}$ obtained from previously published XRD studies at $293 \mathrm{~K}$ with a projection along $\langle 110\rangle$ of the orthorhombic Pbca unit cell, and ${ }^{1} \mathrm{H} \rightarrow{ }^{13} \mathrm{C} \mathrm{CP}$-MAS NMR build-up curves (dots) for the four distinguishable carbon sites in $\left\{\mathrm{C}_{4}\right\}_{2} \mathrm{Pbl}_{4}$ spectra acquired at $9.4 \mathrm{~T}, 8 \mathrm{kHz}$ MAS and at $300 \mathrm{~K}$, accompanied by the monoexponential fitted $\mathrm{CP}$ signal intensity buildup (solid lines). (b) Site-specific ${ }^{13} \mathrm{C}\left\{{ }^{1} \mathrm{H}\right\} \mathrm{CP}$ build-up time constants (top), $T_{\mathrm{CP}}$, for different carbon atoms in alkylammonium spacers in $\{\mathrm{C} 4\}_{2} \mathrm{Pbl}_{4},\{\mathrm{C} 8\}_{2} \mathrm{Pbl}_{4}$ and $\{\mathrm{C} 12\}_{2} \mathrm{Pbl}_{4}$ compared with calculated isotropic displacement parameters (bottom) derived from roomtemperature single-crystal XRD measurements and analyses. (c and d) Comparison of the solid-state $2 \mathrm{D}^{13} \mathrm{C}\left\{{ }^{1} \mathrm{H}\right\} \mathrm{CP}-\mathrm{VC}$ NMR spectrum acquired at $14.1 \mathrm{~T}$ for $(\mathrm{a})$ the $\{\mathrm{PhC} 2\}_{2} \mathrm{Pbl}_{4}(n=1) \mathrm{RP}$ phase and $(\mathrm{b})$ the $\{\mathrm{PhC} 2\}$ l precursor salt. The separation of signals $\Delta=\left(D_{\mathrm{CH}} / \sqrt{ } 2\right)$ that leads to the estimation of ${ }^{13} \mathrm{C}-{ }^{1} \mathrm{H}$ dipole-dipole couplings of (c) $20.8 \mathrm{kHz}$ and (d) $12.6 \mathrm{kHz}$. Adapted with permission from ref. 309 . Copyright $2021 \mathrm{American}$ Chemical Society.

information to other characterization techniques to study dynamics and site-specific disorder, including X-ray diffraction and inelastic neutron scattering.
Aromatic spacers such as phenylethylammonium $\{\mathrm{PhC} 2\}$ cations exhibit different dynamic motions in RP phases. For example, the phenyl ring rotation in $\{\mathrm{PhC} 2\}$ is an important 
reorientation mode that can affect both the spacer dynamics and dielectric environment of RP phases. Dipolar-mediated 2D ${ }^{13} \mathrm{C}\left\{{ }^{1} \mathrm{H}\right\}$ cross-polarization variable contact (CP-VC) experiments can directly probe the room-temperature $\mathrm{C}_{2}$ rotational mode of $\{\mathrm{PhC} 2\} .{ }^{309}$ Fig. 14c and d compares 2D CP-VC spectra of $\{\mathrm{PhC} 2\}$ within the RP phase and iodide salt, which show that dipolar frequency splittings (inset arrows) for aromatic carbon sites are much higher in the RP phase, $\left\{\mathrm{PhC}_{2}\right\}_{2} \mathrm{PbI}_{4}\left(D_{\mathrm{CH}}=\sqrt{ } 2 \Delta=20.8\right.$ $\mathrm{kHz}$, close to a theoretically rigid $\mathrm{CH}$ bonds), than in the precursor iodide salt, $\{\mathrm{PhC} 2\} \mathrm{I}\left(D_{\mathrm{CH}}=\sqrt{ } 2 \Delta=12.6 \mathrm{kHz}\right)$. This analysis indicates that templating by lead iodide octahedra makes phenylethylammonium cations more rigid. Analysis of CP build-up processes provide a useful probe of molecular dynamics at $\mu \mathrm{s}$ to $\mathrm{ms}$ timescales in low-dimensional MHPs without requiring temperature variations.

\section{Contact layers}

In a layer-by-layer device stack (Fig. 1) obtained by solution- and vapor-processing techniques, the MHP film forms an interface with the HTL and ETLs. Energy alignment of the valence and conduction band of the MHP and transport layers (or HOMO and LUMO levels) is essential to the performance of the device. The structural integrity and stability of transport layers is crucially important for device operation. ${ }^{43}$ The transport layers can also determine the ambient stability of MHP layers. Charge transfer between MHP photoactive layers and transport layers is sensitive to the atomic interface between the two. Significant gain in the MHPs device efficiency and stability can be obtained by tailoring the contact layers, chemically doping ETL and HTLs, and processing techniques. ${ }^{68-70,72-75,419-421}$ Many studies have attempted to determine the precise molecular structure of this interface. Organic semiconductors are commonly used as HTLs, either in pure form or doped with inorganic salts such as, for example, spiro-OMeTAD $(2,20,7,70$-tetrakis $(N, N$-di- $p$ methoxyphenylamine)9,90-spirobifluorene) doped with hydrophilic LiTFSI (lithium bis(trifluoromethylsulfonyl)-imide) or tert-butylpyridine.$^{\mathbf{9 9 , 4 2 0}}$ Synthetic modifications of organic HTLs, e.g. fluorinated analogues of spiro-OMeTAD, ${ }^{\mathbf{1 4 4}}$ can also improve MHP device stability and performance. In addition, the formation of self-assembled monolayers (SAMs) at the interface between MHP and transport layers can improve the stability and performance of assembled devices. ${ }^{\mathbf{2 2 2 , 4 2 3}}$

The local structures of organic semiconductors, with and without molecular dopants, have been characterized by SSNMR spectroscopy. ssNMR studies have focused on providing insight into intermolecular interactions in pristine and doped conducting polymers. ${ }^{62,421,424-427}$ The roles of Li-TFSI doping on spiro-OMeTAD has been elucidated by ${ }^{7} \mathrm{Li}$ MAS NMR spectroscopy. ${ }^{424}$ A comparison of ${ }^{7} \mathrm{Li}$ NMR spectra showed different displacements of ${ }^{7} \mathrm{Li}$ signals corresponding to neat Li-TFSI, doped Li-TFSI:spiro-OMeTAD, and the oxidized product of LiTFSI:spiro-OMeTAD (upon exposure to air over $12 \mathrm{~h}$ ). These findings indicate a doping mechanism that is triggered by consumption of the $\mathrm{Li}^{+}$ions during device operation, which is troublesome because the concentration of $\mathrm{Li}^{+}$must be maintained at approximately $20 \mathrm{~mol} \%$ with respect to spiro-OMeTAD for optimal device performance. ssNMR spectroscopy has also offered insight into the molecular doping of other conjugated polymers that show promise as HTL materials, such as poly-3hexylthiophene (P3HT) and PBTTT- $_{14}$ doped with 2,3,5,6tetrafluoro-7,7,8,8-tetracyanoquinodimethane $\quad\left(\mathrm{F}_{4}\right.$ TCNQ). ${ }^{425}$ Cochran et al., used combined $1 \mathrm{D}^{19} \mathrm{~F}$ and $2 \mathrm{D}{ }^{1} \mathrm{H}\left\{{ }^{13} \mathrm{C}\right\}$ ssNMR analysis to provide crucial insights into the co-facial arrangement of $\mathrm{F}_{4}$ TCNQ and PBTTT- $\mathrm{C}_{14}$, where charge transfer can be $100 \%$ efficient in the solid state. ${ }^{428}$ In a study by Yurash et al., the local structures and binding properties of small molecule Lewis acid dopants such as tris(pentafluorophenyl)borane (BCF) in doped organic semiconductors have also been characterized by $1 \mathrm{D}^{11} \mathrm{~B},{ }^{13} \mathrm{C}\left\{{ }^{1} \mathrm{H}\right\}$ and ${ }^{13} \mathrm{C}\left\{{ }^{19} \mathrm{~F}\right\} \mathrm{CP}$-MAS and $2 \mathrm{D}^{1} \mathrm{H}^{-}{ }^{19} \mathrm{~F}$ and ${ }^{1} \mathrm{H}-{ }^{1} \mathrm{H}$ correlation ssNMR spectroscopy. ${ }^{62,421}$

The transport layers can also serve to prevent environmental pollution from MHP devices upon degradation. In a recent work by Lee et al., a HTL material was synthesized that can chelate Pb ions to prevent degradation and avoid lead leakage. ${ }^{\mathbf{4 2 9}}$ The lead capturing ability of alkoxy-poly tetraethylene glycol was examined by solution ${ }^{1} \mathrm{H}$ NMR spectroscopy as a function of the concentration of lead iodide in dimethylformamide. The ${ }^{1} \mathrm{H}$ signals of TEG groups were displaced to lower $\mathrm{ppm}$ values as the concentration of lead ions increased, which can be used to estimate the $\mathrm{Pb}$ binding constants. This example, along with the studies of conjugated polymers described above, illustrate the important role that NMR can play to examine interfaces between MHPs and contact layers for high-performing devices.

\section{Outlook}

\subsection{Materials design and interfacial engineering}

The search for improved perovskite absorbers and light emitters is enticing. We envision that the characterization of interfacial structures, both between device layers and within MHP materials, will demand further scrutiny to improve performance in a variety of applications. The remarkable optoelectronic properties of MHPs lend them to applications in high-performance light-emitting devices such as LEDs and lasers, flexible and wearable electronics, and tandem solar cell architectures, and it is likely that we will see these areas rapidly develop in the immediate future.

One of the key materials design challenges is to rationally control halide mixing and transport properties of existing and novel MHP phases. This problem has only recently been tackled in depth using electrical measurements, ${ }^{\mathbf{4 3 0 - 4 3 2}}$ and ssNMR has the potential to provide unique insights into the atomic-level mechanism of ionic transport in new materials. SSNMR will continue to offer insight into synthesis, processing and device performance puzzles as research into MHPs extends to new materials, stability and performance benchmarks.

MHPs composed of mixed A-site, B-site and halide species will continue to pose characterization challenges that SSNMR spectroscopy is particularly well-suited to address. ssNMR has provided, in some cases, the only direct probe of clustering and local disorder in mixed-phase MHPs. Low-dimensional phases in particular present a compelling case for ssNMR applications, because minority phases, disordered or defective regions, or 
even glassy and amorphous sub-phases may dominate photophysical properties. The density of interfaces in these materials is also much higher than dense 3D MHP phases. Careful accounting of intrinsic interfacial structures and dynamics in low-dimensional MHPs may yield unexpected insights and engineering solutions. There is a wide range of sSNMR approaches that have not yet been attempted with these materials, and may prove lucrative to better understand hollow, layered, colloidal and quantum-confined MHP phases.

\subsection{NMR methodology}

Improvements in sSNMR resolution and detection limits are crucially important for the structural elucidation of masslimited MHPs and contact layers. The vast majority of sSNMR experiments are carried out on bulk MHP materials and HTLS (microcrystalline samples of 1-100 mg). The main challenge of NMR spectroscopy is its low sensitivity, which inhibits the investigation of MHPs in device stacks, particularly when lowsensitivity nuclei are involved. Although sensitivity-enhanced methods have been demonstrated, ${ }^{\mathbf{3 1 4}}$ the most versatile and promising method for enhancing sensitivity in NMR - DNP SENS - has yet to be optimized to yield large enhancements comparable to those achievable in other material solids. ${ }^{334}$ DNP experiments achieve their maximum sensitivity enhancements at cryogenic temperatures of 20-110 K. However, at cryogenic temperatures many MHPs undergo phase transitions and the heterogeneous interfaces manifest much broader linewidths with signals from MHPs and contact layers yielding to severe spectral overlap. DNP NMR protocols suitable for ambient/nearambient temperatures might be sought to fully explore the potential of ssNMR spectroscopy for the investigation of device stacks. An efficient MAS DNP strategy for MHPs would allow routine investigation of MHP thin films, charge-selective transport layers, and extremely dilute surface passivation agents. Notably, it would also allow 2D correlation experiments between dilute and low-sensitivity nuclei, which are currently out of reach for the conventional NMR techniques.

While ssNMR studies of nuclei of high importance to MHP research have been demonstrated (Fig. 4a), there remain pertinent nuclei that are notoriously challenging to detect, owing to their high quadrupole moment and low sensitivity. These include, for example, ${ }^{17} \mathrm{O},{ }^{33} \mathrm{~S},{ }^{35} \mathrm{Cl},{ }^{49} \mathrm{Ti}$ and ${ }^{67} \mathrm{Zn}$. Compounds with these elements are frequency employed in different layers of device stacks. ssNMR of these nuclei will benefit from the application of the highest available magnetic fields, ${ }^{\mathbf{4 3 3}, \mathbf{4 3 4}}$ fast MAS, ${ }^{435}$ and the development r.f pulse sequences suitable for the direct and indirect detection of NMR nuclei ${ }^{\mathbf{4 3 6}-438}$ in conjunction with sensitivity enhanced techniques. ${ }^{439}$ The hypothetical 2D experiments correlating NMR signals originating from $\mathrm{A}$ and $\mathrm{X}$ sites (e.g., $\mathrm{X}=\mathrm{Cl}, \mathrm{Br}, \mathrm{I}$ ), or $\mathrm{X}$ sites and contact layers, would be exceedingly challenging to obtain. In addition, ${ }^{119} \mathrm{Sn}$ and ${ }^{207} \mathrm{~Pb}$ spectra of MHPs are characterized by very large chemical shift ranges and may feature substantial chemical shifts anisotropies, which make the necessary bandwidth challenging for conventional 1D experiments. The use of low magnetic fields, fast MAS, short high-powered adiabatic pulses (SHAPs) for refocusing ${ }^{\mathbf{4 4 0}}$ as well as microcoils to increase the RF strength ${ }^{441}$ can be viewed as viable strategies to resolve some of these issues.

\subsection{Extending NMR length scales}

While ssNMR is particularly well suited to address short-range structural and dynamics problems in MHPs, full potential of the technique for the study of MHP-HTL and MHP-ETL contacts and other intrinsic and extrinsic interfaces in MHP-based devices is yet to be explored. For example, there is an increasing interest in mapping ion diffusion at interfaces, understanding degradation processes at $\mathrm{MHP} /$ contact layer interfaces, and probing the chemistry of low-dimensional perovskites. Each of these challenges will benefit from the application of SSNMR spectroscopy. SSNMR techniques that allow structure elucidation beyond a nanometer distance are expected to be suitable for the investigation of layers and interfaces in device stacks. In addition, approaches that combine experiment and modelling such as NMR crystallography and modelling of $\mathrm{CP}$ or SD build-up curves, are expected to provide unique insight into low-dimensional MHPs, most notably at interfaces. There are many areas where it can provide unique structural insights, and may require additional method development. For example, the assignment of experimental NMR spectra of MHPs $^{386}$ often requires fully relativistic first principles calculations that include spin orbit coupling. Inspiration can be taken from prior literature combining sSNMR experiments and modelling of material solids. ${ }^{\mathbf{4 4 2 - 4 4 5}}$ In addition, the development of PFG-based NMR methods would help in understanding the diffusion properties of small molecules and ions in MHPs, nanocrystals, across grain boundaries and contact layers.

\subsection{In situ characterization}

Solid-state NMR is also expected to play an increasing role in in situ characterization of materials degradation in the presence of light, temperature and moisture. For such applications to be realized, ssNMR probes must be integrated with in situ photoillumination, moisture and temperature controls. We expect that existing sSNMR protocols can operate in parallel with new developments of in situ and in operando approaches. Kinetics of crystallization, additive engineering and degradation reactions in MHP-based devices can be probed by SSNMR techniques in conjunction with other characterization tools to reach consensus on the environmental stability of MHPs and contact layers. In mixed dimensional MHPs, we envision that in situ ssNMR spectroscopy may be leveraged in conjunction with other complementary techniques to build more complete understanding of layer-by-layer structural evolution, formation kinetics, stability and properties.

In situ and in operando studies of MHPs may be uniquely enabled by NQR techniques. NQR spectroscopy can be further developed towards a broader range of MHP compositions and sample preparations, including single crystals, thin films and device stacks. Improved NQR methodology and wider availability of NQR spectrometers will complement insights 
obtained from ssNMR techniques. The short experiment times accessible with NQR are promising for in situ and operando studies of molecular events occurring on relatively short timescales.

\subsection{Data repository}

Data mining and machine leaning (ML) techniques are among the most interesting modern tools of materials discovery. Harnessing the power of such protocols for MHP research requires accurate, well-categorized and available experimental data. While databases for crystal structures (Cambridge Structural Database-CSD; ${ }^{446}$ Inorganic Crystal Structure Database-ICSD), ${ }^{447}$ and structure prediction and modelling (The Materials Project) ${ }^{448}$ are well-established, we hope that ssNMR databases may be built and integrated to accelerate MHP research. Data classes for different MHP compositions including spectra with labeled chemical shifts, $T_{1}$ and $T_{2}$ relaxation rates, distance, orientation and ambient stability constraints, and even the activation energies of ion migration and molecular reorientations would be tremendously valuable for data-driven MHP discovery. In addition, raw ssNMR data can be deposited in different open-source formats (e.g., ASCII format, fid and .ser formats generated by TopSpin software) for future data analysis.

\section{Author contributions}

The manuscript was written through the contributions of all authors.

\section{Conflicts of interest}

There are no conflicts to declare.

\section{Acknowledgements}

Authors thank Dr Douglas Fabini for helpful discussion and review of the manuscript. We thank J. Lee, S. K. Lee and Vlad Michaelis for providing us with figures. G. N. M. R gratefully acknowledges the financial support University of Lille, UCCS laboratory, the IR-RMN-THC FR-3050 CNRS France for conducting some of the ssNMR experiments and results discussed in this review. G. N. M. R. gratefully acknowledges the European Union's Horizon 2020 research and innovation programme under the Marie Skłodowska-Curie grant no. 795091.

\section{References}

1 H.-R. Wenk and A. Bulakh, Minerals: Their Constitution and Origin, Cambridge University Press, 2nd edn, 2016.

2 W. Li, Z. Wang, F. Deschler, S. Gao, R. H. Friend and A. K. Cheetham, Nat. Rev. Mater., 2017, 2, 1-18.

3 M. D. Smith, B. A. Connor and H. I. Karunadasa, Chem. Rev., 2019, 119, 3104-3139.

4 L. Mao, C. C. Stoumpos and M. G. Kanatzidis, J. Am. Chem. Soc., 2018, 141, 1171-1190.

5 X. Li, J. M. Hoffman and M. G. Kanatzidis, Chem. Rev., 2021, 121, 2230-2291.
6 G. Grancini and M. K. Nazeeruddin, Nat. Rev. Mater., 2019, $4,4$.

7 B. Saparov and D. B. Mitzi, Chem. Rev., 2016, 116, 45584596.

8 F. Zhang, H. Lu, J. Tong, J. J. Berry, M. C. Beard and K. Zhu, Energy Environ. Sci., 2020, 13, 1154-1186.

9 J. Y. Kim, J.-W. Lee, H. S. Jung, H. Shin and N.-G. Park, Chem. Rev., 2020, 120, 7867-7918.

10 A. Kojima, K. Teshima, Y. Shirai and T. Miyasaka, J. Am. Chem. Soc., 2009, 131, 6050-6051.

11 M. M. Lee, J. Teuscher, T. Miyasaka, T. N. Murakami and H. J. Snaith, Science, 2012, 338, 643-647.

12 H.-S. Kim, C.-R. Lee, J.-H. Im, K.-B. Lee, T. Moehl, A. Marchioro, S.-J. Moon, R. Humphry-Baker, J.-H. Yum, J. E. Moser, M. Grätzel and N.-G. Park, Sci. Rep., 2012, 2, 591. 13 NREL, Best Research-Cell Efficiency Chart, https:// www.nrel.gov/pv/cell-efficiency.html, (accessed April 6, 2021).

14 M. Green, E. Dunlop, J. Hohl-Ebinger, M. Yoshita, N. Kopidakis and X. Hao, Prog. Photovoltaics, 2021, 29, 3-15. 15 X.-K. Liu, W. Xu, S. Bai, Y. Jin, J. Wang, R. H. Friend and F. Gao, Nat. Mater., 2021, 20, 10-21.

16 Z.-K. Tan, R. S. Moghaddam, M. L. Lai, P. Docampo, R. Higler, F. Deschler, M. Price, A. Sadhanala, L. M. Pazos, D. Credgington, F. Hanusch, T. Bein, H. J. Snaith and R. H. Friend, Nat. Nanotechnol., 2014, 9, 687-692.

17 S. D. Stranks and H. J. Snaith, Nat. Nanotechnol., 2015, 10, 391-402.

18 Y. Cao, N. Wang, H. Tian, J. Guo, Y. Wei, H. Chen, Y. Miao, W. Zou, K. Pan, Y. He, H. Cao, Y. Ke, M. Xu, Y. Wang, M. Yang, K. Du, Z. Fu, D. Kong, D. Dai, Y. Jin, G. Li, H. Li, Q. Peng, J. Wang and W. Huang, Nature, 2018, 562, 249-253.

19 K. Lin, J. Xing, L. N. Quan, F. P. G. de Arquer, X. Gong, J. Lu, L. Xie, W. Zhao, D. Zhang, C. Yan, W. Li, X. Liu, Y. Lu, J. Kirman, E. H. Sargent, Q. Xiong and Z. Wei, Nature, 2018, 562, 245-248.

20 T. Chiba, Y. Hayashi, H. Ebe, K. Hoshi, J. Sato, S. Sato, Y.-J. Pu, S. Ohisa and J. Kido, Nat. Photonics, 2018, 12, 681-687.

21 B. Zhao, S. Bai, V. Kim, R. Lamboll, R. Shivanna, F. Auras, J. M. Richter, L. Yang, L. Dai, M. Alsari, X.-J. She, L. Liang, J. Zhang, S. Lilliu, P. Gao, H. J. Snaith, J. Wang, N. C. Greenham, R. H. Friend and D. Di, Nat. Photonics, 2018, 12, 783-789.

22 W. Xu, Q. Hu, S. Bai, C. Bao, Y. Miao, Z. Yuan, T. Borzda, A. J. Barker, E. Tyukalova, Z. Hu, M. Kawecki, H. Wang, Z. Yan, X. Liu, X. Shi, K. Uvdal, M. Fahlman, W. Zhang, M. Duchamp, J.-M. Liu, A. Petrozza, J. Wang, L.-M. Liu, W. Huang and F. Gao, Nat. Photonics, 2019, 13, 418-424.

23 Q. Wang, X. Wang, Z. Yang, N. Zhou, Y. Deng, J. Zhao, X. Xiao, P. Rudd, A. Moran, Y. Yan and J. Huang, Nat. Commun., 2019, 10, 5633.

24 Y. Wei, Z. Cheng and J. Lin, Chem. Soc. Rev., 2019, 48, 310350.

25 Z. He, C. Zhang, Y. Dong and S.-T. Wu, Crystals, 2019, 9, 59. 
26 H. Dong, C. Zhang, X. Liu, J. Yao and Y. Sheng Zhao, Chem. Soc. Rev., 2020, 49, 951-982.

27 G. Xing, N. Mathews, S. S. Lim, N. Yantara, X. Liu, D. Sabba, M. Grätzel, S. Mhaisalkar and T. C. Sum, Nat. Mater., 2014, 13, 476-480.

28 Y. Jia, R. A. Kerner, A. J. Grede, B. P. Rand and N. C. Giebink, Nat. Photonics, 2017, 11, 784-788.

29 T. J. S. Evans, A. Schlaus, Y. Fu, X. Zhong, T. L. Atallah, M. S. Spencer, L. E. Brus, S. Jin and X.-Y. Zhu, Adv. Opt. Mater., 2018, 6, 1700982.

30 S. Yakunin, L. Protesescu, F. Krieg, M. I. Bodnarchuk, G. Nedelcu, M. Humer, G. De Luca, M. Fiebig, W. Heiss and M. V. Kovalenko, Nat. Commun., 2015, 6, 8056.

31 H. Wang and D. H. Kim, Chem. Soc. Rev., 2017, 46, 52045236.

32 L. Li, S. Ye, J. Qu, F. Zhou, J. Song and G. Shen, Small, 2021, 2005606, early view.

33 X. Wang, M. Li, B. Zhang, H. Wang, Y. Zhao and B. Wang, Org. Electron., 2018, 52, 172-183.

34 M. Ahmadi, T. $\mathrm{Wu}$ and B. $\mathrm{Hu}$, Adv. Mater., 2017, 29, 1605242.

35 F. P. García de Arquer, A. Armin, P. Meredith and E. H. Sargent, Nat. Rev. Mater., 2017, 2, 1-17.

36 H. Wei and J. Huang, Nat. Commun., 2019, 10, 1066.

37 Y. C. Kim, K. H. Kim, D.-Y. Son, D.-N. Jeong, J.-Y. Seo, Y. S. Choi, I. T. Han, S. Y. Lee and N.-G. Park, Nature, 2017, 550, 87-91.

38 Q. Dong, Y. Fang, Y. Shao, P. Mulligan, J. Qiu, L. Cao and J. Huang, Science, 2015, 347, 967-970.

39 Y. He, L. Matei, H. J. Jung, K. M. McCall, M. Chen, C. C. Stoumpos, Z. Liu, J. A. Peters, D. Y. Chung, B. W. Wessels, M. R. Wasielewski, V. P. Dravid, A. Burger and M. G. Kanatzidis, Nat. Commun., 2018, 9, 1609.

40 Y. Zhou, J. Chen, O. M. Bakr and O. F. Mohammed, ACS Energy Lett., 2021, 6, 739-768.

41 H. Utzat, W. Sun, A. E. K. Kaplan, F. Krieg, M. Ginterseder, B. Spokoyny, N. D. Klein, K. E. Shulenberger, C. F. Perkinson, M. V. Kovalenko and M. G. Bawendi, Science, 2019, 363, 1068-1072.

42 G. Rainò, M. A. Becker, M. I. Bodnarchuk, R. F. Mahrt, M. V. Kovalenko and T. Stöferle, Nature, 2018, 563, 671-675.

43 P. Schulz, D. Cahen and A. Kahn, Chem. Rev., 2019, 119, 3349-3417.

44 E. M. Tennyson, T. A. S. Doherty and S. D. Stranks, Nat. Rev. Mater., 2019, 4, 573-587.

45 L. M. Herz, ACS Energy Lett., 2017, 2, 1539-1548.

46 I. A. Howard, T. Abzieher, I. M. Hossain, H. Eggers, F. Schackmar, S. Ternes, B. S. Richards, U. Lemmer and U. W. Paetzold, Adv. Mater., 2019, 31, 1806702.

47 C. Liu, Y.-B. Cheng and Z. Ge, Chem. Soc. Rev., 2020, 49, 1653-1687.

48 Z. Li, T. R. Klein, D. H. Kim, M. Yang, J. J. Berry, M. F. A. M. van Hest and K. Zhu, Nat. Rev. Mater., 2018, 3, 1-20.

49 L. Qiu, S. He, L. K. Ono, S. Liu and Y. Qi, ACS Energy Lett., 2019, 4, 2147-2167.
50 F. Huang, M. Li, P. Siffalovic, G. Cao and J. Tian, Energy Environ. Sci., 2019, 12, 518-549.

51 J. Yuan, A. Hazarika, Q. Zhao, X. Ling, T. Moot, W. Ma and J. M. Luther, Joule, 2020, 4, 1160-1185.

52 D. Prochowicz, M. Saski, P. Yadav, M. Grätzel and J. Lewiński, Acc. Chem. Res., 2019, 52, 3233-3243.

53 B. A. Rosales, L. Wei and J. Vela, J. Solid State Chem., 2019, 271, 206-215.

54 J. A. Raiford, S. T. Oyakhire and S. F. Bent, Energy Environ. Sci., 2020, 13, 1997-2023.

55 A. Alaei, A. Circelli, Y. Yuan, Y. Yang and S. S. Lee, Mater. Adv., 2021, 2, 47-63.

56 Q. A. Akkerman, G. Rainò, M. V. Kovalenko and L. Manna, Nat. Mater., 2018, 17, 394.

57 Y. Yang and J. You, Nature, 2017, 544, 155-156.

58 T. Leijtens, K. Bush, R. Cheacharoen, R. Beal, A. Bowring and M. D. McGehee, J. Mater. Chem. A, 2017, 5, 1148311500.

59 A. Walsh and S. D. Stranks, ACS Energy Lett., 2018, 3, 19831990.

60 L. M. Herz, J. Phys. Chem. Lett., 2018, 9, 6853-6863.

61 Y. Yuan and J. Huang, Acc. Chem. Res., 2016, 49, 286-293.

62 M. Seifrid, G. N. M. Reddy, B. F. Chmelka and G. C. Bazan, Nat. Rev. Mater., 2020, 5, 910-930.

63 B. Reif, S. E. Ashbrook, L. Emsley and M. Hong, Nat. Rev. Dis. Primers, 2021, 1, 1-23.

64 L. Piveteau, V. Morad and M. V. Kovalenko, J. Am. Chem. Soc., 2020, 142, 19413-19437.

65 S. R. Smock, Y. Chen, A. J. Rossini and R. L. Brutchey, Acc. Chem. Res., 2021, 54, 707-718.

66 I. L. Moudrakovski, in Annual Reports on NMR Spectroscopy, Elsevier, 2021, vol. 102.

67 W. M. J. Franssen and A. P. M. Kentgens, Solid State Nucl. Magn. Reson., 2019, 100, 36-44.

68 K. Wang, S. Olthof, W. S. Subhani, X. Jiang, Y. Cao, L. Duan, H. Wang, M. Du and S. Liu, Nano Energy, 2020, 68, 104289.

69 X. Sun, X. Yu and Z. Li, ACS Appl. Energy Mater., 2020, 3, 10282-10302.

70 X. Zhao and M. Wang, Mater. Today Energy, 2018, 7, 208220.

71 G.-W. Kim, H. Choi, M. Kim, J. Lee, S. Y. Son and T. Park, Adv. Energy Mater., 2020, 10, 1903403.

72 K. Mahmood, S. Sarwar and M. Taqi Mehran, $R S C A d v$., 2017, 7, 17044-17062.

73 H. Duc Pham, L. Xianqiang, W. Li, S. Manzhos, A. K. Ko Kyaw and P. Sonar, Energy Environ. Sci., 2019, 12, 11771209.

74 A. Krishna and A. C. Grimsdale, J. Mater. Chem. A, 2017, 5, 16446-16466.

75 L. Hu, M. Li, K. Yang, Z. Xiong, B. Yang, M. Wang, X. Tang, Z. Zang, X. Liu, B. Li, Z. Xiao, S. Lu, H. Gong, J. Ouyang and K. Sun, J. Mater. Chem. A, 2018, 6, 16583-16589.

76 Arramel, H. Pan, A. Xie, S. Hou, X. Yin, C. S. Tang, N. T. Hoa, M. D. Birowosuto, H. Wang, C. Dang, A. Rusydi, A. T. S. Wee and J. Wu, Nano Res., 2019, 12, 77-84.

77 E. E. Perry, J. G. Labram, N. R. Venkatesan, H. Nakayama and M. L. Chabinyc, Adv. Electron. Mater., 2018, 4, 1800087. 
78 J. Euvrard, Y. Yan and D. B. Mitzi, Nat. Rev. Mater., 2021, 119.

79 N. K. Noel, S. N. Habisreutinger, A. Pellaroque, F. Pulvirenti, B. Wenger, F. Zhang, Y.-H. Lin, O. G. Reid, J. Leisen, Y. Zhang, S. Barlow, S. R. Marder, A. Kahn, H. J. Snaith, C. B. Arnold and B. P. Rand, Energy Environ. Sci., 2019, 12, 3063-3073.

80 Q. Chen, J. Wu, X. Ou, B. Huang, J. Almutlaq, A. A. Zhumekenov, X. Guan, S. Han, L. Liang, Z. Yi, J. Li, X. Xie, Y. Wang, Y. Li, D. Fan, D. B. L. Teh, A. H. All, O. F. Mohammed, O. M. Bakr, T. Wu, M. Bettinelli, H. Yang, W. Huang and X. Liu, Nature, 2018, 561, 88-93.

81 J. Yoon, H. Sung, G. Lee, W. Cho, N. Ahn, H. Suk Jung and M. Choi, Energy Environ. Sci., 2017, 10, 337-345.

82 E. Köhnen, M. Jošt, A. B. Morales-Vilches, P. Tockhorn, A. Al-Ashouri, B. Macco, L. Kegelmann, L. Korte, B. Rech, R. Schlatmann, B. Stannowski and S. Albrecht, Sustainable Energy Fuels, 2019, 3, 1995-2005.

83 J. Zhang, W. Zhang, H.-M. Cheng and S. R. P. Silva, Mater. Today, 2020, 39, 66-88.

84 H. S. Jung, G. S. Han, N.-G. Park and M. J. Ko, Joule, 2019, 3, 1850-1880.

85 D. Yang, R. Yang, S. Priya and S. Liu, Angew. Chem., Int. Ed., 2019, 58, 4466-4483.

86 Y.-S. Jung, K. Hwang, Y.-J. Heo, J.-E. Kim, D. Vak and D.-Y. Kim, Adv. Opt. Mater., 2018, 6, 1701182.

87 T. W. Jones, A. Osherov, M. Alsari, M. Sponseller, B. C. Duck, Y.-K. Jung, C. Settens, F. Niroui, R. Brenes, C. V. Stan, Y. Li, M. Abdi-Jalebi, N. Tamura, J. E. Macdonald, M. Burghammer, R. H. Friend, V. Bulović, A. Walsh, G. J. Wilson, S. Lilliu and S. D. Stranks, Energy Environ. Sci., 2019, 12, 596-606.

88 C. Wang, L. Ma, D. Guo, X. Zhao, Z. Zhou, D. Lin, F. Zhang, W. Zhao, J. Zhang and Z. Nie, J. Mater. Chem. C, 2020, 8, 3374-3379.

89 N. Rolston, K. A. Bush, A. D. Printz, A. Gold-Parker, Y. Ding, M. F. Toney, M. D. McGehee and R. H. Dauskardt, Adv. Energy Mater., 2018, 8, 1802139.

90 J. Zhao, Y. Deng, H. Wei, X. Zheng, Z. Yu, Y. Shao, J. E. Shield and J. Huang, Sci. Adv., 2017, 3, eaao5616.

91 R. M. Kennard, C. J. Dahlman, R. A. DeCrescent, J. A. Schuller, K. Mukherjee, R. Seshadri and M. L. Chabinyc, Chem. Mater., 2021, 33, 298-309.

92 N. Zhou, Y. Bekenstein, C. N. Eisler, D. Zhang, A. M. Schwartzberg, P. Yang, A. P. Alivisatos and J. A. Lewis, Sci. Adv., 2019, 5, eaav8141.

93 H. Li and W. Zhang, Chem. Rev., 2020, 120, 9835-9950.

94 R. Wang, M. Mujahid, Y. Duan, Z.-K. Wang, J. Xue and Y. Yang, Adv. Funct. Mater., 2019, 29, 1808843.

95 J. Yang, B. D. Siempelkamp, D. Liu and T. L. Kelly, ACS Nano, 2015, 9, 1955-1963.

96 D. Bryant, N. Aristidou, S. Pont, I. Sanchez-Molina, T. Chotchunangatchaval, S. Wheeler, J. R. Durrant and S. A. Haque, Energy Environ. Sci., 2016, 9, 1655-1660.

97 J. M. Howard, E. M. Tennyson, S. Barik, R. Szostak, E. Waks, M. F. Toney, A. F. Nogueira, B. R. A. Neves and M. S. Leite, J. Phys. Chem. Lett., 2018, 9, 3463-3469.
98 N. Aristidou, C. Eames, I. Sanchez-Molina, X. Bu, J. Kosco, M. S. Islam and S. A. Haque, Nat. Commun., 2017, 8, 15218. 99 Z. Hawash, L. K. Ono, S. R. Raga, M. V. Lee and Y. Qi, Chem. Mater., 2015, 27, 562-569.

100 J. A. Christians, P. Schulz, J. S. Tinkham, T. H. Schloemer, S. P. Harvey, B. J. Tremolet de Villers, A. Sellinger, J. J. Berry and J. M. Luther, Nat. Energy, 2018, 3, 68-74.

101 I. Spanopoulos, W. Ke and M. G. Kanatzidis, Helv. Chim. Acta, 2021, 104, e2000173.

102 T. H. Schloemer, J. A. Christians, J. M. Luther and A. Sellinger, Chem. Sci., 2019, 10, 1904-1935.

103 A. N. Singh, S. Kajal, J. Kim, A. Jana, J. Y. Kim and K. S. Kim, Adv. Energy Mater., 2020, 10, 2000768.

104 F. Zhang and K. Zhu, Adv. Energy Mater., 2020, 10, 1902579. 105 J. A. Christians, S. N. Habisreutinger, J. J. Berry and J. M. Luther, ACS Energy Lett., 2018, 3, 2136-2143.

106 V. M. Goldschmidt, Naturwissenschaften, 1926, 14, 477-485. 107 C. Li, X. Lu, W. Ding, L. Feng, Y. Gao and Z. Guo, Acta Crystallogr., Sect. B: Struct. Sci., 2008, 64, 702-707.

108 G. Kieslich, S. Sun and A. K. Cheetham, Chem. Sci., 2015, 6, 3430-3433.

109 M. R. Filip and F. Giustino, Proc. Natl. Acad. Sci. U. S. A., 2018, 115, 5397-5402.

110 D. H. Fabini, R. Seshadri and M. G. Kanatzidis, MRS Bull., 2020, 45, 467-477.

111 D. W. de Quilettes, S. M. Vorpahl, S. D. Stranks, H. Nagaoka, G. E. Eperon, M. E. Ziffer, H. J. Snaith and D. S. Ginger, Science, 2015, 348, 683-686.

112 J.-C. Blancon, H. Tsai, W. Nie, C. C. Stoumpos, L. Pedesseau, C. Katan, M. Kepenekian, C. M. M. Soe, K. Appavoo, M. Y. Sfeir, S. Tretiak, P. M. Ajayan, M. G. Kanatzidis, J. Even, J. J. Crochet and A. D. Mohite, Science, 2017, 355, 1288-1292.

113 D. W. deQuilettes, S. Jariwala, S. Burke, M. E. Ziffer, J. T.-W. Wang, H. J. Snaith and D. S. Ginger, ACS Nano, 2017, 11, 11488-11496.

114 O. G. Reid, M. Yang, N. Kopidakis, K. Zhu and G. Rumbles, ACS Energy Lett., 2016, 1, 561-565.

115 J. Xing, Q. Wang, Q. Dong, Y. Yuan, Y. Fang and J. Huang, Phys. Chem. Chem. Phys., 2016, 18, 30484-30490.

116 J. S. Yun, J. Seidel, J. Kim, A. M. Soufiani, S. Huang, J. Lau, N. J. Jeon, S. I. Seok, M. A. Green and A. Ho-Baillie, Adv. Energy Mater., 2016, 6, 1600330.

117 Y. Shao, Y. Fang, T. Li, Q. Wang, Q. Dong, Y. Deng, Y. Yuan, H. Wei, M. Wang, A. Gruverman, J. Shield and J. Huang, Energy Environ. Sci., 2016, 9, 1752-1759.

118 B. Chen, P. N. Rudd, S. Yang, Y. Yuan and J. Huang, Chem. Soc. Rev., 2019, 48, 3842-3867.

119 X.-D. Wang, W.-G. Li, J.-F. Liao and D.-B. Kuang, Sol. RRL, 2019, 3, 1800294.

120 M. Jung, S.-G. Ji, G. Kim and S. Il Seok, Chem. Soc. Rev., 2019, 48, 2011-2038.

121 N. J. Jeon, J. H. Noh, Y. C. Kim, W. S. Yang, S. Ryu and S. I. Seok, Nat. Mater., 2014, 13, 897-903.

122 R. Munir, A. D. Sheikh, M. Abdelsamie, H. Hu, L. Yu, K. Zhao, T. Kim, O. E. Tall, R. Li, D.-M. Smilgies and A. Amassian, Adv. Mater., 2017, 29, 1604113. 
123 J. C. Hamill, J. Schwartz and Y.-L. Loo, ACS Energy Lett., 2018, 3, 92-97.

124 R. A. Kerner, L. Zhao, Z. Xiao and B. P. Rand, J. Mater. Chem. A, 2016, 4, 8308-8315.

125 A. Dubey, N. Adhikari, S. Mabrouk, F. Wu, K. Chen, S. Yang and Q. Qiao, J. Mater. Chem. A, 2018, 6, 2406-2431.

126 J. Ye, M. M. Byranvand, C. O. Martínez, R. L. Hoye, M. Saliba and L. Polavarapu, Angew. Chem., Int. Ed., 2021, 60, 2-27.

127 A. Mahapatra, D. Prochowicz, M. Mahdi Tavakoli, S. Trivedi, P. Kumar and P. Yadav, J. Mater. Chem. A, 2020, 8, 27-54.

128 C. G. Bischak, M. Lai, Z. Fan, D. Lu, P. David, D. Dong, H. Chen, A. S. Etman, T. Lei, J. Sun, M. Grünwald, D. T. Limmer, P. Yang and N. S. Ginsberg, Matter, 2020, 3, 534-545.

129 H. T. Pham, T. Duong, K. J. Weber and J. Wong-Leung, ACS Mater. Lett., 2020, 2, 415-424.

130 M. U. Rothmann, W. Li, Y. Zhu, U. Bach, L. Spiccia, J. Etheridge and Y.-B. Cheng, Nat. Commun., 2017, 8, 1-8.

131 I. M. Hermes, S. A. Bretschneider, V. W. Bergmann, D. Li, A. Klasen, J. Mars, W. Tremel, F. Laquai, H.-J. Butt, M. Mezger, R. Berger, B. J. Rodriguez and S. A. L. Weber, J. Phys. Chem. C, 2016, 120, 5724-5731.

132 M. Chabin and F. Gilletta, J. Appl. Crystallogr., 1980, 13, 539-543.

133 F. Bertolotti, L. Protesescu, M. V. Kovalenko, S. Yakunin, A. Cervellino, S. J. L. Billinge, M. W. Terban, J. S. Pedersen, N. Masciocchi and A. Guagliardi, ACS Nano, 2017, 11, 3819-3831.

134 M. Li, T. Liu, Y. Wang, W. Yang and X. Lü, Matter Radiat. Extremes, 2020, 5, 018201.

135 X. Xiao, W. Li, Y. Fang, Y. Liu, Y. Shao, S. Yang, J. Zhao, X. Dai, R. Zia and J. Huang, Nat. Commun., 2020, 11, 2215.

136 H. Röhm, T. Leonhard, M. J. Hoffmann and A. Colsmann, Energy Environ. Sci., 2017, 10, 950-955.

137 H. Röhm, T. Leonhard, M. J. Hoffmann and A. Colsmann, Adv. Funct. Mater., 2020, 30, 1908657.

138 E. Strelcov, Q. Dong, T. Li, J. Chae, Y. Shao, Y. Deng, A. Gruverman, J. Huang and A. Centrone, Sci. Adv., 2017, 3, e1602165.

139 B. Huang, G. Kong, E. N. Esfahani, S. Chen, Q. Li, J. Yu, N. Xu, Y. Zhang, S. Xie, H. Wen, P. Gao, J. Zhao and J. Li, npj Quantum Mater., 2018, 3, 1-8.

140 A. Gómez, Q. Wang, A. R. Goñi, M. Campoy-Quiles and A. Abate, Energy Environ. Sci., 2019, 12, 2537-2547.

141 J. N. Wilson, J. M. Frost, S. K. Wallace and A. Walsh, APL Mater., 2019, 7, 010901.

142 N. J. Jeon, H. Na, E. H. Jung, T.-Y. Yang, Y. G. Lee, G. Kim, H.-W. Shin, S. Il Seok, J. Lee and J. Seo, Nat. Energy, 2018, 3, 682-689.

143 X. Zheng, Y. Hou, C. Bao, J. Yin, F. Yuan, Z. Huang, K. Song, J. Liu, J. Troughton, N. Gasparini, C. Zhou, Y. Lin, D.-J. Xue, B. Chen, A. K. Johnston, N. Wei, M. N. Hedhili, M. Wei, A. Y. Alsalloum, P. Maity, B. Turedi, C. Yang, D. Baran, T. D. Anthopoulos, Y. Han, Z.-H. Lu, O. F. Mohammed,
F. Gao, E. H. Sargent and O. M. Bakr, Nat. Energy, 2020, 5, 131-140.

144 M. Jeong, I. W. Choi, E. M. Go, Y. Cho, M. Kim, B. Lee, S. Jeong, Y. Jo, H. W. Choi, J. Lee, J.-H. Bae, S. K. Kwak, D. S. Kim and C. Yang, Science, 2020, 369, 1615-1620.

145 W. S. Yang, B.-W. Park, E. H. Jung, N. J. Jeon, Y. C. Kim, D. U. Lee, S. S. Shin, J. Seo, E. K. Kim, J. H. Noh and S. I. Seok, Science, 2017, 356, 1376-1379.

146 M. Saliba, T. Matsui, J.-Y. Seo, K. Domanski, J.-P. CorreaBaena, M. K. Nazeeruddin, S. M. Zakeeruddin, W. Tress, A. Abate, A. Hagfeldt and M. Grätzel, Energy Environ. Sci., 2016, 9, 1989-1997.

147 N. J. Jeon, J. H. Noh, W. S. Yang, Y. C. Kim, S. Ryu, J. Seo and S. I. Seok, Nature, 2015, 517, 476-480.

148 J. J. Yoo, G. Seo, M. R. Chua, T. G. Park, Y. Lu, F. Rotermund, Y.-K. Kim, C. S. Moon, N. J. Jeon, J.-P. Correa-Baena, V. Bulović, S. S. Shin, M. G. Bawendi and J. Seo, Nature, 2021, 590, 587-593.

149 H. Lu, A. Krishna, S. M. Zakeeruddin, M. Grätzel and A. Hagfeldt, iScience, 2020, 23, 101359.

150 R. E. Beal, N. Z. Hagström, J. Barrier, A. Gold-Parker, R. Prasanna, K. A. Bush, D. Passarello, L. T. Schelhas, K. Brüning, C. J. Tassone, H.-G. Steinrück, M. D. McGehee, M. F. Toney and A. F. Nogueira, Matter, 2020, 2, 207-219.

151 H. Grüninger, M. Bokdam, N. Leupold, P. Tinnemans, R. Moos, G. A. De Wijs, F. Panzer and A. P. M. Kentgens, J. Phys. Chem. C, 2021, 125, 1742-1753.

152 D. J. Kubicki, D. Prochowicz, A. Hofstetter, P. Péchy, S. M. Zakeeruddin, M. Grätzel and L. Emsley, J. Am. Chem. Soc., 2017, 139, 10055-10061.

153 D. J. Kubicki, D. Prochowicz, A. Hofstetter, S. M. Zakeeruddin, M. Grätzel and L. Emsley, J. Am. Chem. Soc., 2017, 139, 14173-14180.

154 D. J. Kubicki, D. Prochowicz, A. Hofstetter, S. M. Zakeeruddin, M. Grätzel and L. Emsley, J. Am. Chem. Soc., 2018, 140, 7232-7238.

155 H. X. Dang, K. Wang, M. Ghasemi, M.-C. Tang, M. De Bastiani, E. Aydin, E. Dauzon, D. Barrit, J. Peng, D.-M. Smilgies, S. De Wolf and A. Amassian, Joule, 2019, 3, 1746-1764.

156 J.-P. Correa-Baena, Y. Luo, T. M. Brenner, J. Snaider, S. Sun, X. Li, M. A. Jensen, N. T. P. Hartono, L. Nienhaus, S. Wieghold, J. R. Poindexter, S. Wang, Y. S. Meng, T. Wang, B. Lai, M. V. Holt, Z. Cai, M. G. Bawendi, L. Huang, T. Buonassisi and D. P. Fenning, Science, 2019, 363, 627-631.

157 J. H. Noh, S. H. Im, J. H. Heo, T. N. Mandal and S. I. Seok, Nano Lett., 2013, 13, 1764-1769.

158 L. Protesescu, S. Yakunin, M. I. Bodnarchuk, F. Krieg, R. Caputo, C. H. Hendon, R. X. Yang, A. Walsh and M. V. Kovalenko, Nano Lett., 2015, 15, 3692-3696.

159 A. J. Knight and L. M. Herz, Energy Environ. Sci., 2020, 13, 2024-2046.

160 E. T. Hoke, D. J. Slotcavage, E. R. Dohner, A. R. Bowring, H. I. Karunadasa and M. D. McGehee, Chem. Sci., 2015, 6, 613-617. 
161 M. C. Brennan, S. Draguta, P. V. Kamat and M. Kuno, ACS Energy Lett., 2018, 3, 204-213.

162 D. W. deQuilettes, W. Zhang, V. M. Burlakov, D. J. Graham, T. Leijtens, A. Osherov, V. Bulović, H. J. Snaith, D. S. Ginger and S. D. Stranks, Nat. Commun., 2016, 7, 11683.

163 Z. Andaji-Garmaroudi, M. Anaya, A. J. Pearson and S. D. Stranks, Adv. Energy Mater., 2020, 10, 1903109.

164 E. Shi and L. Dou, Acc. Mater. Res., 2020, 1, 213-224.

165 R. A. Scheidt and P. V. Kamat, J. Chem. Phys., 2019, 151, 134703.

166 T. Elmelund, R. A. Scheidt, B. Seger and P. V. Kamat, ACS Energy Lett., 2019, 4, 1961-1969.

167 R. M. Kennard, C. J. Dahlman, H. Nakayama, R. A. DeCrescent, J. A. Schuller, R. Seshadri, K. Mukherjee and M. L. Chabinyc, ACS Appl. Mater. Interfaces, 2019, 11, 25313-25321.

168 Y. Wang, Z. Chen, F. Deschler, X. Sun, T.-M. Lu, E. A. Wertz, J.-M. Hu and J. Shi, ACS Nano, 2017, 11, 3355-3364.

169 L. Dou, M. Lai, C. S. Kley, Y. Yang, C. G. Bischak, D. Zhang, S. W. Eaton, N. S. Ginsberg and P. Yang, Proc. Natl. Acad. Sci. U. S. A., 2017, 114, 7216-7221.

170 N. T. Shewmon, H. Yu, I. Constantinou, E. Klump and F. So, ACS Appl. Mater. Interfaces, 2016, 8, 33273-33279.

171 T. A. S. Doherty, A. J. Winchester, S. Macpherson, D. N. Johnstone, V. Pareek, E. M. Tennyson, S. Kosar, F. U. Kosasih, M. Anaya, M. Abdi-Jalebi, Z. AndajiGarmaroudi, E. L. Wong, J. Madéo, Y.-H. Chiang, J.-S. Park, Y.-K. Jung, C. E. Petoukhoff, G. Divitini, M. K. L. Man, C. Ducati, A. Walsh, P. A. Midgley, K. M. Dani and S. D. Stranks, Nature, 2020, 580, 360-366.

172 Y. Liu, Y. Zhang, X. Zhu, J. Feng, I. Spanopoulos, W. Ke, Y. He, X. Ren, Z. Yang, F. Xiao, K. Zhao, M. Kanatzidis and S. Liu, Adv. Mater., 2021, 33, 2006010.

173 Q. Zhang, F. Hao, J. Li, Y. Zhou, Y. Wei and H. Lin, Sci. Technol. Adv. Mater., 2018, 19, 425-442.

174 G. Schileo and G. Grancini, J. Mater. Chem. C, 2021, 9, 6776.

175 W. Ke and M. G. Kanatzidis, Nat. Commun., 2019, 10, 965.

176 A. B. F. Vitoreti, S. Agouram, M. Solis de la Fuente, V. Muñoz-Sanjosé, M. A. Schiavon and I. Mora-Seró, J. Phys. Chem. C, 2018, 122, 14222-14231.

177 J. Liu, G. Wang, Z. Song, X. He, K. Luo, Q. Ye, C. Liao and J. Mei, J. Mater. Chem. A, 2017, 5, 9097-9106.

178 B. Zhao, M. Abdi-Jalebi, M. Tabachnyk, H. Glass, V. S. Kamboj, W. Nie, A. J. Pearson, Y. Puttisong, K. C. Gödel, H. E. Beere, D. A. Ritchie, A. D. Mohite, S. E. Dutton, R. H. Friend and A. Sadhanala, Adv. Mater., 2017, 29, 1604744.

179 Z. Yang, A. Rajagopal, S. B. Jo, C.-C. Chueh, S. Williams, C.-C. Huang, J. K. Katahara, H. W. Hillhouse and A. K.-Y. Jen, Nano Lett., 2016, 16, 7739-7747.

180 D. Bartesaghi, A. Ray, J. Jiang, R. K. M. Bouwer, S. Tao and T. J. Savenije, APL Mater., 2018, 6, 121106.

181 D. Parobek, B. J. Roman, Y. Dong, H. Jin, E. Lee, M. Sheldon and D. H. Son, Nano Lett., 2016, 16, 7376-7380.
182 F. Yang, D. Hirotani, G. Kapil, M. A. Kamarudin, C. H. Ng, Y. Zhang, Q. Shen and S. Hayase, Angew. Chem., Int. Ed., 2018, 57, 12745-12749.

183 R. Nie, R. Raj Sumukam, S. Harshavardhan Reddy, M. Banavoth and S. Il Seok, Energy Environ. Sci., 2020, 13, 2363-2385.

184 Z. Xiao, Z. Song and Y. Yan, Adv. Mater., 2019, 31, 1803792.

185 W. Ke, C. C. Stoumpos and M. G. Kanatzidis, Adv. Mater., 2019, 31, 1803230.

186 A. H. Slavney, T. Hu, A. M. Lindenberg and H. I. Karunadasa, J. Am. Chem. Soc., 2016, 138, 2138-2141.

187 G. Volonakis, M. R. Filip, A. A. Haghighirad, N. Sakai, B. Wenger, H. J. Snaith and F. Giustino, J. Phys. Chem. Lett., 2016, 7, 1254-1259.

188 E. T. McClure, M. R. Ball, W. Windl and P. M. Woodward, Chem. Mater., 2016, 28, 1348-1354.

189 M. R. Filip, S. Hillman, A. A. Haghighirad, H. J. Snaith and F. Giustino, J. Phys. Chem. Lett., 2016, 7, 2579-2585.

190 A. H. Slavney, L. Leppert, A. Saldivar Valdes, D. Bartesaghi, T. J. Savenije, J. B. Neaton and H. I. Karunadasa, Angew. Chem., Int. Ed., 2018, 57, 12765-12770.

191 A. Leblanc, N. Mercier, M. Allain, J. Dittmer, V. Fernandez and T. Pauporté, Angew. Chem., Int. Ed., 2017, 56, 1606716072.

192 A. Leblanc, N. Mercier, M. Allain, J. Dittmer, T. Pauporté, V. Fernandez, F. Boucher, M. Kepenekian and C. Katan, ACS Appl. Mater. Interfaces, 2019, 11, 20743-20751.

193 C.-M. Tsai, Y.-P. Lin, M. K. Pola, S. Narra, E. Jokar, Y.-W. Yang and E. W.-G. Diau, ACS Energy Lett., 2018, 3, 2077-2085.

194 W. Ke, C. C. Stoumpos, M. Zhu, L. Mao, I. Spanopoulos, J. Liu, O. Y. Kontsevoi, M. Chen, D. Sarma, Y. Zhang, M. R. Wasielewski and M. G. Kanatzidis, Sci. Adv., 2017, 3, e1701293.

195 I. Spanopoulos, W. Ke, C. C. Stoumpos, E. C. Schueller, O. Y. Kontsevoi, R. Seshadri and M. G. Kanatzidis, J. Am. Chem. Soc., 2018, 140, 5728-5742.

196 W. Ke, I. Spanopoulos, Q. Tu, I. Hadar, X. Li, G. S. Shekhawat, V. P. Dravid and M. G. Kanatzidis, J. Am. Chem. Soc., 2019, 141, 8627-8637.

197 M. Worku, Y. Tian, C. Zhou, H. Lin, M. Chaaban, L. Xu, Q. He, D. Beery, Y. Zhou, X. Lin, Y. Su, Y. Xin and B. Ma, Sci. Adv., 2020, 6, eaaz5961.

198 A. Senocrate, I. Spanopoulos, N. Zibouche, J. Maier, M. S. Islam and M. G. Kanatzidis, Chem. Mater., 2021, 33, 719-726.

199 W. Ke, C. C. Stoumpos, I. Spanopoulos, M. Chen, M. R. Wasielewski and M. G. Kanatzidis, ACS Energy Lett., 2018, 3, 1470-1476.

200 J. A. McNulty, A. M. Z. Slawin and P. Lightfoot, Dalton Trans., 2020, 49, 15171-15174.

201 Y. I. Dolzhenko, T. Inabe and Y. Maruyama, Bull. Chem. Soc. Jpn., 1986, 59, 563-567.

202 T. Ishihara, J. Takahashi and T. Goto, Solid State Commun., 1989, 69, 933-936. 
203 J. Calabrese, N. L. Jones, R. L. Harlow, N. Herron, D. L. Thorn and Y. Wang, J. Am. Chem. Soc., 1991, 113, 2328-2330.

204 D. B. Mitzi, C. A. Feild, W. T. A. Harrison and A. M. Guloy, Nature, 1994, 369, 467-469.

205 D. B. Mitzi, Inorg. Chem., 2000, 39, 6107-6113.

206 Y. Gao, E. Shi, S. Deng, S. B. Shiring, J. M. Snaider, C. Liang, B. Yuan, R. Song, S. M. Janke, A. Liebman-Peláez, P. Yoo, M. Zeller, B. W. Boudouris, P. Liao, C. Zhu, V. Blum, Y. Yu, B. M. Savoie, L. Huang and L. Dou, Nat. Chem., 2019, 11, 1151-1157.

207 C. Liu, W. Huhn, K.-Z. Du, A. Vazquez-Mayagoitia, D. Dirkes, W. You, Y. Kanai, D. B. Mitzi and V. Blum, Phys. Rev. Lett., 2018, 121, 146401.

208 W. A. Dunlap-Shohl, E. Tomas Barraza, A. Barrette, S. Dovletgeldi, G. Findik, D. J. Dirkes, C. Liu, M. K. Jana, V. Blum, W. You, K. Gundogdu, A. D. Stiff-Roberts and D. B. Mitzi, Mater. Horiz., 2019, 6, 1707-1716.

209 J. V. Passarelli, D. J. Fairfield, N. A. Sather, M. P. Hendricks, H. Sai, C. L. Stern and S. I. Stupp, J. Am. Chem. Soc., 2018, 140, 7313-7323.

210 J. Xue, R. Wang, X. Chen, C. Yao, X. Jin, K.-L. Wang, W. Huang, T. Huang, Y. Zhao, Y. Zhai, D. Meng, S. Tan, R. Liu, Z.-K. Wang, C. Zhu, K. Zhu, M. C. Beard, Y. Yan and Y. Yang, Science, 2021, 371, 636-640.

211 J. V. Passarelli, C. M. Mauck, S. W. Winslow, C. F. Perkinson, J. C. Bard, H. Sai, K. W. Williams, A. Narayanan, D. J. Fairfield, M. P. Hendricks, W. A. Tisdale and S. I. Stupp, Nat. Chem., 2020, 12, 672-682. 212 T. Ishihara, J. Takahashi and T. Goto, Phys. Rev. B: Condens. Matter Mater. Phys., 1990, 42, 11099-11107.

213 K. Tanaka, T. Takahashi, T. Ban, T. Kondo, K. Uchida and N. Miura, Solid State Commun., 2003, 127, 619-623.

214 L. Pedesseau, D. Sapori, B. Traore, R. Robles, H.-H. Fang, M. A. Loi, H. Tsai, W. Nie, J.-C. Blancon, A. Neukirch, S. Tretiak, A. D. Mohite, C. Katan, J. Even and M. Kepenekian, ACS Nano, 2016, 10, 9776-9786.

215 C. Katan, N. Mercier and J. Even, Chem. Rev., 2019, 119, 3140-3192.

216 E. A. Muljarov, S. G. Tikhodeev, N. A. Gippius and T. Ishihara, Phys. Rev. B: Condens. Matter Mater. Phys, 1995, 51, 14370-14378.

217 J.-C. Blancon, A. V. Stier, H. Tsai, W. Nie, C. C. Stoumpos, B. Traoré, L. Pedesseau, M. Kepenekian, F. Katsutani, G. T. Noe, J. Kono, S. Tretiak, S. A. Crooker, C. Katan, M. G. Kanatzidis, J. J. Crochet, J. Even and A. D. Mohite, Nat. Commun., 2018, 9, 2254.

218 K. Leng, W. Fu, Y. Liu, M. Chhowalla and K. P. Loh, Nat. Rev. Mater., 2020, 5, 482-500.

219 R. A. DeCrescent, N. R. Venkatesan, C. J. Dahlman, R. M. Kennard, M. L. Chabinyc and J. A. Schuller, ACS Nano, 2019, 13, 10745-10753.

220 C. M. M. Soe, G. P. Nagabhushana, R. Shivaramaiah, H. Tsai, W. Nie, J.-C. Blancon, F. Melkonyan, D. H. Cao, B. Traoré, L. Pedesseau, M. Kepenekian, C. Katan, J. Even, T. J. Marks, A. Navrotsky, A. D. Mohite, C. C. Stoumpos and M. G. Kanatzidis, Proc. Natl. Acad. Sci. U. S. A., 2019, 116, 58-66.

221 L. Mao, R. M. Kennard, B. Traore, W. Ke, C. Katan, J. Even, M. L. Chabinyc, C. C. Stoumpos and M. G. Kanatzidis, Chem, 2019, 5, 2593-2604.

222 C. C. Stoumpos, D. H. Cao, D. J. Clark, J. Young, J. M. Rondinelli, J. I. Jang, J. T. Hupp and M. G. Kanatzidis, Chem. Mater., 2016, 28, 2852-2867.

223 E. Shi, S. Deng, B. Yuan, Y. Gao, Akriti, L. Yuan, C. S. Davis, D. Zemlyanov, Y. Yu, L. Huang and L. Dou, ACS Nano, 2019, 13, 1635-1644.

224 K. Wang, C. Wu, Y. Jiang, D. Yang, K. Wang and S. Priya, Sci. $A d v ., 2019$, 5, eaau3241.

225 L. Mao, Y. Wu, C. C. Stoumpos, B. Traore, C. Katan, J. Even, M. R. Wasielewski and M. G. Kanatzidis, J. Am. Chem. Soc., 2017, 139, 11956-11963.

226 Y. Fu, X. Jiang, X. Li, B. Traore, I. Spanopoulos, C. Katan, J. Even, M. G. Kanatzidis and E. Harel, J. Am. Chem. Soc., 2020, 142, 4008-4021.

227 D. Pan, Y. Fu, N. Spitha, Y. Zhao, C. R. Roy, D. J. Morrow, D. D. Kohler, J. C. Wright and S. Jin, Nat. Nanotechnol., 2021, 16, 159-165.

228 E. Shi, B. Yuan, S. B. Shiring, Y. Gao, Akriti, Y. Guo, C. Su, M. Lai, P. Yang, J. Kong, B. M. Savoie, Y. Yu and L. Dou, Nature, 2020, 580, 614-620.

229 J. Li, Q. Yu, Y. He, C. C. Stoumpos, G. Niu, G. G. Trimarchi, H. Guo, G. Dong, D. Wang, L. Wang and M. G. Kanatzidis, J. Am. Chem. Soc., 2018, 140, 11085-11090.

230 B. A. Connor, L. Leppert, M. D. Smith, J. B. Neaton and H. I. Karunadasa, J. Am. Chem. Soc., 2018, 140, 5235-5240.

231 L. Mao, P. Guo, M. Kepenekian, I. Spanopoulos, Y. He, C. Katan, J. Even, R. D. Schaller, R. Seshadri, C. C. Stoumpos and M. G. Kanatzidis, J. Am. Chem. Soc., 2020, 142, 8342-8351.

232 M. A. Hope, T. Nakamura, P. Ahlawat, A. Mishra, M. Cordova, F. Jahanbakhshi, M. Mladenović, R. Runjhun, L. Merten, A. Hinderhofer, B. I. Carlsen, D. J. Kubicki, R. Gershoni-Poranne, T. Schneeberger, L. C. Carbone, Y. Liu, S. M. Zakeeruddin, J. Lewinski, A. Hagfeldt, F. Schreiber, U. Rothlisberger, M. Grätzel, J. V. Milić and L. Emsley, J. Am. Chem. Soc., 2021, 143, 1529-1538.

233 C. J. Dahlman, N. R. Venkatesan, P. T. Corona, R. M. Kennard, L. Mao, N. C. Smith, J. Zhang, R. Seshadri, M. E. Helgeson and M. L. Chabinyc, ACS Nano, 2020, 14, 11294-11308.

234 C. M. M. Soe, C. C. Stoumpos, M. Kepenekian, B. Traoré, H. Tsai, W. Nie, B. Wang, C. Katan, R. Seshadri, A. D. Mohite, J. Even, T. J. Marks and M. G. Kanatzidis, J. Am. Chem. Soc., 2017, 139, 16297-16309.

235 J. M. Hoffman, J. Strzalka, N. C. Flanders, I. Hadar, S. A. Cuthriell, Q. Zhang, R. D. Schaller, W. R. Dichtel, L. X. Chen and M. G. Kanatzidis, Adv. Mater., 2020, 32, 2002812.

236 J. Dong, S. Shao, S. Kahmann, A. J. Rommens, D. Hermida-Merino, G. H. ten Brink, M. A. Loi and G. Portale, Adv. Funct. Mater., 2020, 30, 2001294. 
237 T. Li, A. M. Zeidell, G. Findik, W. A. Dunlap-Shohl, J. Euvrard, K. Gundogdu, O. D. Jurchescu and D. B. Mitzi, Chem. Mater., 2019, 31, 4267-4274.

238 C. J. Dahlman, R. A. DeCrescent, N. R. Venkatesan, R. M. Kennard, G. Wu, M. A. Everest, J. A. Schuller and M. L. Chabinyc, Chem. Mater., 2019, 31, 5832-5844.

239 A. H. Proppe, R. Quintero-Bermudez, H. Tan, O. Voznyy, S. O. Kelley and E. H. Sargent, J. Am. Chem. Soc., 2018, 140, 2890-2896.

240 X. Zhang, R. Munir, Z. Xu, Y. Liu, H. Tsai, W. Nie, J. Li, T. Niu, D.-M. Smilgies, M. G. Kanatzidis, A. D. Mohite, K. Zhao, A. Amassian and S. Liu, Adv. Mater., 2018, 30, 1707166.

241 R. Quintero-Bermudez, A. Gold-Parker, A. H. Proppe, R. Munir, Z. Yang, S. O. Kelley, A. Amassian, M. F. Toney and E. H. Sargent, Nat. Mater., 2018, 17, 900.

242 A. H. Proppe, M. H. Elkins, O. Voznyy, R. D. Pensack, F. Zapata, L. V. Besteiro, L. N. Quan, R. QuinteroBermudez, P. Todorovic, S. O. Kelley, A. O. Govorov, S. K. Gray, I. Infante, E. H. Sargent and G. D. Scholes, J. Phys. Chem. Lett., 2019, 10, 419-426.

243 Y. Lin, Y. Fang, J. Zhao, Y. Shao, S. J. Stuard, M. M. Nahid, H. Ade, Q. Wang, J. E. Shield, N. Zhou, A. M. Moran and J. Huang, Nat. Commun., 2019, 10, 1008.

244 K. Zheng, Y. Chen, Y. Sun, J. Chen, P. Chábera, R. Schaller, M. J. Al-Marri, S. E. Canton, Z. Liang and T. Pullerits, J. Mater. Chem. A, 2018, 6, 6244-6250.

245 N. Liu, P. Liu, H. Ren, H. Xie, N. Zhou, Y. Gao, Y. Li, H. Zhou, Y. Bai and Q. Chen, ACS Appl. Mater. Interfaces, 2020, 12, 3127-3133.

246 M. Yuan, L. N. Quan, R. Comin, G. Walters, R. Sabatini, O. Voznyy, S. Hoogland, Y. Zhao, E. M. Beauregard, P. Kanjanaboos, Z. Lu, D. H. Kim and E. H. Sargent, Nat. Nanotechnol., 2016, 11, 872-877.

247 R. F. Moral, L. G. Bonato, J. C. Germino, W. X. Coelho Oliveira, R. Kamat, J. Xu, C. J. Tassone, S. D. Stranks, M. F. Toney and A. F. Nogueira, Chem. Mater., 2019, 31, 9472-9479.

248 N. R. Venkatesan, R. M. Kennard, R. A. DeCrescent, H. Nakayama, C. J. Dahlman, E. E. Perry, J. A. Schuller and M. L. Chabinyc, Chem. Mater., 2018, 30, 8615-8623.

249 M. V. Kovalenko, L. Protesescu and M. I. Bodnarchuk, Science, 2017, 358, 745-750.

250 J. Shamsi, A. S. Urban, M. Imran, L. De Trizio and L. Manna, Chem. Rev., 2019, 119, 3296-3348.

251 Y. Zhang, T. D. Siegler, C. J. Thomas, M. K. Abney, T. Shah, A. De Gorostiza, R. M. Greene and B. A. Korgel, Chem. Mater., 2020, 32, 5410-5423.

252 Y. Fu, H. Zhu, J. Chen, M. P. Hautzinger, X.-Y. Zhu and S. Jin, Nat. Rev. Mater., 2019, 4, 169.

253 E. Shi, Y. Gao, B. P. Finkenauer, Akriti, A. H. Coffey and L. Dou, Chem. Soc. Rev., 2018, 47, 6046-6072.

254 H. Huang, M. I. Bodnarchuk, S. V. Kershaw, M. V. Kovalenko and A. L. Rogach, ACS Energy Lett., 2017, 2, 2071-2083.

255 M. Kazes, T. Udayabhaskararao, S. Dey and D. Oron, Acc. Chem. Res., 2021, 54, 1409-1418.
256 J. Xue, R. Wang and Y. Yang, Nat. Rev. Mater., 2020, 5, 809827.

257 T. Chiba and J. Kido, J. Mater. Chem. C, 2018, 6, 1186811877.

258 M. I. Bodnarchuk, S. C. Boehme, S. ten Brinck, C. Bernasconi, Y. Shynkarenko, F. Krieg, R. Widmer, B. Aeschlimann, D. Günther, M. V. Kovalenko and I. Infante, ACS Energy Lett., 2019, 4, 63-74.

259 F. Yan, S. T. Tan, X. Li and H. V. Demir, Small, 2019, 15, 1902079.

260 J. Song, J. Li, X. Li, L. Xu, Y. Dong and H. Zeng, Adv. Mater., 2015, 27, 7162-7167.

261 S. Toso, D. Baranov, C. Giannini, S. Marras and L. Manna, ACS Mater. Lett., 2019, 1, 272-276.

262 Y. Nagaoka, K. Hills-Kimball, R. Tan, R. Li, Z. Wang and O. Chen, Adv. Mater., 2017, 29, 1606666.

263 Y. Tong, E.-P. Yao, A. Manzi, E. Bladt, K. Wang, M. Döblinger, S. Bals, P. Müller-Buschbaum, A. S. Urban, L. Polavarapu and J. Feldmann, Adv. Mater., 2018, 30, 1801117.

264 M. C. Brennan, S. Toso, I. M. Pavlovetc, M. Zhukovskyi, S. Marras, M. Kuno, L. Manna and D. Baranov, ACS Energy Lett., 2020, 5, 1465-1473.

265 J. Jagielski, S. F. Solari, L. Jordan, D. Scullion, B. Blülle, Y.-T. Li, F. Krumeich, Y.-C. Chiu, B. Ruhstaller, E. J. G. Santos and C.-J. Shih, Nat. Commun., 2020, 11, 387.

266 Y. Liu, M. Siron, D. Lu, J. Yang, R. dos Reis, F. Cui, M. Gao, M. Lai, J. Lin, Q. Kong, T. Lei, J. Kang, J. Jin, J. Ciston and P. Yang, J. Am. Chem. Soc., 2019, 141, 13028-13032.

267 Z. Dang, B. Dhanabalan, A. Castelli, R. Dhall, K. C. Bustillo, D. Marchelli, D. Spirito, U. Petralanda, J. Shamsi, L. Manna, R. Krahne and M. P. Arciniegas, Nano Lett., 2020, 20, 18081818.

268 D. Zhang, Y. Yu, Y. Bekenstein, A. B. Wong, A. P. Alivisatos and P. Yang, J. Am. Chem. Soc., 2016, 138, 13155-13158.

269 C. J. Thomas, Y. Zhang, A. Guillaussier, K. Bdeir, O. F. Aly, H. G. Kim, J. Noh, L. C. Reimnitz, J. Li, F. L. Deepak, D.-M. Smilgies, D. J. Milliron and B. A. Korgel, Chem. Mater., 2019, 31, 9750-9758.

270 X. Zhao, J. D. A. Ng, R. H. Friend and Z.-K. Tan, ACS Photonics, 2018, 5, 3866-3875.

271 Y. Wei, Z. Cheng and J. Lin, Chem. Soc. Rev., 2019, 48, 310350.

272 P. Cottingham and R. L. Brutchey, Chem. Mater., 2018, 30, 6711-6716.

273 A. Swarnkar, A. R. Marshall, E. M. Sanehira, B. D. Chernomordik, D. T. Moore, J. A. Christians, T. Chakrabarti and J. M. Luther, Science, 2016, 354, 92-95.

274 G. Almeida, I. Infante and L. Manna, Science, 2019, 364, 833-834.

275 D. P. Nenon, K. Pressler, J. Kang, B. A. Koscher, J. H. Olshansky, W. T. Osowiecki, M. A. Koc, L.-W. Wang and A. P. Alivisatos, J. Am. Chem. Soc., 2018, 140, 1776017772.

276 M. A. Boles, D. Ling, T. Hyeon and D. V. Talapin, Nat. Mater., 2016, 15, 141-153. 
277 M. Ben-Nun, J. Cao and K. R. Wilson, J. Phys. Chem. A, 1997, 101, 8743-8761.

278 J. Cao and K. R. Wilson, J. Phys. Chem. A, 1998, 102, 95239530.

279 C. Li, A. Wang, X. Deng, S. Wang, Y. Yuan, L. Ding and F. Hao, ACS Photonics, 2020, 7, 1893-1907.

280 X. Wu, L. Z. Tan, X. Shen, T. Hu, K. Miyata, M. T. Trinh, R. Li, R. Coffee, S. Liu, D. A. Egger, I. Makasyuk, Q. Zheng, A. Fry, J. S. Robinson, M. D. Smith, B. Guzelturk, H. I. Karunadasa, X. Wang, X. Zhu, L. Kronik, A. M. Rappe and A. M. Lindenberg, Sci. Adv., 2017, 3, e1602388.

281 E. J. VandenBussche, C. P. Clark, R. J. Holmes and D. J. Flannigan, ACS Omega, 2020, 5, 31867-31871.

282 B. Guzelturk, T. Winkler, T. W. J. Van de Goor, M. D. Smith, S. A. Bourelle, S. Feldmann, M. Trigo, S. W. Teitelbaum, H.-G. Steinrück, G. A. de la Pena, R. Alonso-Mori, D. Zhu, T. Sato, H. I. Karunadasa, M. F. Toney, F. Deschler and A. M. Lindenberg, Nat. Mater., 2021, 1-6.

283 L. M. Herz, Annu. Rev. Phys. Chem., 2016, 67, 65-89.

284 N. Mondal, A. De, S. Das, S. Paul and A. Samanta, Nanoscale, 2019, 11, 9796-9818.

285 Z. Li, Y. Chen and C. Burda, J. Phys. Chem. C, 2019, 123, 3255-3269.

286 J. Shi, Y. Li, Y. Li, D. Li, Y. Luo, H. Wu and Q. Meng, Joule, 2018, 2, 879-901.

287 J.-P. Correa-Baena, M. Saliba, T. Buonassisi, M. Grätzel, A. Abate, W. Tress and A. Hagfeldt, Science, 2017, 358, 739-744.

288 D. Meggiolaro, F. Ambrosio, E. Mosconi, A. Mahata and F. D. Angelis, Adv. Energy Mater., 2020, 10, 1902748.

289 C. Katan, A. D. Mohite and J. Even, Nat. Mater., 2018, 17, 377-379.

290 P. P. Joshi, S. F. Maehrlein and X. Zhu, Adv. Mater., 2019, 31, 1803054.

291 D. H. Fabini, T. A. Siaw, C. C. Stoumpos, G. Laurita, D. Olds, K. Page, J. G. Hu, M. G. Kanatzidis, S. Han and R. Seshadri, J. Am. Chem. Soc., 2017, 139, 16875-16884.

292 E. M. Mozur, A. E. Maughan, Y. Cheng, A. Huq, N. Jalarvo, L. L. Daemen and J. R. Neilson, Chem. Mater., 2017, 29, 10168-10177.

293 J. D. Dow and D. Redfield, Phys. Rev. B: Solid State, 1972, 5, 594-610.

294 M. Ledinsky, T. Schönfeldová, J. Holovský, E. Aydin, Z. Hájková, L. Landová, N. Neyková, A. Fejfar and S. De Wolf, J. Phys. Chem. Lett., 2019, 10, 1368-1373.

295 A. Raja, L. Waldecker, J. Zipfel, Y. Cho, S. Brem, J. D. Ziegler, M. Kulig, T. Taniguchi, K. Watanabe, E. Malic, T. F. Heinz, T. C. Berkelbach and A. Chernikov, Nat. Nanotechnol., 2019, 14, 832-837.

296 A. M. A. Leguy, A. R. Goñi, J. M. Frost, J. Skelton, F. Brivio, X. Rodríguez-Martínez, O. J. Weber, A. Pallipurath, M. Isabel Alonso, M. Campoy-Quiles, M. T. Weller, J. Nelson, A. Walsh and P. R. F. Barnes, Phys. Chem. Chem. Phys., 2016, 18, 27051-27066.

297 A. Poglitsch and D. Weber, J. Chem. Phys., 1987, 87, 63736378.
298 S. Govinda, B. P. Kore, M. Bokdam, P. Mahale, A. Kumar, S. Pal, B. Bhattacharyya, J. Lahnsteiner, G. Kresse, C. Franchini, A. Pandey and D. D. Sarma, J. Phys. Chem. Lett., 2017, 8, 4113-4121.

299 J. R. Neilson, Neutron News, 2021, 32, 11-12.

300 X. Hu, D. Zhang, T. Chen, A. Z. Chen, E. N. Holmgren, Q. Zhang, D. M. Pajerowski, M. Yoon, G. Xu, J. J. Choi and S.-H. Lee, J. Chem. Phys., 2019, 152, 014703.

301 T. Chen, B. J. Foley, B. Ipek, M. Tyagi, J. R. D. Copley, C. M. Brown, J. J. Choi and S.-H. Lee, Phys. Chem. Chem. Phys., 2015, 17, 31278-31286.

302 X. Gong, O. Voznyy, A. Jain, W. Liu, R. Sabatini, Z. Piontkowski, G. Walters, G. Bappi, S. Nokhrin, O. Bushuyev, M. Yuan, R. Comin, D. McCamant, S. O. Kelley and E. H. Sargent, Nat. Mater., 2018, 17, 550556.

303 A. Senocrate, I. Moudrakovski and J. Maier, Phys. Chem. Chem. Phys., 2018, 20, 20043-20055.

304 C. Roiland, G. Trippé-Allard, K. Jemli, B. Alonso, J.-C. Ameline, R. Gautier, T. Bataille, L. L. Pollès, E. Deleporte, J. Even and C. Katan, Phys. Chem. Chem. Phys., 2016, 18, 27133-27142.

305 R. E. Wasylishen, O. Knop and J. B. Macdonald, Solid State Commun., 1985, 56, 581-582.

306 G. M. Bernard, R. E. Wasylishen, C. I. Ratcliffe, V. Terskikh, Q. Wu, J. M. Buriak and T. Hauger, J. Phys. Chem. A, 2018, 122, 1560-1573.

307 T. Ueda, K. Shimizu, H. Ohki and T. Okuda, Z. Naturforsch. A, 1996, 51, 910-914.

308 T. Ueda, M. Omo, K. Shimizu, H. Ohki and T. Okuda, $Z$. Naturforsch. A, 1997, 52, 502-508.

309 C. J. Dahlman, R. M. Kennard, P. Paluch, N. R. Venkatesan, M. L. Chabinyc and G. N. Manjunatha Reddy, Chem. Mater., 2021, 33, 642-656.

310 M. Lai, A. Obliger, D. Lu, C. S. Kley, C. G. Bischak, Q. Kong, T. Lei, L. Dou, N. S. Ginsberg, D. T. Limmer and P. Yang, Proc. Natl. Acad. Sci. U. S. A., 2018, 115, 11929-11934.

311 A. Senocrate and J. Maier, J. Am. Chem. Soc., 2019, 141, 8382-8396.

312 D. J. Kubicki, D. Prochowicz, E. Salager, A. Rakhmatullin, C. P. Grey, L. Emsley and S. D. Stranks, J. Am. Chem. Soc., 2020, 142, 7813-7826.

313 A. Karmakar, A. Bhattacharya, D. Sarkar, G. M. Bernard, A. Mar and V. K. Michaelis, Chem. Sci., 2021, 12, 3253-3263.

314 M. P. Hanrahan, L. Men, B. A. Rosales, J. Vela and A. J. Rossini, Chem. Mater., 2018, 30, 7005-7015.

315 L. Avram and Y. Cohen, Chem. Soc. Rev., 2014, 44, 586-602. 316 A. J. Ilott, N. M. Trease, C. P. Grey and A. Jerschow, Nat. Commun., 2014, 5, 4536.

317 S. Chandrashekar, N. M. Trease, H. J. Chang, L.-S. Du, C. P. Grey and A. Jerschow, Nat. Mater., 2012, 11, 311-315.

318 A. J. Ilott, M. Mohammadi, H. J. Chang, C. P. Grey and A. Jerschow, Proc. Natl. Acad. Sci. U. S. A., 2016, 113, 10779-10784.

319 M. J. Duer, Introduction to Solid-State NMR Spectroscopy, Wiley-Blackwell, 2005. 
320 M. H. Levitt, Spin Dynamics: Basics of Nuclear Magnetic Resonance, John Wiley \& Sons, 2013.

321 K. Schmidt-Rohr and H. W. Spiess, Multidimensional SolidState NMR and Polymers, Elsevier, 2012.

322 H. Kirchhain and L. van Wüllen, Prog. Nucl. Magn. Reson. Spectrosc., 2019, 114-115, 71-85.

323 P. Florian, D. Massiot, B. Poe, I. Farnan and J.-P. Coutures, Solid State Nucl. Magn. Reson., 1995, 5, 233-238.

324 M. Concistrè, O. G. Johannessen, E. Carignani, M. Geppi and M. H. Levitt, Acc. Chem. Res., 2013, 46, 1914-1922.

325 T. Meier, S. Khandarkhaeva, S. Petitgirard, T. Körber, A. Lauerer, E. Rössler and L. Dubrovinsky, J. Magn. Reson., 2018, 292, 44-47.

326 A. Chamas, L. Qi, H. S. Mehta, J. A. Sears, S. L. Scott, E. D. Walter and D. W. Hoyt, Magn. Reson. Imaging, 2019, 56, 37-44.

327 A. Senocrate, I. Moudrakovski, T. Acartürk, R. Merkle, G. Y. Kim, U. Starke, M. Grätzel and J. Maier, J. Phys. Chem. C, 2018, 122, 21803-21806.

328 W.-C. Qiao, J. Wu, R. Zhang, W. Ou-Yang, X. Chen, G. Yang, Q. Chen, X. L. Wang, H. F. Wang and Y.-F. Yao, Matter, 2020, 3, 1-13.

329 J. Gottwald, D. E. Demco, R. Graf and H. W. Spiess, Chem. Phys. Lett., 1995, 243, 314-323.

330 E. Vinogradov, P. K. Madhu and S. Vega, Chem. Phys. Lett., 2002, 354, 193-202.

331 A. Lesage, D. Sakellariou, S. Hediger, B. Eléna, P. Charmont, S. Steuernagel and L. Emsley, J. Magn. Reson., 2003, 163, 105-113.

332 P. Hodgkinson, Prog. Nucl. Magn. Reson. Spectrosc., 2005, 46, 197-222.

333 B. C. Gerstein, R. G. Pembleton, R. C. Wilson and L. M. Ryan, J. Chem. Phys., 1977, 66, 361-362.

334 A. J. Rossini, A. Zagdoun, M. Lelli, A. Lesage, C. Copéret and L. Emsley, Acc. Chem. Res., 2013, 46, 1942-1951.

335 A. J. Rossini, A. Zagdoun, F. Hegner, M. Schwarzwälder, D. Gajan, C. Copéret, A. Lesage and L. Emsley, J. Am. Chem. Soc., 2012, 134, 16899-16908.

336 S. Björgvinsdóttir, B. J. Walder, A. C. Pinon and L. Emsley, J. Am. Chem. Soc., 2018, 140, 7946-7951.

337 M. Lelli, S. R. Chaudhari, D. Gajan, G. Casano, A. J. Rossini, O. Ouari, P. Tordo, A. Lesage and L. Emsley, J. Am. Chem. Soc., 2015, 137, 14558-14561.

338 L. Piveteau, T.-C. Ong, A. J. Rossini, L. Emsley, C. Copéret and M. V. Kovalenko, J. Am. Chem. Soc., 2015, 137, 1396413971.

339 D. Prochowicz, P. Yadav, M. Saliba, D. J. Kubicki, M. M. Tavakoli, S. M. Zakeeruddin, J. Lewiński, L. Emsley and M. Grätzel, Nano Energy, 2018, 49, 523-528.

340 E. M. Mozur, M. A. Hope, J. C. Trowbridge, D. M. Halat, L. L. Daemen, A. E. Maughan, T. R. Prisk, C. P. Grey and J. R. Neilson, Chem. Mater., 2020, 32, 6266-6277.

341 A. Kanwat, N. Yantara, Y. F. Ng, T. J. N. Hooper, P. J. S. Rana, B. Febriansyah, P. C. Harikesh, T. Salim, P. Vashishtha, S. G. Mhaisalkar and N. Mathews, ACS Energy Lett., 2020, 5, 1804-1813.
342 A. J. Lehner, D. H. Fabini, H. A. Evans, C.-A. Hébert, S. R. Smock, J. Hu, H. Wang, J. W. Zwanziger, M. L. Chabinyc and R. Seshadri, Chem. Mater., 2015, 27, 7137-7148.

343 T. Baikie, N. S. Barrow, Y. Fang, P. J. Keenan, P. R. Slater, R. O. Piltz, M. Gutmann, S. G. Mhaisalkar and T. J. White, J. Mater. Chem. A, 2015, 3, 9298-9307.

344 A. Senocrate, I. Moudrakovski, G. Y. Kim, T.-Y. Yang, G. Gregori, M. Grätzel and J. Maier, Angew. Chem., Int. Ed., 2017, 56, 7755-7759.

345 D. J. Kubicki, D. Prochowicz, A. Hofstetter, M. Saski, P. Yadav, D. Bi, N. Pellet, J. Lewiński, S. M. Zakeeruddin, M. Grätzel and L. Emsley, J. Am. Chem. Soc., 2018, 140, 3345-3351.

346 Z.-J. Yong, S.-Q. Guo, J.-P. Ma, J.-Y. Zhang, Z.-Y. Li, Y.-M. Chen, B.-B. Zhang, Y. Zhou, J. Shu, J.-L. Gu, L.-R. Zheng, O. M. Bakr and H.-T. Sun, J. Am. Chem. Soc., 2018, 140, 9942-9951.

347 Y.-F. Chen, Y.-T. Tsai, L. Hirsch and D. M. Bassani, J. Am. Chem. Soc., 2017, 139, 16359-16364.

348 W. M. J. Franssen, S. G. D. van Es, R. Dervişoğlu, G. A. de Wijs and A. P. M. Kentgens, J. Phys. Chem. Lett., 2017, 8, 61-66.

349 K. Saalwächter, F. Lange, K. Matyjaszewski, C.-F. Huang and R. Graf, J. Magn. Reson., 2011, 212, 204-215.

350 K. Saalwächter, ChemPhysChem, 2013, 14, 3000-3014.

351 R. Chatterjee, I. M. Pavlovetc, K. Aleshire, G. V. Hartland and M. Kuno, ACS Energy Lett., 2018, 3, 469-475.

352 S. Maheshwari, S. Patwardhan, G. C. Schatz, N. Renaud and F. C. Grozema, Phys. Chem. Chem. Phys., 2019, 21, 1656416572.

353 B. A. Rosales, L. Men, S. D. Cady, M. P. Hanrahan, A. J. Rossini and J. Vela, Chem. Mater., 2016, 28, 6848-6859.

354 B. A. Rosales, M. P. Hanrahan, B. W. Boote, A. J. Rossini, E. A. Smith and J. Vela, ACS Energy Lett., 2017, 2, 906-914.

355 A. M. Askar, A. Karmakar, G. M. Bernard, M. Ha, V. V. Terskikh, B. D. Wiltshire, S. Patel, J. Fleet, K. Shankar and V. K. Michaelis, J. Phys. Chem. Lett., 2018, 9, 2671-2677.

356 A. Karmakar, A. Bhattacharya, G. M. Bernard, A. Mar and V. K. Michaelis, ACS Mater. Lett., 2021, 3, 261-267.

357 J. Jeong, M. Kim, J. Seo, H. Lu, P. Ahlawat, A. Mishra, Y. Yang, M. A. Hope, F. T. Eickemeyer, M. Kim, Y. J. Yoon, I. W. Choi, B. P. Darwich, S. J. Choi, Y. Jo, J. H. Lee, B. Walker, S. M. Zakeeruddin, L. Emsley, U. Rothlisberger, A. Hagfeldt, D. S. Kim, M. Grätzel and J. Y. Kim, Nature, 2021, 592, 381-385.

358 M. Aebli, L. Piveteau, O. Nazarenko, B. M. Benin, F. Krieg, R. Verel and M. V. Kovalenko, Sci. Rep., 2020, 10, 8229.

359 M. Maczzka, M. Ptak, D. L. M. Vasconcelos, L. Giriunas, P. T. C. Freire, M. Bertmer, J. Banys and M. Simenas, J. Phys. Chem. C, 2020, 124, 26999-27008.

360 A. Karmakar, A. M. Askar, G. M. Bernard, V. V. Terskikh, M. Ha, S. Patel, K. Shankar and V. K. Michaelis, Chem. Mater., 2018, 30, 2309-2321.

361 M. Ozaki, Y. Katsuki, J. Liu, T. Handa, R. Nishikubo, S. Yakumaru, Y. Hashikawa, Y. Murata, T. Saito, 
Y. Shimakawa, Y. Kanemitsu, A. Saeki and A. Wakamiya, ACS Omega, 2017, 2, 7016-7021.

362 M. Ha, A. Karmakar, G. M. Bernard, E. Basilio, A. Krishnamurthy, A. M. Askar, K. Shankar, S. Kroeker and V. K. Michaelis, J. Phys. Chem. C, 2020, 124, 1501515027.

363 K. Yamada, K. Fujise, S. Hino, Y. Yamane and T. Nakagama, Chem. Lett., 2019, 48, 749-752.

364 K. Yamada, Y. Kuranaga, K. Ueda, S. Goto, T. Okuda and Y. Furukawa, Bull. Chem. Soc. Jpn., 1998, 71, 127-134.

365 D. J. Kubicki, D. Prochowicz, A. Hofstetter, B. J. Walder and L. Emsley, ACS Energy Lett., 2020, 5, 2964-2971.

366 A. Karmakar, G. M. Bernard, A. Meldrum, A. O. Oliynyk and V. K. Michaelis, J. Am. Chem. Soc., 2020, 142, 10780-10793.

367 A. M. Askar, G. M. Bernard, B. Wiltshire, K. Shankar and V. K. Michaelis, J. Phys. Chem. C, 2017, 121, 1013-1024.

368 M. A. A. Kazemi, P. Raval, K. Cherednichekno, J.-N. Chotard, A. Krishna, A. Demortiere, G. N. M. Reddy and F. Sauvage, Small Methods, 2021, 5, 2000834.

369 T. Leijtens, R. Prasanna, A. Gold-Parker, M. F. Toney and M. D. McGehee, ACS Energy Lett., 2017, 2, 2159-2165.

370 M. A. Ruiz-Preciado, D. J. Kubicki, A. Hofstetter, L. McGovern, M. H. Futscher, A. Ummadisingu, R. Gershoni-Poranne, S. M. Zakeeruddin, B. Ehrler, L. Emsley, J. V. Milić and M. Grätzel, J. Am. Chem. Soc., 2020, 142, 1645-1654.

371 A. Abate, M. Saliba, D. J. Hollman, S. D. Stranks, K. Wojciechowski, R. Avolio, G. Grancini, A. Petrozza and H. J. Snaith, Nano Lett., 2014, 14, 3247-3254.

372 L. Piveteau, M. Aebli, N. Yazdani, M. Millen, L. Korosec, F. Krieg, B. M. Benin, V. Morad, C. Piveteau, T. Shiroka, A. Comas-Vives, C. Copéret, A. M. Lindenberg, V. Wood, R. Verel and M. V. Kovalenko, ACS Cent. Sci., 2020, 6, 1138-1149.

373 I. Spanopoulos, I. Hadar, W. Ke, P. Guo, E. M. Mozur, E. Morgan, S. Wang, D. Zheng, S. Padgaonkar, G. N. M. Reddy, E. A. Weiss, M. C. Hersam, R. Seshadri, R. D. Schaller and M. G. Kanatzidis, J. Am. Chem. Soc., 2021, 143, 7069-7080.

374 J. Lee, W. Lee, K. Kang, T. Lee and S. K. Lee, Chem. Mater., 2021, 33, 370-377.

375 J. V. Milić, J. Im, D. J. Kubicki, A. Ummadisingu, J. Seo, Y. Li, M. A. Ruiz-Preciado, M. I. Dar, S. M. Zakeeruddin, L. Emsley and M. Grätzel, Adv. Energy Mater., 2019, 9, 1900284.

376 K. L. Svane, A. C. Forse, C. P. Grey, G. Kieslich, A. K. Cheetham, A. Walsh and K. T. Butler, J. Phys. Chem. Lett., 2017, 8, 6154-6159.

377 C. Quarti, E. Furet and C. Katan, Helv. Chim. Acta, 2021, 104, e2000231.

378 D. Bi, X. Li, J. V. Milić, D. J. Kubicki, N. Pellet, J. Luo, T. LaGrange, P. Mettraux, L. Emsley, S. M. Zakeeruddin and M. Grätzel, Nat. Commun., 2018, 9, 4482.

379 E. A. Alharbi, A. Y. Alyamani, D. J. Kubicki, A. R. Uhl, B. J. Walder, A. Q. Alanazi, J. Luo, A. Burgos-Caminal, A. Albadri, H. Albrithen, M. H. Alotaibi, J.-E. Moser,
S. M. Zakeeruddin, F. Giordano, L. Emsley and M. Grätzel, Nat. Commun., 2019, 10, 3008.

380 X. Zheng, B. Chen, J. Dai, Y. Fang, Y. Bai, Y. Lin, H. Wei, X. C. Zeng and J. Huang, Nat. Energy, 2017, 2, 1-9.

381 A. Krishna, M. A. A. Kazemi, M. Sliwa, G. N. M. Reddy, L. Delevoye, O. Lafon, A. Felten, M. T. Do, S. Gottis and F. Sauvage, Adv. Funct. Mater., 2020, 30, 1909737.

382 T.-S. Su, F. T. Eickemeyer, M. A. Hope, F. Jahanbakhshi, M. Mladenović, J. Li, Z. Zhou, A. Mishra, J.-H. Yum, D. Ren, A. Krishna, O. Ouellette, T.-C. Wei, H. Zhou, H.-H. Huang, M. D. Mensi, K. Sivula, S. M. Zakeeruddin, J. V. Milić, A. Hagfeldt, U. Rothlisberger, L. Emsley, H. Zhang and M. Grätzel, J. Am. Chem. Soc., 2020, 142, 19980-19991.

383 Y. Chen, S. R. Smock, A. H. Flintgruber, F. A. Perras, R. L. Brutchey and A. J. Rossini, J. Am. Chem. Soc., 2020, 142, 6117-6127.

384 A. A. M. Brown, T. J. N. Hooper, S. A. Veldhuis, X. Y. Chin, A. Bruno, P. Vashishtha, J. N. Tey, L. Jiang, B. Damodaran, S. H. Pu, S. G. Mhaisalkar and N. Mathews, Nanoscale, 2019, 11, 12370-12380.

385 J. Shamsi, D. Kubicki, M. Anaya, Y. Liu, K. Ji, K. Frohna, C. P. Grey, R. H. Friend and S. D. Stranks, ACS Energy Lett., 2020, 5, 1900-1907.

386 A. Abfalterer, J. Shamsi, D. J. Kubicki, C. N. Savory, J. Xiao, G. Divitini, W. Li, S. Macpherson, K. Gałkowski, J. L. MacManus-Driscoll, D. O. Scanlon and S. D. Stranks, ACS Mater. Lett., 2020, 2, 1644-1652.

387 R. Grisorio, E. Fanizza, I. Allegretta, D. Altamura, M. Striccoli, R. Terzano, C. Giannini, V. Vergaro, G. Ciccarella, N. Margiotta and G. P. Suranna, Nanoscale, 2020, 12, 623-637.

388 R. Grisorio, M. E. D. Clemente, E. Fanizza, I. Allegretta, D. Altamura, M. Striccoli, R. Terzano, C. Giannini, M. Irimia-Vladu and G. Paolo Suranna, Nanoscale, 2019, 11, 986-999.

389 G. Almeida, O. J. Ashton, L. Goldoni, D. Maggioni, U. Petralanda, N. Mishra, Q. A. Akkerman, I. Infante, H. J. Snaith and L. Manna, J. Am. Chem. Soc., 2018, 140, 14878-14886.

390 S. R. Smock, T. J. Williams and R. L. Brutchey, Angew. Chem., Int. Ed., 2018, 57, 11711-11715.

391 J. De Roo, M. Ibáñez, P. Geiregat, G. Nedelcu, W. Walravens, J. Maes, J. C. Martins, I. Van Driessche, M. V. Kovalenko and Z. Hens, ACS Nano, 2016, 10, 20712081.

392 M. Reddy G. N., R. Ballesteros-Garrido, J. Lacour and S. Caldarelli, Angew. Chem., Int. Ed., 2013, 52, 3255-3258.

393 G. N. M. Reddy, M. Yemloul and S. Caldarelli, Magn. Reson. Chem., 2017, 55, 492-497.

394 J. Gong, M. Yang, X. Ma, R. D. Schaller, G. Liu, L. Kong, Y. Yang, M. C. Beard, M. Lesslie, Y. Dai, B. Huang, K. Zhu and T. Xu, J. Phys. Chem. Lett., 2016, 7, 2879-2887.

395 C. Motta, F. El-Mellouhi, S. Kais, N. Tabet, F. Alharbi and S. Sanvito, Nat. Commun., 2015, 6, 7026.

396 W. M. J. Franssen, C. M. M. van Heumen and A. P. M. Kentgens, Inorg. Chem., 2020, 59, 3730-3739. 
397 A. A. Shmyreva, M. Safdari, I. Furó and S. V. Dvinskikh, J. Chem. Phys., 2016, 144, 224201.

398 R. R. Sharp, J. Chem. Phys., 1972, 57, 5321-5330.

399 R. R. Sharp, J. Chem. Phys., 1974, 60, 1149-1157.

400 J. Korringa, Physica, 1950, 16, 601-610.

401 T.-Y. Yang, G. Gregori, N. Pellet, M. Grätzel and J. Maier, Angew. Chem., Int. Ed., 2015, 54, 7905-7910.

402 A. Baumann, S. Väth, P. Rieder, M. C. Heiber, K. Tvingstedt and V. Dyakonov, J. Phys. Chem. Lett., 2015, 6, 2350-2354.

403 J. Haruyama, K. Sodeyama, L. Han and Y. Tateyama, J. Am. Chem. Soc., 2015, 137, 10048-10051.

404 S. Meloni, T. Moehl, W. Tress, M. Franckevičius, M. Saliba, Y. H. Lee, P. Gao, M. K. Nazeeruddin, S. M. Zakeeruddin, U. Rothlisberger and M. Graetzel, Nat. Commun., 2016, 7, 10334.

405 M. H. Futscher, J. Min Lee, L. McGovern, L. A. Muscarella, T. Wang, M. Irfan Haider, A. Fakharuddin, L. SchmidtMende and B. Ehrler, Mater. Horiz., 2019, 6, 1497-1503.

406 D. W. Ferdani, S. R. Pering, D. Ghosh, P. Kubiak, A. B. Walker, S. E. Lewis, A. L. Johnson, P. J. Baker, M. Saiful Islam and P. J. Cameron, Energy Environ. Sci., 2019, 12, 2264-2272.

407 A. Pockett, G. E. Eperon, N. Sakai, H. J. Snaith, L. M. Peter and P. J. Cameron, Phys. Chem. Chem. Phys., 2017, 19, 59595970.

408 O. Almora, I. Zarazua, E. Mas-Marza, I. Mora-Sero, J. Bisquert and G. Garcia-Belmonte, J. Phys. Chem. Lett., 2015, 6, 1645-1652.

409 C. Li, S. Tscheuschner, F. Paulus, P. E. Hopkinson, J. Kießling, A. Köhler, Y. Vaynzof and S. Huettner, Adv. Mater., 2016, 28, 2446-2454.

410 N. Onoda-Yamamuro, T. Matsuo and H. Suga, J. Chem. Thermodyn., 1991, 23, 987-999.

411 K. Yamada, H. Kawaguchi, T. Matsui, T. Okuda and S. Ichiba, Bull. Chem. Soc. Jpn., 1990, 63, 2521-2525.

412 T. Shi, H.-S. Zhang, W. Meng, Q. Teng, M. Liu, X. Yang, Y. Yan, H.-L. Yip and Y.-J. Zhao, J. Mater. Chem. A, 2017, 5, 15124-15129.

413 J. Mizusaki, K. Arai and K. Fueki, Solid State Ionics, 1983, 11, 203-211.

414 Y. Lin, Y. Bai, Y. Fang, Q. Wang, Y. Deng and J. Huang, ACS Energy Lett., 2017, 2, 1571-1572.

415 X. Xiao, J. Dai, Y. Fang, J. Zhao, X. Zheng, S. Tang, P. N. Rudd, X. C. Zeng and J. Huang, ACS Energy Lett., 2018, 3, 684-688.

416 F. Jiang, J. Pothoof, F. Muckel, R. Giridharagopal, J. Wang and D. S. Ginger, ACS Energy Lett., 2021, 6, 100-108.

417 N. S. Dahod, W. Paritmongkol, A. Stollmann, C. Settens, S.-L. Zheng and W. A. Tisdale, J. Phys. Chem. Lett., 2019, 10, 2924-2930.

418 W. Paritmongkol, N. S. Dahod, A. Stollmann, N. Mao, C. Settens, S.-L. Zheng and W. A. Tisdale, Chem. Mater., 2019, 31, 5592-5607.

419 A. Gheno, S. Vedraine, B. Ratier and J. Bouclé, Metals, 2016, 6, 21.
420 Y. Saygili, H.-S. Kim, B. Yang, J. Suo, A. B. Muñoz-Garcia, M. Pavone and A. Hagfeldt, ACS Energy Lett., 2020, 5, 1271-1277.

421 B. Yurash, D. Leifert, G. N. M. Reddy, D. X. Cao, S. Biberger, V. V. Brus, M. Seifrid, P. J. Santiago, A. Köhler, B. F. Chmelka, G. C. Bazan and T.-Q. Nguyen, Chem. Mater., 2019, 31, 6715-6725.

422 E. Yalcin, M. Can, C. Rodriguez-Seco, E. Aktas, R. Pudi, W. Cambarau, S. Demic and E. Palomares, Energy Environ. Sci., 2019, 12, 230-237.

423 C. M. Wolff, L. Canil, C. Rehermann, N. Ngoc Linh, F. Zu, M. Ralaiarisoa, P. Caprioglio, L. Fiedler, M. Stolterfoht, S. Kogikoski, I. Bald, N. Koch, E. L. Unger, T. Dittrich, A. Abate and D. Neher, ACS Nano, 2020, 14, 1445-1456.

424 A. Abate, T. Leijtens, S. Pathak, J. Teuscher, R. Avolio, M. E. Errico, J. Kirkpatrik, J. M. Ball, P. Docampo, I. McPherson and H. J. Snaith, Phys. Chem. Chem. Phys., 2013, 15, 2572-2579.

425 J. Hynynen, D. Kiefer, L. Yu, R. Kroon, R. Munir, A. Amassian, M. Kemerink and C. Müller, Macromolecules, 2017, 50, 8140-8148.

426 A. Karki, G.-J. A. H. Wetzelaer, G. N. M. Reddy, V. Nádaždy, M. Seifrid, F. Schauer, G. C. Bazan, B. F. Chmelka, P. W. M. Blom and T.-Q. Nguyen, Adv. Funct. Mater., 2019, 29, 1901109.

427 M. T. Seifrid, G. N. M. Reddy, C. Zhou, B. F. Chmelka and G. C. Bazan, J. Am. Chem. Soc., 2019, 141, 5078-5082.

428 J. E. Cochran, M. J. N. Junk, A. M. Glaudell, P. L. Miller, J. S. Cowart, M. F. Toney, C. J. Hawker, B. F. Chmelka and M. L. Chabinyc, Macromolecules, 2014, 47, 6836-6846.

429 J. Lee, G.-W. Kim, M. Kim, S. A. Park and T. Park, Adv. Energy Mater., 2020, 10, 1902662.

430 L. McGovern, M. H. Futscher, L. A. Muscarella and B. Ehrler, J. Phys. Chem. Lett., 2020, 11, 7127-7132.

431 M. H. Futscher, M. K. Gangishetty, D. N. Congreve and B. Ehrler, ACS Appl. Electron. Mater., 2020, 2, 1522-1528.

432 M. H. Futscher, M. K. Gangishetty, D. N. Congreve and B. Ehrler, J. Chem. Phys., 2020, 152, 044202.

433 Z. Gan, I. Hung, X. Wang, J. Paulino, G. Wu, I. M. Litvak, P. L. Gor'kov, W. W. Brey, P. Lendi, J. L. Schiano, M. D. Bird, I. R. Dixon, J. Toth, G. S. Boebinger and T. A. Cross, J. Magn. Reson., 2017, 284, 125-136.

434 V. Martins, J. Xu, X. Wang, K. Chen, I. Hung, Z. Gan, C. Gervais, C. Bonhomme, S. Jiang, A. Zheng, B. E. G. Lucier and Y. Huang, J. Am. Chem. Soc., 2020, 142, 14877-14889.

435 A. Samoson, J. Magn. Reson., 2019, 306, 167-172.

436 F. A. Perras, A. Venkatesh, M. P. Hanrahan, T. W. Goh, W. Huang, A. J. Rossini and M. Pruski, J. Magn. Reson., 2017, 276, 95-102.

437 Y. Hong, G. N. Manjunatha Reddy and Y. Nishiyama, Solid State Nucl. Magn. Reson., 2020, 106, 101651.

438 A. Venkatesh, M. P. Hanrahan and A. J. Rossini, Solid State Nucl. Magn. Reson., 2017, 84, 171-181.

439 H. Nagashima, J. Trébosc, Y. Kon, K. Sato, O. Lafon and J.-P. Amoureux, J. Am. Chem. Soc., 2020, 142, 10659-10672. 
440 C. E. Avalos, B. J. Walder, J. Viger-Gravel, A. Magrez and L. Emsley, Phys. Chem. Chem. Phys., 2019, 21, 1100-1109.

441 K. Takeda, Solid State Nucl. Magn. Reson., 2012, 47-48, 1-9.

442 H. Al-Johani, E. Abou-Hamad, A. Jedidi, C. M. Widdifield, J. Viger-Gravel, S. S. Sangaru, D. Gajan, D. H. Anjum, S. Ould-Chikh, M. N. Hedhili, A. Gurinov, M. J. Kelly, M. El Eter, L. Cavallo, L. Emsley and J.-M. Basset, Nat. Chem., 2017, 9, 890-895.

443 A. R. Oganov, C. J. Pickard, Q. Zhu and R. J. Needs, Nat. Rev. Mater., 2019, 4, 331-348.
444 P. Hodgkinson, Prog. Nucl. Magn. Reson. Spectrosc., 2020, 118-119, 10-53.

445 D. L. Bryce, IUCrJ, 2017, 4, 350-359.

446 The Cambridge Structural Database (CSD), https:// www.ccdc.cam.ac.uk/solutions/csd-core/components/csd/.

447 Inorganic Crystal Structure Database, https:// icsd.products.fiz-karlsruhe.de/.

448 The Materials Project, https://materialsproject.org/. 